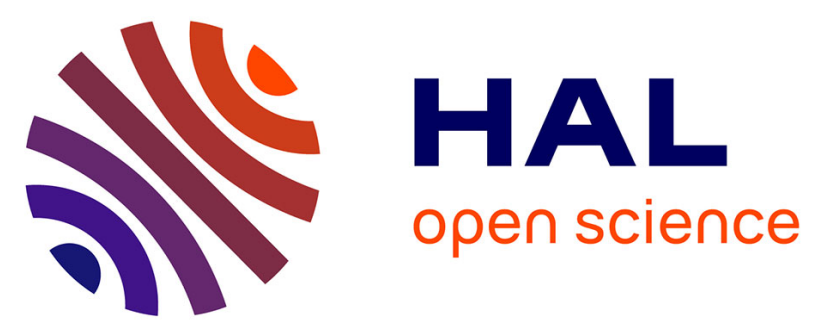

\title{
A new cranial reconstruction of Coelurosauravus elivensis Piveteau, 1926 (Diapsida, Weigeltisauridae) and its implications on the paleoecology of the first gliding vertebrates
}

\author{
Valentin Buffa, Eberhard Frey, J.-Sébastien Steyer, Michel Laurin
}

\section{To cite this version:}

Valentin Buffa, Eberhard Frey, J.-Sébastien Steyer, Michel Laurin. A new cranial reconstruction of Coelurosauravus elivensis Piveteau, 1926 (Diapsida, Weigeltisauridae) and its implications on the paleoecology of the first gliding vertebrates. Journal of Vertebrate Paleontology, 2021, 41 (2), 10.1080/02724634.2021.1930020 . hal-03372903

\section{HAL Id: hal-03372903 \\ https://hal.sorbonne-universite.fr/hal-03372903}

Submitted on 11 Oct 2021

HAL is a multi-disciplinary open access archive for the deposit and dissemination of scientific research documents, whether they are published or not. The documents may come from teaching and research institutions in France or abroad, or from public or private research centers.
L'archive ouverte pluridisciplinaire HAL, est destinée au dépôt et à la diffusion de documents scientifiques de niveau recherche, publiés ou non, émanant des établissements d'enseignement et de recherche français ou étrangers, des laboratoires publics ou privés. 


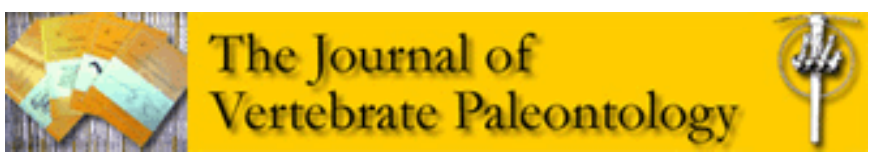

\section{A new cranial reconstruction of Coelurosauravus elivensis Piveteau, 1926 (Diapsida, Weigeltisauridae) and its implications on the paleoecology of the first gliding vertebrates}

\begin{tabular}{|r|l|}
\hline Journal: & Journal of Vertebrate Paleontology \\
\hline Manuscript ID & JVP-2020-0140.R1 \\
\hline Manuscript Type: & Article \\
\hline Date Submitted by the & $\mathrm{n} / \mathrm{a}$ \\
\hline Complete List of Authors: & $\begin{array}{l}\text { Buffa, Valentin; Muséum National d'Histoire Naturelle, Origines et } \\
\text { Évolution } \\
\text { Frey, Eberhard; Staatliches Museum für Naturkunde Karlsruhe, } \\
\text { Geosciences } \\
\text { Steyer, Jean-Sébastien; Muséum National d'Histoire Naturelle, Origines } \\
\text { et Évolution } \\
\text { Laurin, Michel; Muséum National d'Histoire Naturelle, Origines et } \\
\text { Évolution }\end{array}$ \\
\hline Key Words: & $\begin{array}{l}\text { Frill, Gliding reptiles, Ornamentation, Permian, Reflectance } \\
\text { Transformation Imaging, Weigeltisauridae }\end{array}$ \\
\hline &
\end{tabular}


A new cranial reconstruction of Coelurosauravus elivensis Piveteau, 1926 (Diapsida,

Weigeltisauridae) and its implications on the paleoecology of the first gliding vertebrates

VALENTIN BUFFA, ${ }^{* 1}$ EBERHARD FREY, ${ }^{2}$ J.-SÉBASTIEN STEYER, ${ }^{1}$ and MICHEL

\section{LAURIN $^{1}$}

${ }^{1}$ Centre de Recherche en Paléontologie - Paris, UMR 7207 CNRS-MNHN-SU, Muséum national d'Histoire naturelle, CP38, 8 rue Buffon, 75005 Paris, France, valentin.buffa@edu.mnhn.fr;

${ }^{2}$ Abteilung Geowissenshaften, Staatliches Museum für Naturkunde Karlsruhe, Germany

RH: BUFFA ET AL.-COELUROSAURAVUS SKULL

\footnotetext{
* Corresponding author
} 


\begin{abstract}
The cranial skeleton of the enigmatic gliding neodiapsid reptile
Coelurosauravus elivensis (Lower Sakamena Formation, Lopingian, Southwestern
\end{abstract}

Madagascar) is re-described in detail. All previously referred specimens are re-examined under both direct observations and Reflectance Transformation Imaging. Their exquisite preservation yields detailed three-dimensional information on the outline of individual bones and their osteological relationships, which are missing in the Laurasian remains. In contrast to previous studies, the ontogenetic maturity of all specimens is re-affirmed. Previously unidentified elements of the palate, braincase and mandible are described, and a novel reconstruction is proposed, including the first palatal reconstruction in a weigeltisaurid reptile. C. elivensis has the smallest skull of all weigeltisaurids and differs from other species in its facial ornamentation, parietosquamosal frill and larger anterior maxillary dentition. We also provide extensive comparisons with contemporaneous reptiles, possibly closely related taxa and more recent analogs, as well as a preliminary discussion of the functional anatomy of the peculiar cranial morphology of weigeltisaurids. The cranial skeleton is a truss construction with large orbits and temporal fenestrae. By analogy with extant chamaeleonids, the elongate parietosquamosal frill is associated with an increase in length and diameter of the temporal jaw adductors, resulting in an increased gape and/or bite force and speed. Additionally, the spikes and frills of weigeltisaurids most likely served as a display and defensive structure. 


\section{INTRODUCTION}

Diapsids were the most conspicuous components of tetrapod diversity during the Mesozoic Era. Despite being rare elements of the preceding late Paleozoic fossil record (Modesto and Reisz, 2003; Reisz et al., 2011; Sues, 2019), early diapsids show a conspicuous morphological disparity, with well-recorded terrestrial, semi-aquatic and aerial taxa (Carroll, 1975, 1978, 1981; Gow, 1975; Currie, 1981). Among those, the Lopingian Weigeltisauridae were the first amniotes to use aerial gliding locomotion (Carroll, 1978; Evans, 1982; Bulanov and Sennikov, 2015a-c) and are a key group to understand the range of alternative adaptations for gliding flight in amniotes.

Weigeltisaurids include several taxa known from either Laurasia or Gondwana (Bulanov and Sennikov, 2015a-c): Weigeltisaurus jaekeli (Weigelt, 1930a) (Lopingian, Germany and England), Coelurosauravus elivensis Piveteau, 1926 (Lopingian, Madagascar), Glaurung schneideri Bulanov and Sennikov, 2015c (Lopingian, Germany), Rautiania alexandri Bulanov and Sennikov, 2006 (Lopingian, Russia) and Rautiania minichi Bulanov and Sennikov, 2006 (Lopingian, Russia). Wapitisaurus problematicus Brinkman, 1988 (Early Triassic, Canada), known from a poorly preserved skull, has been interpreted as a weigeltisaurid but this attribution is doubtful (Bulanov and Sennikov, 2010). Therefore, this taxon will not be further considered here, pending its systematic revision.

The peculiar cranial anatomy of weigeltisaurids has been subject to a lot of attention since the description of Coelurosauravus (Piveteau, 1926), and there have been numerous controversies on their cranial osteology (Carroll, 1978; Evans, 1982; Evans and Haubold, 1987; Schaumberg et al., 2007). However, recent studies by Bulanov and Sennikov (2015a-c) 
and the discovery of numerous isolated three-dimensional weigeltisaurid remains in the Permian of Russia (Bulanov and Sennikov, 2006, 2010, 2014) have led to a better understanding of the comparative anatomy within the group.

Historically, weigeltisaurids were first informally considered as pterosaurs (Weigelt, 1930a:626), and have since been considered as dinosaur relatives (Boule, 1910; Piveteau, 1926), rhynchocephalians (Weigelt, 1930a), early (“pelycosaur-grade”) synapsids (Kuhn, 1939) or stem-saurians (Huene, 1956; Carroll, 1978; Evans and Haubold, 1987; Laurin, 1991). Recent phylogenetic analyses, however, recover weigeltisaurids as close relatives of saurians (e.g., Ezcurra et al., 2014; Schoch and Sues, 2018a; Pritchard and Sues, 2019; Sobral et al., 2020) with some recovering a close relationship to either drepanosauromorphs (Merck, 2003; Senter, 2004) or 'paliguanids' (Müller, 2004).

However, previous descriptions lack comparisons to a broad array of taxa and a phylogenetic context. The anatomy of weigeltisaurids is unique in many aspects, and detailed comparisons with contemporaneous reptiles, potentially closely related taxa, and both extinct and extant analogs is paramount to better understand the morphology, paleoecology and evolution of these enigmatic gliding reptiles. This study aims at describing novel details on the skull of weigeltisaurids, with a focus on the material of Coelurosauravus from the Lopingian of Madagascar.

Institutional Abbreviations-MNHN, Muséum national d'Histoire naturelle, Paris, France; SMNK, Staatliches Museum für Naturkunde Karlsruhe, Karlsruhe, Germany; SSWG, Sektion Geologie, Ernst-Moritz-Arndt Universität, Griefswald, Germany. 
Age and Provenance-All specimens described here come from the upper beds of the Lower Sakamena Formation (southwestern Madagascar), currently considered as Wuchiapingian in age (Piveteau, 1926; Currie, 1981; Hankel, 1994; Lucas, 2017). These specimens were collected in 1907-1908 by J.-M. Colcanap, a captain of the French colonial infantry, and are among the first vertebrate remains to be collected from this formation. The exact locality is unknown, but it is likely in the vicinity of Mount Eliva, near the upstream portion of the Sakamena River. A comprehensive review of the first excavations of Colcanap and the provenance of this material is currently underway by the lead author (VB, unpubl. data). Therefore, a geological section cannot be presented at the current state of investigation.

Most studies agree on the continental nature of these deposits (e.g., Besairie, 1972; Smith, 2000). During the Lopingian, the faunal and floral community preserved in the Lower Sakamena Formation inhabited a wetland area in a roughly North-South running rift valley under a temperate, warm and humid climate, with seasonal rainfalls and possible monsoons (Besairie, 1973; Wescott and Diggens, 1998; Smith, 2000).

Preservation-All specimens referred to C. elivensis are preserved in very finegrained nodules formed by concentric precipitation around the entire trunk region (Fig. 1, Supplemental Data 1), as described for other Malagasy Permian reptiles (Smith, 2000). These nodules are split along their greatest diameter mostly along the coronal plane of the skeleton, each half of the split nodule exposing either the ventral or dorsal aspect. All specimens consist of skeletal remains preserved in connection, but most of the bones have been eroded, possibly further removed by etching (Fig. 1). Thus, only the external mold of the bones is preserved. The nodular matrix has a light brown color, but in some cases, the external molds of the bones are dark grey, likely evidence of recent bone removal.

Despite missing bone, the material from Madagascar bears information on the $3 \mathrm{D}$ outline of individual bones and their anatomical arrangement. Anatomical details were 
observed using silicone casts ( $1 \mu \mathrm{m}$ resolution). The study of this material thus brings key $3 \mathrm{D}$ anatomical information, which is absent in the compacted specimens from western Europe (Glaurung, Weigeltisaurus, Frey et al., 1997; Schaumberg et al., 2007; Bulanov and Sennikov, 2015b-c) and in the isolated bones from eastern Europe (Rautiania, Bulanov and Sennikov, 2006, 2010), where the anatomical arrangement is missing.

\title{
MATERIAL AND METHODS
}

\begin{abstract}
Material-All specimens previously referred to Coelurosauravus elivensis were examined. Original specimens or high-fidelity epoxy resin casts of specimens previously referred to Weigeltisaurus were also studied for comparative purposes (Table 1).
\end{abstract}

Taxonomic Remarks - Most European weigeltisaurid specimens have previously been attributed to Coelurosauravus, with Weigeltisaurus being considered a subjective junior synonym at the time (Evans and Haubold, 1987). More recently, Coelurosauravus was restricted to the specimens from Madagascar (Bulanov and Sennikov, 2015a) and Weigeltisaurus was re-established as a valid taxon, based on SSWG 113/7, the holotype of Weigeltisaurus jaekeli (Bulanov and Sennikov, 2015b). Bulanov and Sennikov (2015b:1110) also tentatively and informally refer all German specimens to Weigeltisaurus sp. (explicitly not to the species Weigeltisaurus jaekeli) with evidence only being given for the Ellrich specimen SMNK-PAL 2882. However, there was no mention of the British specimen, which thus remains of unclear attribution. All German and British material lacking cranial material can not be identified more precisely than to Weigeltisauridae because most diagnostic characters are cranial. Furthermore, as was argued by Haubold and Schaumberg (1985:194), Gracilisaurus ottoi Weigelt, 1930b, considered as a junior subjective synonym of 
Weigeltisaurus jaekeli by Evans and Haubold (1987), instead has priority provided both taxa are synonyms (Weigelt, 1930a:675, 1930b:279). A re-examination of G. ottoi is thus needed to reassess this synonymy.

Because of this uncertainty, and in accordance with Schaumberg et al. (2007; Table 1), we restrict the use of the species name Weigeltisaurus jaekeli to the holotype only. All other German and British specimens are referred to by their collection numbers and housing institution name or locality reference. In addition, previous studies refer to the C. elivensis material using patrimonial numbers, although the MNHN collections have more recent MNHN.F.MAP designations for the Malagasy Permian collection. We favor the latter and provide correspondence with the previously used patrimonial numbers (Table 1). Lastly, in the absence of articulated material from eastern Europe, we refer to individual specimens in open nomenclature as Rautiania sp. following the use of Bulanov and Sennikov (2010).

Reflectance Transformation Imaging (RTI) - The individual bones are often jumbled and thus difficult to identify in the Malagasy material. RTI is a method that computes a single 'interactive specimen' on which the illumination can be oriented at will (Hammer et al., 2002). This method was used in order to compensate for the nature of preservation of the specimens, using a custom-made portable light dome (an updated version of that used in Béthoux et al., 2016; Cui et al., 2018). Sets of 54 photographs under different LED sources were compiled using the RTIBuilder software. The resulting RTI files provided in Supplemental Data 1 can be opened using the software RTIViewer (both softwares are freely available at www.culturalheritageimaging.org). As a result, this study is one of the first usages of RTI to study fossil vertebrate specimens. 


\section{SYSTEMATIC PALEONTOLOGY}

NEODIAPSIDA Benton, 1985 sensu Reisz, Modesto and Scott, 2011

WEIGELTISAURIDAE Kuhn, 1939

COELUROSAURAVUS ELIVENSIS Piveteau, 1926

Daedalosaurus madagascariensis Carroll, 1978:149, figs. 5-7.

Lectotype-MNHN.F.MAP325a (Fig. 1), external mold of the dorsal surface of a partially preserved specimen (Piveteau, 1926:pl.17-1; Carroll, 1978:fig. 2; Evans, 1982:fig. 16B; Evans and Haubold, 1987:figs. 3B, 13C, 16B, D, 17; Bulanov and Sennikov, 2015a:pl.51b).

Paralectotype-MNHN.F.MAP317a-b (part and counterpart), external mold of the ventral surface of a partially preserved specimen preserved on two slabs (Piveteau, 1926:pl.17-3; Carroll, 1978:fig. 3; Evans, 1982:figs. 15-16A; Evans and Haubold, 1987:figs. 3A, 13A-B; Bulanov and Sennikov, 2015a:pl.5-2).

Referred Material-MNHN.F.MAP327a-b, external mold of a sub-complete specimen preserved on two slabs (Carroll, 1978:figs. 5-7; Evans, 1982:figs. 14, 17-18; Evans and Haubold, 1987: figs. 4-5, 12, 14-15A, 21).

Type Horizon-Top of the Lower Sakamena Formation, Lopingian.

Type Locality—Sakamena River, upstream region, exact location unknown, Southwestern Madagascar. 
Emended Diagnosis (Modified from Evans and Haubold, 1987)—Maxillary teeth with symmetrical apices; anterior maxillary teeth significantly larger than mid-/posterior teeth; anterior and dorsal jugal processes subequal (shared with Rautiania); ornamented dorsal jugal process; parietal posttemporal process uniform in width (shared with Glaurung); tubercles on parietal posttemporal process (shared with Glaurung).

Remarks - Piveteau (1926) first described this taxon based on both MNHN.F.MAP325a and MNHN.F.MAP317a without designating a holotype. Carroll (1978) later designated MNHN.F.MAP325a as the "type" (Carroll, 1978:144), which was later considered as the holotype by Evans (1982) and Evans and Haubold (1987). Following the designation of Carroll (1978) among the two syntypes of Piveteau (1926), and in accordance with the International Code of Zoological Nomenclature (ICZN, 1999, article 74.5), MNHN.F.MAP325a is here considered as the lectotype of Coelurosauravus elivensis. In addition, MNHN.F.MAP317b, counterpart of the paralectotype MNHN.F.MAP317a first described by Piveteau (1926) is also considered as a paralectotype.

We do not follow the diagnosis of Evans and Haubold (1987), which was erected for an assemblage of both Coelurosauravus and Weigeltisaurus specimens, the latter at that time having been considered as a junior subjective synonym of the former. This diagnosis would be better adapted for the family Weigeltisauridae, which is currently under review by the authors.

\section{OSTEOLOGICAL REDESCRIPTION}

The material of Coelurosauravus allows for an almost complete examination of the skull (Fig. 2). The individual bones and sutures are hard to identify in the lectotype due to late 
diagenetic compression, but are readily visible in the similarly preserved MNHN.F.MAP317b (Figs. 3, 4A-B). In addition, MNHN.F.MAP317a preserves several slightly compressed bones of the palate and braincase that previously had not been identified (Fig. 4C-D).

MNHN.F.MAP327b shows several exquisitely preserved bones, with a portion of the right side of the skull roof preserved in natural arrangement in internal view, and other scattered bones from the left side, palate and posterior skull bones (Fig. 5). Due to its exquisite preservation, this specimen has played a key role in previous studies and reconstructions of the skull of Coelurosauravus (Bulanov and Sennikov, 2015a:414).

Our detailed examination of all known specimens of Coelurosauravus resulted in a new reconstruction of the skull for this taxon (Fig. 2). Most of our interpretations agree with those of Bulanov and Sennikov (2015a:fig. 3) but some significant differences are discussed below.

\section{Ontogenetic Stage of Specimens}

Bulanov and Sennikov (2015a:422) commented on the small size of all Coelurosauravus skulls compared to other weigleltisaurids, and interpreted these specimens as "juveniles". The reconstructed skull length for Coelurosauravus is indeed just ca. $35 \mathrm{~mm}$ (Table 2), which is about half of the relative size of that of the Weigeltisaurus holotype, Glaurung, and Rautiania (ca. $60 \mathrm{~mm}$, Table 2; Bulanov and Sennikov, 2010, 2015a-c), and is also significantly smaller than that of the Ellrich specimen (ca. $50 \mathrm{~mm}$, Table 2). Their hypothesis is also supported by the tubercular parietal ornamentation of Coelurosauravus, which, in Rautiania, is characteristic of immature individuals, while mature ones bear parietal spikes (Bulanov and Sennikov, 2015a). 
However, our detailed examination of the Coelurosauravus specimens and the evaluation of commonly used size-independent criteria to assess ontogenetic maturity in extinct reptiles (recently reviewed in Griffin et al., 2021) do not show any evidence of immaturity. The cranial bones of all Coelurosauravus specimens are well-ossified and bear well-defined processes (Figs. 3-5), identical to those of individuals of other weigeltisaurids taxa considered mature by Bulanov and Sennikov (2006, 2010, 2015a-c). In extant saurians, the ossification of cranial bones increases during postnatal ontogeny (e.g. Rieppel, 1992; Maisano, 2002). Thus, completely ossified bones are indicative of maturity (Evans, 2008; Griffin et al., 2021).

The postcranium conforms well with this evaluation. The neurocentral sutures are closed on all specimens, the long bones bear well-ossified epiphyses and processes in all specimens, and all carpal and tarsal bones are present and well-ossified (Fig. 1; Carroll, 1978; Evans and Haubold, 1987). This matches the Weigeltisaurus and Rautiania specimens considered mature by Bulanov and Sennikov (2010, 2015b). Although the timing of the appearance of these features is variable among extant and extinct saurians (Griffin et al., 2021 and references therein), these characters are commonly used as indicators of morphological maturity in extinct reptiles, in particular in coeval stem-saurians from the Lopingian of Madagascar (Currie, 1981; Currie and Carroll, 1984; Caldwell, 1995).

Conversely, the presence of large orbits and pineal foramen, which are seen in Coelurosauravus (Fig. 2), are commonly used as criteria indicating skeletal immaturity (Bhullar, 2012; Griffin et al., 2021). However, as both structures are also present in the larger Ellrich specimen (Table 2) and in the more mature individuals of Rautiania (Bulanov and Sennikov, 2006), we do not consider them as indicative of immaturity in weigeltisaurids, at least with regard to currently known specimens. 
The parietal posttemporal processes of the lectotype and paralectotype are unornamented, while those of MNHN.F.MAP327b - the Coelurosauravus specimen with the shortest parietal bone (Table 2) - bear low tubercles on the medial and lateral margins of the posttemporal process. In extant reptiles, the timing of the appearance of cranial dermal ornamentation is highly variable, appearing at embryonic stages in crocodilians (Vickaryous and Hall, 2008) and chamaeleonids (Rieppel, 1993a), but much later during postnatal development in some other squamates (Evans, 2008; Glynne et al., 2020). The use of this character to assess maturity is thus highly clade-specific, and this seems to be the case for extinct reptiles as well (Griffin et al., 2021). However, the sculpturing of dermal bones regardless of the sculpturing type and timing of appearance - generally increases with age in tetrapods (Vickaryous and Hall, 2008; Witzmann et al., 2010; Buffrénil et al., 2015, 2016). Thus, despite the difference in size, we agree with Bulanov and Sennikov (2015a) that the ornamentation of MNHN.F.MAP327b indicates a more mature ontogenetic stage than the slightly larger specimens of Coelurosauravus. We agree with Bulanov and Sennikov (2015a) that this minor variability may reflect asynchronous osteogenesis in different individuals due to various unknown factors, or simply individual variation rather than subtle interspecific variation. Furthermore, the minor differences in frill length are not correlated to those of the humeral length, which conforms with slight intraspecific variations (Table 2). Substantial intraspecific variation in skull shape and size, especially concerning cranial crests, has similarly been reported in chamaeleonid (Measey et al., 2009; da Silva and Tolley, 2013) and phrynosomatid squamates (Powell et al., 2017).

Lastly, Bulanov and Sennikov (2015a) argue that the tubercular parietal ornamentation indicates an immature stage in Coelurosauravus, although they consider the same type of ornamentation as plesiomorphic for weigeltisaurids based on the mature specimen of Glaurung (Buanov and Sennikov, 2015c). Based on the size-independent criteria described 


\title{
Skull Roof
}

In summary, we disagree with Bulanov and Sennikov (2015a) in considering all Coelurosauravus specimens as immature individuals. Instead, we consider them morphologically mature and comparable to other known weigeltisaurid specimens based on various size-independent criteria. Our interpretation suggests that the total skull length varies between weigeltisaurid taxa, with Coelurosauravus having the smallest skull of all members of the group.

\author{
All specimens show the ornamented frill typical of weigeltisaurids. The parietal and \\ squamosal bones are indeed at least three times as long as wide and form a frill posterior to \\ the skull (Figs. 3-4). The quadratojugal also makes a small contribution to the anteroventral \\ portion of the frill (Fig. 2). As reconstructed, the frill of weigeltisaurids thus encompasses the \\ entire posterior skull roof and temporal regions (Fig. 2; Bulanov and Sennikov, 2015a-b). \\ This morphology is very reminiscent of the parietosquamosal frill of ceratopsian dinosaurs \\ (e.g., Sampson et al., 1997; Dodson et al., 2007) which occupies the same regions, well \\ visible in lateral view. In contrast, the parietal crests or roofed helmets of crested squamates \\ typically only involves the posterior skull roof while the temporal region is not involved,
}


especially its ventral portion. This morphology is best exemplified by chamaeleonids (Rieppel, 1981, 1987; Rieppel and Crumly, 1997; Anderson and Higham, 2013). As such, the cranial frill of weigeltisaurids will hereafter be termed 'parietosquamosal frill' in analogy to ceratopsians. We stress that this does not indicate homology of the weigeltisaurids and ceratopsian frills, but only topological similarities.

As in all weigeltisaurids, the Coelurosauravus specimens show sharp spikes on the circumorbital bones, as well as prominent spikes on the squamosal. Based on computed tomography, Bulanov and Sennikov (2010) described these spikes as hollow and vascularized and postulated that they derived from osteoderms that fused to the dermal bones of the skull. However, no trace of this fusion can be seen, casting doubt on this interpretation (Bulanov and Sennikov, 2010:pl. 9). We note that although fusion of putative osteoderms to the skull bones is rare in reptiles (Vickaryous and Sire, 2009), small dermal ossifications typically fuse to the frill of ceratopsians during ontogeny (Samson et al., 1997; Dodson et al., 2007; Horner and Goodwin, 2006, 2008), and this could have been also the case in weigeltisaurids.

Rostrum-Bulanov and Sennikov (2015a:fig. 3A) reconstructed Coelurosauravus with a very slender rostrum, accentuated by a laterally concave maxilla and a broad postorbital region in dorsal view. However, the anterior extent of the rostrum is missing in all specimens, and the maxilla of MNHN.F.MAP327a is only visible in medial view (Fig. 5) so a definite outline of the rostrum cannot be ascertained. What is preserved of the nasal is rectangular and does not suggest a transversally constricted rostrum. Thus, we reconstruct Coelurosauravus with a gradually tapering rostrum, as is typical of contemporaneous diapsids such as Claudiosaurus or Youngina (Gow, 1975; Carroll, 1981), and similar to the skull reconstruction of Rautiania (Bulanov and Sennikov, 2006:fig. 1). The general outline and length of the rostrum in our reconstruction (Fig. 2) is inferred from the proportions of the 
more complete Weigeltisaurus holotype and the Ellrich specimen (SMNK-PAL 34899a, SMNK-PAL 2882, VB pers. obs.)

Premaxilla - The supranarial process of the right premaxilla is preserved in MNHN.F.MAP327b (Fig. 5). Owing to the preservation of the neighboring skull bones, this process is presumably preserved close to its natural position. It is about six times as long as wide. It deeply incises the nasal posteromedially, contributing substantially to the anterior skull roof, which is typical of weigeltisaurids. It has a wedge-shaped posterior end (contra Bulanov and Sennikov, 2015a:417), identical to that of Rautiania (Bulanov and Sennikov, 2010), the Weigeltisaurus holotype (Bulanov and Sennikov, 2015b) and the Ellrich specimen (VB, per. obs.; Pritchard et al., in press). The rest of the bone is missing. Therefore, the entire outline of the bone cannot be reconstructed.

All stem-saurians possess a slender supranarial process emerging dorsally from the premaxilla. This might be a synapomorphy of diapsids (deBraga and Reisz, 1995). However, the length of this process is highly variable, being short in some taxa (e.g., Petrolacosaurus, Reisz, 1981) and elongate in others, generally in those taxa with an elongate snout (e.g., Youngina, Gow, 1975). Some early saurians also show a complete reduction of the supranarial process, such as the gliding kuehneosaurids (Robinson, 1962; Evans, 2009) or some archosauromorphs (Dilkes, 1998; Flynn et al., 2010).

Maxilla - The left maxilla is preserved in medial view in MNHN.F.MAP327b (Fig. 6). It is about three times as long as high and likely represents the longest bone in the snout (Figs. 2, 6). It tapers in height anteriorly but its anterior portion is missing. It is thus impossible to describe the participation of this bone to the naris.

The maxilla gradually increases in height posteriorly up to the highest part of the maxillary dorsal lamina, at about the anteroposterior midpoint of the bone. This lamina 
abutted the nasal and prefrontal, and it is incised by a small preorbital fenestra (sensu Bulanov and Sennikov, 2015a:420), as is typical in weigeltisaurids (Bulanov and Sennikov, 2015a-b). As clearly seen in MNHN.F.MAP327b, this fenestra deeply incises the maxilla, which forms its entire anterior, ventral and posterior margins. In contrast, both the maxilla and nasal contribute equally to the anterior and posterior margins of the preorbital fenestra in the Weigeltisaurus holotype (Fig. 6C-D; Bulanov and Sennikov, 2015b). The dorsal margin of the maxilla between the naris and preorbital fenestra is straight and oriented anteroventrally, as in the Weigeltisaurus holotype (Fig. 6C-D) and the Ellrich specimen (VB, pers. obs.). In contrast this margin is rounded and longitudinally shorter in both Rautiania morphotypes (Bulanov and Sennikov, 2006), which might be a synapomorphy of this taxon.

The dorsal lamina of the maxilla is low and expands only slightly above the alveolar portion in early eureptiles and araeoscelidians (e.g., Heaton, 1979; Reisz, 1981). However, it is at least 1.5 times higher than the alveolar portion in most early neodiapsids (e.g., Acerosodontosaurus, Youngina, Gow, 1975; Currie, 1980). The latter condition is also prevalent in early archosauromorphs (e.g., Prolacerta, Protorosaurus, Modesto and Sues, 2004; Gottmann-Quesada and Sander, 2009) and some early lepidosauromorphs (Gephyrosaurus, Sophineta, Evans, 1980; Evans and Borsuk-Białynicka, 2009). In some taxa with a high dorsal lamina of the maxilla, this lamina is longitudinally shortened so that it is roughly as high as long in lateral view. This is the case in Claudiosaurus (Carroll, 1981) and some early lepidosauromorphs (e.g., Fraxinisaura, Marmoretta, Evans, 1991; Schoch and Sues, 2018b).

The posterior margin of the dorsal lamina of the maxilla of MNHN.F.MAP327a is concave as in other weigeltisaurids (Fig. 6C-D; Bulanov and Sennikov, 2015b) and bears continuous suture facets for the lacrimal and prefrontal bones (Fig. 6). It merged continuously with the suborbital process, which forms a straight posteroventrally oriented dorsal margin. 
The suborbital process extends posteriorly, contributing broadly to the anteroventral orbital margin in MNHN.F.MAP327b, which is typical for weigeltisaurids (Fig. 6; Bulanov and Sennikov, 2015b). Posteriorly, this process bears a dorsal articular surface for the jugal (Fig. 6). The maxilla is generally excluded from the anteroventral orbital margin in early neodiapsids and saurians by a lacrimojugal and/or a prefrontojugal contact (e.g., Carroll, 1981; Gottmann-Quesada and Sander, 2009). In particular, this appears to be the case in drepanosauromorphs (Renesto et al., 2010). In contrast, the maxilla participates in the anteroventral orbital margin in kuehneosaurids (Robinson, 1962), early lepidosauromorphs (Marmoretta, Sophineta, Waldman and Evans, 1994; Evans and Borsuk-Białynicka, 2009), rhyncocephalians (Diphydontosaurus, Gephyrosaurus; Evans, 1980; Whiteside, 1986) but not in squamates (Eichstaettisaurus, Huehuecuetzpalli, Reynoso 1998; Simões et al., 2017 and see Evans, 2008).

The medial surface of the dorsal lamina bears a deep concavity situated ventral to the preorbital foramen, extending anteroventrally to the limit of the preserved portion of the bone (Fig. 6). Its position is similar to the nasal gland cavity described in lepidosauromorphs, although the latter seems much shallower (e.g. Evans, 2008; Evans \& Borsuk-Białynicka 2009). As was argued by Bulanov and Sennikov (2015a:420), this cavity of MNHN.F.MAP327b is in continuity with the lacrimal and prefrontal suture facets, and more probably housed the nasolacrimal duct. This interpretation conforms to the reconstructed pathway of the nasolacrimal duct in Orovenator (Ford and Benson, 2019:fig. 5). Such a cavity could not be identified on the Ellrich specimen (VB, pers. obs.; Pritchard et al., in press), the only western European specimen which preserves the maxilla in medial view. The maxilla of MNHN.F.MAP327b also bears a slender shallow cavity just dorsal to the alveolar shelf, which is situated vertical to the apex of the dorsal lamina (Fig. 6). This cavity probably housed the dorsal alveolar canal, although no foramina are visible. More posteriorly, the 
alveolar shelf bears a shallow rhomboidal suture facet for the palatine (Fig. 6). According to Bulanov and Sennikov (2015a:420), this suggests that the choanae of Coelurosauravus were longitudinally elongate and protruded posteriorly as in Youngina. Evans and Haubold (1987:fig. 21) interpreted an elongate recess positioned posteriorly between the jugal facet and the alveolar margin as the suture facet for the ectopterygoid (Fig. 6). However, owing to the width of the ectopterygoid, this surface is too close to that for the palatine (Fig. 2). We thus reconstruct the ectopterygoid more posteriorly, and it is possible that it also contacted the jugal. This conforms well with the length of the pterygoid bone and the position of the transverse flange (Fig. 2). We are, however, unable to anatomically identify the surface described by Evans and Haubold (1987).

The alveolar shelf of Coelurosauravus is horizontal, transversely wide, and its dorsal and ventral margins taper posteriorly (Fig. 6). There are 18 incompletely preserved teeth and two empty alveoli. The teeth are arranged in a densely packed row, as in all weigeltisaurids (Bulanov and Sennikov, 2006, 2015b). The tooth count is similar to that estimated for Rautiania minichi and the Weigeltisaurus holotype (Bulanov and Sennikov, 2006, 2015b), but significantly less than the 30 teeth estimated for Rautiania alexandri (Bulanov and Sennikov, 2006).

Bulanov and Sennikov (2015a:420) considered that the apices of the posterior teeth are not reproduced in latex casts. We were unable to observe the bottom of the tooth cavities as they are deeply encased in the matrix. However, based on the complete rendering of some teeth on both Bulanov and Sennikov's (2015a:pl. 5) cast and ours (Fig. 6), we think that at least some cavities are empty, such as that of preserved tooth 14. The preserved teeth of MNHN.F.MAP327b thus seem to gradually decrease in height posteriorly. In contrast, the anterior teeth are not significantly larger than the more posterior ones in the Weigeltisaurus holotype (Fig. 6), the Ellrich specimen (VB pers. obs.; Pritchard et al., in press), or in both 
Rautiania morphotypes (Bulanov and Sennikov, 2006). The posteriormost portion of the maxilla is edentulous.

There are no caniniform teeth in the maxilla of MNHN.F.MAP327b, and their absence is considered as a synapomorphy of neodiapsids (Laurin, 1991). The teeth all bear conical and sharply pointed crowns without carinae. The few completely preserved apices are roughly vertical (Fig. 6), while those of the Weigeltisaurus holotype (Fig. 6) and the Ellrich specimen (VB pers. obs.; Pritchard et al., in press) are slightly recurved. The teeth of MNHN.F.MAP327b are roughly circular in cross-section. In contrast, Rautiania, exhibits labiolingually compressed mid-posterior teeth (Bulanov and Sennikov, 2006, 2010) while the posterior teeth of Glaurung are labiolingually compressed with slightly mesiodistally expanded apices (Bulanov and Sennikov, 2015c).

There is no lingual shelf covering the base of the teeth on MNHN.F.MAP327b (Fig. 6). Following recent definitions, this suggests a pleurodont dentition whereby "the teeth are attached to the lingual surface of the labial wall of the jaw" (LeBlanc et al., 2020:1), resulting in an asymmetric tooth attachment (Jenkins et al., 2017; Bertin et al., 2018; LeBlanc et al., 2020). This agrees with previous descriptions of weigeltisaurids including Coelurosauravus (Carroll, 1978; Evans and Haubold, 1987).

Pleurodonty is often used to suggest lepidosauromorph affinities (e.g., Schoch and Sues, 2018b; Cavicchini et al., 2020). Based on recent definitions (see above), pleurodonty appears to be rare outside lepidosauria, being only reported in early captorhinomorphs (LeBlanc and Reisz, 2015), some thalattosaurians (Druckenmiller et al., 2020), a few sauropterygians (Chun et al., 2016; de Miguel Chaves et al., 2018) and the enigmatic neodiapsid Claudiosaurus (Carroll, 1981). A 'subpleurodont' dentition has also been reported in Palaeagama although no criteria were given (Carroll, 1975). 
Lacrimal-Among weigeltisaurids, the lacrimal has only been tentatively identified as a badly crushed element in the Weigeltisaurus holotype (Bulanov and Sennikov, 2015b:fig. 1). However, we instead interpret the lacrimal of this specimen as a crescentic element just posterior to the maxilla and ventral to the prefrontal (Fig. 6C-D). It forms the ventral half of the anterior orbital margin, but hardly extends onto the snout anteriorly, being restricted anteriorly by the prefrontal and maxilla. This element was previously figured and tentatively identified as prefrontal fragments or the lacrimal by Evans and Haubold (1987:fig. 2). As a result, the lacrimal of the Weigeltisaurus holotype is much better defined than reconstructed by Bulanov and Sennikov (2015b:fig. 2).

Our new interpretation of the lacrimal in the Weigeltisaurus holotype results in a tentative identification of the lacrimal in Coelurosauravus (Fig. 5). Bulanov and Sennikov (2015a:420) identified a slender bone lying near the right prefrontal, pterygoid and quadrate as a broken off and displaced pterygoid quadrate ramus. Owing to the excellent preservation of the neighboring skull bones and the close proximity of this bone and the right prefrontal, we find this interpretation unlikely. Instead, we interpret this bone as a slightly rotated right lacrimal, visible in lateral view (Fig. 5).

The bone lies upside-down relative to the corresponding contact facets on the right prefrontal. The dorsal portion is broad and rounded, its ventral one tapers to a point posteroventrally. The orbital margin of the lacrimal is slightly more robust. There is virtually no facial expansion so that the lacrimal fitted between the prefrontal and maxilla and formed the anterior orbital margin. Presumably, it also formed the lateral wall of the lacrimal foramen.

Strong reduction of the lacrimal bone is uncommon among early diapsids (e.g., Petrolacosaurus, Youngina, Gow, 1975; Reisz, 1981) and archosauromorphs (e.g., Prolacerta, Protorosaurus; Modesto and Sues, 2004; Gottmann-Quesada and Sander, 2009). 
In contrast, the lacrimal of lepidosauromorphs underwent a reduction early in their evolutionary history (Evans, 2003, 2008). This bone is reduced or absent in most of the earliest taxa known from the Triassic (e.g., Clevosaurus, Diphydontosaurus, Megachirella, Sophineta; Whiteside, 1986; Fraser, 1988; Evans and Borsuk-Białynicka, 2009; Simões et al., 2018).

Nasal-The posterior portion of the right nasal is present in situ in ventral view in MNHN.F.MAP327b but is absent on the other Coelurosauravus specimens. The preserved fragment is elongate and quadrangular with a roughly constant width (Fig. 5). Bulanov and Sennikov (2015a:417, pl. 5) identified a bone fragment lying between the right nasal and prefrontal on MNHN.F.MAP327b as the broken off lateral margin of the nasal, bearing the dorsal margin of the preorbital fenestra. However, a break of the nasal appears unlikely to us considering the good preservation of the neighboring bones, and we alternatively identify this structure as the anterior portion of the right prefrontal. Its shape is thus similar to the betterpreserved left prefrontal, and it contributes to the nasolacrimal duct (Fig. 5). The lateral margin of the nasal is obscured and there is neither a trace of the margin of the preorbital fenestra nor of the low anterolateral crest described for the Weigeltisaurus holotype (Bulanov and Sennikov, 2015b).

The suture between the nasal and frontal is very hard to identify and has only been tentatively followed through RTI photographs (Fig. 5). What is visible indicates a serrated anteromedially oriented suture, suggesting that both nasals were probably separated posteromedially by the adjoined anterior processes of the frontals, contrary to the reconstruction of Bulanov and Sennikov (2015a:fig. 3).

Prefrontal-Both prefrontals are preserved in MNHN.F.MAP327b. The right one is visible in ventromedial view in connection with the neighboring bones. The left one is displaced but exquisitely preserved and visible in lateral and posterolateral views (Fig. 5). The 
posterodorsal portion of the right prefrontal is also preserved in situ in MNHN.F.MAP317b (Fig. 4). The prefrontal expands anteriorly onto the posterior snout, and posterodorsally, forming roughly the anterodorsal quarter of the dorsal orbital margins (Fig. 2).

The posterodorsal process of the prefrontal braces the frontal laterally and extends posteriorly over a third of the orbit length (Figs. 4-5), as on the Weigeltisaurus holotype (Fig. 7) and the Ellrich specimen (VB, pers. obs.; Pritchard et al., in press). The dorsal portion of the bone is dorsoventrally thin and extends laterally, bearing a sharp and faintly ornamented ridge (Fig. 5).

Excluding the ornamented ridge, the dorsal and facial portions of the bone gradually merge into each other. The facial portion of the bone extends ventrally over at least half of the height of the orbit. It expands anteroventrally and bears an inverted V-shaped recess with the apex meeting the anterior extent of the lateral ornamented ridge. As was argued by Bulanov and Sennikov (2015a:419), this recess is deeply incised laterally and formed the medial wall of the posterior portion of the posterior portion of the nasolacrimal duct (Fig. 5). Both dorsal and ventral margins of this V-shaped cavity meet the dorsal lamina of the maxilla, with the ventral one thickening into a ventral footplate-like process abutting on the latter bone (Fig. 5). The dorsal margin bears a low, sharp longitudinal ridge for the reception of the dorsal lamina of the maxilla. Presumably, this V-shaped recess was partially covered laterally by the lacrimal (Fig. 2).

Frontal-The frontal is preserved on all specimens. It is preserved on both sides in MNHN.F.MAP317b, where it is visible in dorsal view, although it is unclear whether the anteriormost portion is preserved or not (Figs. 4). We were indeed unable to trace the nasofrontal suture reported by Evans and Haubold (1987:fig. 3) on this specimen, even using RTI photographs. Additionally, both bones are poorly preserved on the lectotype MNHN.F.MAP325a (Fig. 3), and the right frontal is preserved in ventral view on 
MNHN.F.MAP327b, lying in connection with the neighboring bones of the skull roof (Fig. $5)$.

The frontal is elongate and triangular, about three times as long as its minimum length width. The lateral margins of both frontals gradually diverge posteriorly, each bone reaching its maximum width posterior to the orbit (Figs. 2-4). Each bone extends across the entire orbital region. Its suture with the nasal is only tentatively identified on MNHN.F.MAP327b (see above, Fig. 5). The frontal broadly contributes to the mid-dorsal orbital margin, separating the prefrontal and the postorbital (Fig. 2). As seen on MNHN.F.AMP317b, the orbital margin of each frontal bears a faint ornamentation similar to that of the left prefrontal of MNHN.F.MAP327b (see above, Figs. 4-5). Posteriorly, the frontoparietal suture is coarsely sinusoidal ('zigzagged' according to Bulanov and Sennikov, 2015a:417), as is best seen in MNHN.F.MAP317b (Fig. 4). The posterior margin of each frontal is incised at mid-width by the anteromedial process of the parietal, dividing the posterior quarter of the frontals into a posteromedial and a posterolateral process.

As is seen in MNHN.F.MAP327b, the cranial crests of the frontal ventrally reinforce the orbital margin and are continuous with the robust orbital margin of the prefrontal (Fig. 5). Medially, the frontal bears a ventrally projecting lamina that Bulanov and Sennikov (2015a) considered diagnostic of the genus (Fig. 5B, reconstructed in lateral view on Fig. 2C). This lamina differs from the subolfactory processes of squamates, which extend ventromedially from the lateral portion of the frontal (e.g., Gauthier et al., 2012). Presumably, this lamina provided bony support for the interorbital septum in Coelurosauravus. We were unable to identify a similar structure on the Weigeltisaurus holotype (SMNK cast of SSWG 113/7, VB, pers. obs.) or the Ellrich specimen (VB, pers. obs.). However, it might have been obliterated by late diagenetic compression of the German material. 
Postfrontal—We follow Bulanov and Sennikov (2015a:423) in identifying the only bone in the posterolateral corner of the orbit as the postorbital due to its ventral contact with the jugal, which is typical for early amniotes (e.g., Romer, 1956). Consequently, we concur with Bulanov and Sennikov (2015a-c) that the postfrontal bone is absent as a discrete element in weigeltisaurids. Determination of whether this bone was lost or became fused to the postorbital is impossible based on the known material and is out of the scope of this study.

Among eureptiles, the loss of a distinct postfrontal is only reported among saurian taxa (turtles, some archosauromrophs and lepidosauromorphs; Lee, 1995; Conrad, 2008; Nesbitt, 2011), with the proterochampsian archosauriforms providing the earliest appearance of this character in the Middle-Late Triassic (Nesbitt, 2011). As such, the loss of a distinct postfrontal in weigeltisaurids represents the earliest occurrence of this feature in sauropsids.

Postorbital-The right postorbital is partially preserved in dorsal view and lies adjacent to the neighboring bones in the lectotype and MNHN.F.MAP317b (Figs. 3-4). The bone is complete and better preserved in MNHN.F.MAP327a-b, where it lies in connection with the left parietal, far away from the other cranial elements (Figs. 5, 7).

The postorbital has an inverted L-shape and forms the dorsal half of the posterior orbital margin and a small portion of the skull roof (Figs. 2), which is also the case in the Weigeltisaurus holotype (Fig. 6C-D) and the Ellrich specimen (VB pers. obs.). It is thus biradiate and lacks the posterior process that is present in the triradiate postorbital of all other stem-saurians where this region is known (e.g., Carroll, 1975, 1981; Gow, 1975; Currie, 1980, 1981; Reisz, 1981). As a result, the supratemporal bar is absent in weigeltisaurids, although an incipient postorbital posterior process contributing to the dorsal margin of the temporal fenestra has been reported in Glaurung (Bulanov and Sennikov, 2015c, but see discussion below). 
The dorsomedial process of the postorbital is preserved on all Coelurosauravus specimens (Figs. 3-5, 7). It is subtriangular with a convex posterior margin and contributes to the skull roof and the posterodorsal orbital margin. Anteriorly, the dorsomedial process is acuminate and contacts the posterolateral process of the frontal. It underlies the frontal and thus occupies a similar position to the postfrontal of other amniotes (e.g., Romer, 1956). The dorsomedial and ventral processes of the postorbital merge at a roughly right angle, as is the case on the Weigeltisaurus holotype (Fig. 6C-D) and in Rautiania (Bulanov and Sennikov, 2015b). This angled portion fits into the recess in the anterolateral margin of the parietal (Figs. 2, 4, 7).

The ventral process of the postorbital is slender and vertical (Figs. 5, 7). It is elongate and abuts on the dorsal process of the jugal ventrally. It forms the dorsal portion of the posterior orbital margin and the anterior margin of the temporal fenestra (see below). In contrast, the ventral process of the postorbital is acuminate and incises the dorsal process of the jugal on the Weigeltisaurus holotype (Fig. 6C-D). The postorbital of MNHN.F.MAP327a$\mathrm{b}$ bears two robust spikes, one on the dorsomedial process, near its meeting point with the ventral process, and a larger one on the dorsal portion of the ventral process (Fig. 7A). The external surface of the postorbital of MNHN.F.MAP317b is smooth while that of the lectotype bears three slender tooth-like dorsal projections (Fig. 3). The Weigeltisaurus holotype bears a third low ventral tubercle just dorsal to the postorbitojugal suture (Fig. 6C-D; Bulanov and Sennikov, 2015b).

Jugal-The left jugal is visible in lateral view in MNHN.F.MAP327b. It lies disarticulated from the other skull bones (Fig. 5). This bone is triradiate, with subequal anterior and dorsal processes and a 1.3 times longer posterior process. This morphology is similar to that of Rautiania (Bulanov and Sennikov, 2015a:fig. 2N) but contrasts with the 
reduced anterior process of the Weigeltisaurus holotype (Fig. 6C-D) and the Ellrich specimen (Pritchard et al., in press).

As reconstructed, the anterior process of the jugal of Coelurosauravus extends anteriorly ventral to the orbit over almost half the orbital length (Fig. 2). This process is acuminate and bears a ventral suture facet for the maxilla anteriorly. The dorsal process of the jugal is vertical and ends bluntly, abutting on the ventral process of the postorbital and forming the ventral portion of the postorbital bar. It does not interdigitate with the ventral process of the postorbital, in contrast to the Weigeltisaurus holotype where the ventral process of the postorbital fits in a recess on the dorsal process of the jugal (Fig. 6C-D). The posterior process of the jugal is the thinnest and longest, forming most of the ventral margin of the temporal fenestra and the temporal region of the skull. It ends bluntly and presumably contacts the quadratojugal, completing the infratemporal bar.

The jugal of MNHN.F.MAP327b is ornamented. Each process of the bone bears a sharp spike with an elongate base, the main axis of which radiates from the center of the bone (Fig. 5). In addition, the dorsal process bears a small knob-like protrusion near its tip. The external surface of the dorsal process of the jugal is devoid of such ornamentation in Rautiania (Bulanov and Sennikov, 2015a:fig. 2N) and the Weigeltisaurus holotype (Fig. 6CD).

Parietal-The parietal is preserved in all specimens. This bone is hatchet-shaped in dorsal view and contributes to the dorsal portion of the parietosquamosal frill (Fig. 2). Both parietals are preserved in situ in the lectotype and MNHN.F.MAP317a-b (Figs. 3-4). The anterior portion of the right parietal of MNHN.F.MAP327b lies in connection with the neighboring skull bones, while the left one is displaced but perfectly preserved in ventral and dorsal views, lying near the left postorbital and squamosal (Fig. 7). 
The parietal of Coelurosauravus bears a broad, horizontal and greatly elongate posttemporal process that extends the skull table posteriorly, forming a quarter of the total skull length (Table 2). This process forms the dorsolateral margin of the parietosquamosal frill, which is typical of weigeltisaurids (Fig. 7; Bulanov and Sennikov, 2006, 2010, 2015a-c). The posttemporal process extends posteriorly from the posterolateral margin of each parietal, forming a deep posteromedial recess in the occipital part of the skull. The postorbital wedges into a deep recess at the junction between the main body of the parietal and the posttemporal process (Fig. 7).

The posttemporal process is a dorsoventrally thin sheet of bone. It is straight and maintains a constant width before tapering to a blunt end in its posterior quarter (Fig. 7). Among weigeltisaurids, this morphology is most similar to that of Glaurung (Bulanov and Sennikov, 2015c). In contrast, the posttemporal processes of both Rautiania morphotypes and the Weigeltisaurus holotype (Bulanov and Sennikov, 2006, 2015a-b), and of the Ellrich specimen (VB, pers. obs.; Pritchard et al., in press) show some degree of medial curvature and gradually decrease in width posteriorly.

As seen in MNHN.F.MAP327b, the dorsal margin of the posttemporal process is concave between the raised medial and lateral margins, which extend anteriorly onto the skull roof and bear small tubercles creating an irregular crenulated surface (Fig. 7A). The medial margin is supported by a sharp ridge that extends to the anterior margin of the bone, delimiting the anteromedial extent of the posttemporal process (Fig. 7A-B). The posttemporal process of the lectotype and MNHN.F.MAP317a-b is thinner and smooth, which could be attributed to individual variation (see above, Figs. 3-4). The parietal ornamentation of MNHN.F.MAP327a-b is similar to that of Glaurung (Bulanov and Sennikov, 2015c). In contrast, Rautiania, the Weigeltisaurus holotype (Bulanov and Sennikov, 2010, 2015b) and 
the Ellrich specimen (Pritchard et al., in press) all bear prominent dorsolaterally oriented, spikes on the lateral margin of the posttemporal process.

The body of the parietal forms the posterior portion of the skull roof. It bears a broad and convex anterior process incising the middle of the posterior margin of the frontal, forming a coarsely sinusoidal suture (Fig. 4). In contrast, the frontoparietal suture is usually U-shaped in Permo-Triassic reptiles, with the anteromedial process of the parietal extending medial to the frontal (e.g., Carroll, 1981; Reisz, 1981; Gottmann-Quesada and Sander, 2009; Evans, 1980, 2009). In Coelurosauravus, the bone also bears a pointed anterolateral process partially separating the frontal from the postorbital (Fig. 5). The medial margin of the bone is marked by a deep incision in all Coelurosauravus specimens, indicating an extremely large pineal foramen occupying at least half of the interparietal suture (Fig. 7). The surface of the bone immediately posterior to the pineal foramen sharply turns dorsally.

Ventrally, the parietal bears several ridges (Fig. 7C-D). The posterior margin of the bone extends in a sharp transverse ventral postparietal lamina (Fig. 7D). This lamina may have served for the articulation with the supraoccipital, or alternatively as the origin area of the nuchal muscles. Although we found no trace of a postparietal, this lamina could also have served for the articulation with this bone. Paired posparietals indeed seem to be preserved in the Ellrich specimen (VB, pers. obs.; Pritchard et al., in press). The anterolateral margin of the parietal is also sharply turned ventrally at a right angle, continuing anteromedially as a ridge, forming the postorbital sutural facet. A sharp medial ridge extends longitudinally over the ventral surface of the posttemporal process (Fig. 7B). This ridge likely served as the origin area of the external adductor musculature by analogy with the jaw musculature of crested chamaeleonids (see discussion below). This ridge becomes gradually sharper posteriorly before transforming into a sharp ventral lamina in its posterior third. This lamina served as the articulation flange to accommodate the squamosal (Fig. 7D). A shallower parasagittal ridge 
extends from the anterior end of the adductor ridge to the level of the posterior margin of the pineal foramen (Fig. 7). The size, orientation and position relative to the pineal foramen conforms well with similar ridges identified as the point of attachment of the cartilaginous taenia marginalis in other early reptiles (Reisz, 1981; Ford and Benson, 2019). As the taenia marginalis connects the otic capsule to the braincase in reptiles (Romer, 1956), this ridge likely delimited the lateral wall of the neurocranium. A small ovate depression lies between the attachment point of the taenia marginalis and the pineal foramen (Fig. 7D). This depression might be linked to the midbrain, which is roofed by the parietal in reptiles (e.g. Fabbri et al., 2017), but we were unable to assess its homology. Alternatively, this structure might result from a concretion in the nodular matrix that is indistinguishable from the parietal bone on the specimens due to the lack of bone matter.

Squamosal-The left squamosal is preserved in ventral and dorsal views in MNHN.F.MAP327a-b, lying near the left postorbital and parietal (Fig. 7). Both squamosals are preserved in situ in the lectotype and MNHN.F.MAP317a-b (Figs. 3-5).

As in all weigeltisaurids, the squamosal, forms the ventrolateral margin of the parietosquamosal frill and is vastly different from the tetra- or triradiate bone of other early diapsids (e.g., Reisz, 1981). The squamosal is at least four times as long as wide, and is roughly straight on all Coelurosauravus specimens (Figs. 2-6, 7). In contrast, this bone is dorsally curved in Rautiania, the Weigeltisaurus holotype (Bulanov and Sennikov, 2010, 2015b) and the Ellrich specimen (Pritchard et al., in press). The squamosal of Glaurung shows sharply angled dorsal and ventral portions (Schaumberg et al., 2007; Bulanov and Sennikov, 2015c).

As is best seen in MNHN.F.MAP317a, the squamosal is slightly broader anteroventrally than posterodorsally and bears broad suture surfaces for the quadratoquadratojugal complex (Fig. 7). The squamosal also bears an anteroposteriorly thin 
posteromedial lamina (Figs. 4, 7). It fitted into the corresponding suture line on posterior surface of the quadrate. In addition, the main body of the squamosal extends ventrolaterally and fits into a facet on the lateral surface of the quadrate. As such, the squamosal braced the quadrate laterally and posteriorly. The quadrate is also braced laterally and posteriorly in early reptiles, including araeoscelidians (Reisz, 1981), but the posterior lamina is lost in most other neodiapsids in which the quadrate is only braced laterally (Gow, 1975; Currie, 1981).

The squamosal of MNHN.F.MAP327a-b and MNHN.F.MAP317a-b bears five spikes (Fig. 7), which may be the usual number in Coelurosauravus. This is also the number reported for Rautiania (Bulanov and Sennikov, 2010). The number of spikes for the Weigeltisaurus holotype is seven or eight (SMNK-PAL 34899a, VB, pers. obs.). The morphology of those spines shows strong intraspecific variability in Coelurosauravus. On the lectotype and the better preserved MNHN.F.MAP327a-b, the anterior spikes are stout with the width of the base and height being subequal. Furthermore, the spikes are more closely packed than the more widely spaced, sharper and more slender posterior ones, which are 1.2 times longer than wide (Figs. 3, 7). In contrast, MNHN.F.MAP317a-b shows the opposite pattern, with the anterior spikes being sharper than the posterior ones (Fig. 4). In Coelurosauravus, as in Rautiania and the Weigeltisaurus holotype, the spikes extend to the posterodorsal margin of the bone, while the dorsal portion of the bone surface is smooth in Glaurung (Bulanov and Sennikov, 2015c).

Quadratojugal—Based on articulated material of Rautiania, Bulanov and Sennikov (2010) describe the quadratojugal of weigeltisaurids as a very small bone lacking both dorsal and anterior processes but bearing a spike on its external surface, similar to those of the squamosal. The quadratojugal was previously undescribed for Coelurosauravus (Bulanov and Sennikov, 2015a). We tentatively interpret a slightly displaced spike anterior to the left squamosal of the lectotype as a quadratojugal spike (Fig. 3). As preserved, this spike is not 
oriented in the same plane as any of the spikes from the left and right squamosals, suggesting that it is part of a distinct bone or element. The relationship of the quadratojugal to the quadrate is reconstructed based on well-preserved material of Rautiania (Fig. 2; Bulanov and Sennikov, 2010:fig. 1, pl. 9).

The anterior process of the quadratojugal is elongate in stem-saurians such as araeoscelidians or Youngina (Gow, 1975; Reisz, 1981), forming up to half of the infratemporal bar (ITB) although it is reduced in Claudiosaurus (Carroll, 1981) and weigeltisaurids (Bulanov and Sennikov, 2010). In contrast, the anterior process of the quadratojugal is often reduced in saurians regardless of the completeness of the ITB, rarely extending beyond a third of the ITB in early archosauriforms (e.g. Nesbitt, 2011; Ezcurra, 2016).

The dorsal process of the quadratojugal is very small in weigeltisaurids (Bulanov and Sennikov, 2010) and in stem-saurians such as Petrolacosaurus or Claudiosaurus (Carroll, 1981; Reisz, 1981) and possibly Youngina (Gow, 1975, but see Gardner, pers. comm. in Pritchard, 2015). This process is similarly small in early lepidosauromorphs (e.g., Gephyrosaurus, Sophineta, Evans, 1980; Evans and Borsuk-Białynicka, 2009). In kuehneosaurids the quadratojugal is absent (Evans, 2009). In contrast, the dorsal process of the quadratojugal is often well developed in archosauromorphs (Müller, 2003).

Quadrate - The left quadrate is preserved in posteromedial view on MNHN.F.MAP327b (Fig. 5). It is small and vertically oriented. The posterior margin of the bone is straight, expanding into a thin dorsal process. The pterygoid ramus expands anteriorly to an unknown extent, as its anterior portion is missing. The dorsomedial surface of the bone is marked by a deep excavation, presumably the suture line for the squamosal and pterygoid. The posteroventral portion of this excavation forms a notch, which we interpret as the posterior paraquadrate foramen due to its similarity to that described for Rautiania (Fig. 5; 
Bulanov and Sennikov, 2010). Ventrally, the bone bears two articular condyles. Both condyles are separated by a deep sulcus, with the lateral one extending twice as much ventrally as the medial one (Fig. 5).

The quadrate of most saurians has a concave posterior margin, a lateral tympanic crest (Laurin, 1991), and an expanded, slightly convex, dorsal head (e.g., Evans, 1991; Simões et al., 2018; Pritchard and Sues, 2019). That of Paliguana and lepidosauromorphs also bears a lateral tympanic conch (Carroll, 1975; Evans, 2003). The quadrate morphology of weigeltisaurids thus conforms well with that of stem-saurians in lacking a tympanic crest and conch, and having a slender dorsal head (e.g., Hovasaurus, Petrolacosaurus, Youngina, Gow, 1975; Currie, 1981; Reisz, 1981).

\section{Palate}

The palate is only partially preserved in MNHN.F.MAP317a-b and MNHN.F.MAP327b (Figs. 4-5). We here provide the first reconstruction of the palate of Coelurosauravus, which is also the first palatal reconstruction of any weigeltisaurid (Fig. 2B). In all specimens the bones are disarticulated and displaced. There is no trace of the vomers in any of the preserved specimens. As reconstructed, the palate shows a large interpterygoid vacuity and large paired suborbital fenestrae and subtemporal fossae (Fig. 2B).

Palatine - The left palatine is exposed in ventral view in MNHN.F.MAP327b, lying close to the left pterygoid (Fig. 5). The bone is asymmetrical, with the medial margin three times as long as the lateral margin. Both anterior and posterior margins are deeply embayed, separating the palatal surface and maxillary process by a short, robust neck.

The medial portion of the bone reaches its maximum length and minimum thickness (i.e. dorsoventral height) at its medial margin. The entire ventromedial margin of the bone 
bears a deep longitudinal facet for the palatal process of the pterygoid. This facet gradually increases in transverse width posteriorly, reaching its maximum width level with the maxillary process before gradually tapering to a point posteriorly (Fig. 5). The pterygoid facet is framed laterally by a ridge, marking a step-like increase in the thickness of the palatine. This ridge bears an anteromedially oriented row of at least four palatal teeth posterior to the maxillary process (Fig. 5). These teeth are very small, less than $2 \mathrm{~mm}$ in diameter. As reconstructed, the palatine contacted the ectopterygoid posterolaterally (Fig. 2B), although this contact may be artificial, as we are unable to identify a contact area on either the lateral surface of the palatine or the medial surface of the ectopterygoid.

The asymmetrical anterior margin of the bone is concave with the vomerine process extending at least three times further anteriorly than the maxillary process. It thus forms the posterior and posteromedial margins of the choana (Fig. 2). The posterior margin of the palatine is similarly asymmetrical, forming the anterior and anteromedial margins of a posteriorly widening suborbital fenestra. Laterally, the maxillary process expands rapidly and bears an elongate suture facet for the maxilla.

Suborbital Fenestra-The presence of a suborbital fenestra has long been considered a synapomorphy of diapsid reptiles (Laurin and Reisz, 1995; deBraga and Rieppel, 1997). Its outline can be reconstructed in Coelurosauravus based on the margins of the neighboring bones (Fig. 2B). This fenestra is subtriangular and gradually widens posteriorly. Its medial margin is oriented parasagittally and its lateral one anterolaterally. The suborbital fenestra ends bluntly anteriorly, which contrasts to the anteriorly pointed suborbital fenestra of rhyncocephalians (Evans, 1980; Whiteside, 1986; Fraser, 1988).

Diapsids show a trend of an enlargement of the posterior portion of the suborbital fenestra. The fenestra of araeoscelidians is long and narrow, as in Claudiosaurus (Carroll, 1981; Reisz, 1981). That of younginiforms broadens slightly posteriorly although it lacks a 
posterior transverse expansion as the palatine retains a longitudinally oriented lateral margin (Gow, 1975; Carroll, 1981). The proportions of the suborbital fenestra are highly variable in early saurians (e.g. Ezcurra, 2016), although some show a posteriorly widened fenestra reminiscent of that of weigeltisaurids (e.g. Marmoretta, Prolacerta, Evans, 1991; Waldman and Evans, 1994; Modesto and Sues, 2004). A posteriorly expanded suborbital fenestra could support affinities with younginiforms or saurians.

Pterygoid - Both pterygoids are preserved in MNHN.F.MAP327b. The left one lies in ventral view near the left palatine while the right one, exposed in dorsolateral view lies isolated at some distance to the other cranial remains (Fig. 5). Both pterygoids are partially preserved in MNHN.F.MAP317a-b (Fig. 4), but to a larger extend than previously reported by Bulanov and Sennikov (2015a). The right one lies anteriorly, overlying the frontals in ventral view, while the left lies just anterior to the parabasisphenoid.

The entire left palatal ramus is preserved in MNHN.F.MAP327b. It is elongate, thin and crescentic in ventral view, tapering gradually anteriorly before ending in an anterior wedge-shaped extremity. The concave medial margin suggests an elongate interpterygoid vacuity and a contact between both pterygoids restricted to the anterior wedge-shaped terminus of the bone (Fig. 2B). As is evident in both MNHN.F.MAP327b and MNHN.F.MAP317a, the pterygoid indeed bears a slender elongate facet in its anterior extremity. More posteriorly, as seen in MNHN.F.MAP327b, the lateral margin merges smoothly with the transverse flange described below. As is best visible in the posterior region of the original slab, the palatal ramus bears several palatal teeth arranged in two, tightly packed longitudinal rows on the medial side of the bone (Fig. 5).

The transverse flange is visible in all specimens. As best seen on the well preserved left pterygoid of MNHN.F.MAP327b (Fig. 5), this flange extends anteroventrolaterally from the posterolateral corner of the bone and merges smoothly with the palatal ramus. The lateral 
margin of the flange is slightly thickened posteriorly and bears a single row of palatal teeth similar in size to those of the palatal ramus (Fig. 5). As is visible on the right pterygoids of MNHN.F.MAP327b and MNHN.F.MAP317b, the dorsal surface of the transverse flange is slightly convex (Figs. 4-5).

The basicranial process of the pterygoid is preserved on the left pterygoid of MNHN.F.MAP317a and is identified based on its proximity to the parabasisphenoid and the close fit in size between the recess on the pterygoid and the basipterygoid processes of the latter bone (Fig. 4). It is visible in medial aspect, lying near the parabasisphenoid. The basicranial process is a robust, knob-like expansion at the meeting point of the palatal, transverse and quadrate processes of the pterygoid (Figs. 2-3). It bears a deep concave surface that encompasses the neighboring right basipterygoid process of the parabasisphenoid.

The quadrate ramus is preserved on the right pterygoid of MNHN.F.MAP327b, and on the left pterygoid of MNHN.F.MAP317a (Figs. 4-5). It is anteroposteriorly long and dorsoventrally thin. The quadrate ramus of the right pterygoid of MNHN.F.MAP327b gradually expands dorsoventrally into a high dorsal flange. As the medial margin of the bone is unpreserved, we cannot say whether an arcuate flange was present (Fig. 5C-D).

Ectopterygoid - We agree with the identification of the left ectopterygoid of MNHN.F.MAP327b by Bulanov and Sennikov (2015a:422). Based on our interpretation of the pterygoid facet (see below), the bone is preserved in ventral view and lies near in the articulated skull roof portion (Fig. 5).

Similar to the palatine, the anterior and posterior margins of the bone are strongly concave, such that the bone consists of a robust short neck and expanded medial and lateral portions. However, in contrast to the palatine, both parts are of similar size and proportions (Fig. 5). The bone thus forms the posterior and posteromedial margins of the suborbital 
fenestra, and the anterior and anteromedial margins of the subtemporal fossa (Fig. 2). The lateral portion is very similar to that of the palatine. It is robust and bears an elongate lateral margin for the articulation with the external skull bones. It is unclear if this contact was restricted to the jugal or extended over the maxilla. The ectopterygoid lateral contact is restricted to the jugal in most early diapsids (Currie, 1980, 1981; Reisz, 1981). This is also the case in most saurians (Camp, 1945; Evans and Borsuk-Białynicka, 2009; Flynn et al., 2010) although it extends over the maxilla in several groups (Evans, 1980; Spielmann et al., 2008).

A sharp ridge extends anteromedially from the posterior margin of the lateral articular facet of the bone to its anteromedial extremity. Posterior to this ridge, the medial portion of the bone bears a recess, presumably to accommodate the transverse flange of the pterygoid. As reconstructed, the ectopterygoid contacted the palatine anteriorly (Fig. 2B), although we were unable to identify any facet on either bone.

\section{Braincase}

Of the braincase bones, only the parabasisphenoid and a potential basioccipital condyle were previously identified in MNHN.F.MAP317a (Bulanov and Sennikov, 2015a:422). However, our detailed examination of the specimen results in a new interpretation of this region (Figs. 4, 8).

Parabasisphenoid-The parabasisphenoid of MNHN.F.MAP317a is well preserved and lies near its anatomical position (Fig. 8). Additionally, we interpret a flat triangular bone near the right carpus of MNHN.F.MAP327a as the parabasisphenoid due to its similar shape to that of MNHN.F.MAP317a (Fig. 8). This bone was previously identified as an atlantal neural arch by Carroll (1978:fig. 6). In both specimens, the basisphenoid and parasphenoid bones are indistinguishable. 
The parabasisphenoid is edentulous on both Coelurosauravus specimens, as in Youngina and almost all saurians (Gardner et al., 2010; Matsumoto and Evans, 2017). In contrast the parabasisphenoid of most stem-saurians is denticulated (Claudiosaurus, Lanthanolania, Petrolacosaurus, Carroll, 1981; Reisz, 1981; Modesto and Reisz, 2003), which is also the case in kuehneosaurids (Evans, 2009) and the early lepidosauromorph Fraxinisaura (Schoch and Sues, 2018b).

The cultriform process appears very reduced in both Coelurosauravus specimens and is slightly shorter than the basipterygoid processes (Fig. 8). However, this may be an artefact of preservation, suggesting that it was slightly anterodorsally oriented and its anterior portion was encased in the matrix of the lost counterpart block. A strongly reduced cultriform process indeed only occurs in some parareptiles but has otherwise not been described for other early amniotes (e.g., Carroll and Lindsay, 1985).

The main body of the bone forms an equilateral triangle, one corner of which points anteriorly. The basipterygoid processes extend anterolaterally and slightly ventrally from the base of the cultriform process (Fig. 8). They consist of a slightly elongate and constricted neck with a circular cross-section and an expanded convex head with an ovate articular surface facing anterolaterally (Fig. 8).

The parabasiphenoid of MNHN.F.MAP317a bears a pair of small foramina housing the internal carotid artery on its ventral surface, medial to the base of the basipterygoid processes (Fig. 8A). These foramina are not covered ventrally by the ventrolateral crests as is otherwise common among early diapsids (Müller et al., 2011; Ford and Benson, 2019). The ventrolateral crests are robust and low, extending posterolaterally along the lateral sides of the ventral surface of the bone but not meeting anteriorly. Instead, they remain separate. They delimit a deep ventrolateral trough on each side of the bone, presumably the vidian sulci (Fig. $8 \mathrm{~A}$ ), but these do not extend ventrolaterally as a thin lamina to floor this canal, as is the case 
in most early reptiles (Müller et al., 2011). Based on other criteria, we consider

MNHN.F.MAP317a-b as morphologically mature (see above), suggesting that the lack of contribution to the floor of the vidian sulcus does not indicate an immature ontogenetic stage and an incomplete ossification. The extent of these crests and their contribution to the floor of the vidian sulcus seem to be slightly variable in saurian reptiles as well, both inter- and intraspecifically (e.g. Evans, 1980, 1986, 2009). Conversely, a similar morphology is found in most early synapsids excluding varanopids (Ford and Benson, 2019).

The posteroventral surface of the bone is concave between the ventrolateral crests in both Coelurosauravus specimens (Fig. 8). The posterior margin of the parabasisphenoid is roughly straight, with a slightly concave medial portion. There is no trace of posterolateral processes. Most early diapsids exhibit either short (e.g., Claudiosaurus, Petrolacosaurus, Carroll, 1981; Reisz, 1981) or elongate posterolateral processes of the parasphenoid (e.g., Thadeosaurus, Youngina, Currie and Carroll, 1984; Gardner et al., 2010).

Supraoccipital-The supraoccipital is visible in MNHN.F.MAP317b, but is best preserved in the lectotype (Figs. 3-4). It is a quadrangular bone, occupying the space between the medial margins of the posttemporal processes of the parietal. It articulated with the parietal anteriorly, possibly abutting the postparietal lamina of the parietal (Fig. 7), with the exoccipitals posteroventrally, as well as with the bones of the otic capsule, although the articulations with the latter bones are not visible on any of the specimens. The entire dorsal surface of the bone is concave on both specimens and framed by slightly elevated lateral and posterior margins. There is no trace of the dorsal sagittal ridge described for some other early diapsids (e.g., Hovasaurus, Petrolacosaurus, Currie, 1981; Reisz, 1981), although this might be due to late diagenetic compression (Figs. 3-4). The anterolateral processes, if present, are not visible on any Coelurosauravus specimen. The posteroventral margin of the 
supraoccipital is slightly elevated relative to the dorsal surface of the bone. Its median portion is concave, forming the dorsal margin of the foramen magnum medially.

Exoccipital-We identify a small crescentic bone lying near the basioccipital and the atlantal centrum in MNHN.F.MAP317a as the left exoccipital, visible in posterior view (Fig. 8A). The braincase experienced diagenetic compression but very slight displacement of the individual bones. According to our interpretation, the concave medial margin of the bone represents the left lateral margin of the foramen magnum, as in all early diapsids (Evans, 1986; Gardner et al., 2010; Sobral and Müller, 2019). The exoccipital was thus not fused to the neighboring elements in contrast to some early reptiles (e.g., Prolacerta, Youngina, Evans, 1986, 1987; Gardner et al., 2010). The exoccipitals form the lateral margins of the foramen magnum.

The dorsal portion of the exoccipital expands dorsally and dorsomedially, forming a broad contact with the supraoccipital medially and opisthotic laterally. Ventrally, the bone bears as a robust pillar-like expansion that abuts on the basioccipital. The extent of the exoccipitals over the dorsal and ventral margins of the foramen magnum is unknown due to the disarticulation of the material. A recess in the medial margin of the exoccipital lateral to the foramen magnum might represent the foramen for the passage of the hypoglossal nerve (CN XII; Fig. 8A).

Basioccipital-The basioccipital lies near the carpus and the parabasisphenoid of MNHN.F.MAP327a (Fig. 8B-C). It is oriented ventrolaterally and is visible in right ventrolateral view. Despite being figured by Carroll (1978:fig. 6), this bone was previously unidentified. It is a small quadrangular bone with a convex ventral surface. Its anterolateral margins bear robust, low basal tubera (Fig. 8B-C) with lunate suture facets for the articulation with the parabasisphenoid. More posteriorly, the basioccipital is strongly constricted before expanding into a rounded projection forming the ventral portion of the occipital condyle (Fig. 
8B-C). As is visible in posterior view, the occipital portion of the basioccipital is dorsoventrally narrow and presumably only formed the ventral portion of the condyle.

Bulanov and Sennikov (2015a:422, pl. 5) identified a circular bone on MNHN.F.MAP317a as the basioccipital, forming the entire occipital condyle. However, this structure does not conform to the basioccipital of MNHN.F.MAP327a. We instead consider the large circular pit of this element as a deep notochordal pit, and interpret this bone as a vertebral centrum, presumably that of the atlas based on its short length and position. Although the atlantal centrum is pierced by a notochordal pit in most stem-saurians, suggesting a large pit in posterior view (Vaughn, 1955; Carroll, 1981; Reisz, 1981), descriptions of the posterior surface of the atlas centrum are scarce in early diapsids, in part due to the fusion of this element to the axis in many taxa (Romer, 1956). However, the atlantal centrum of MNHN.F.MAP317a conforms well to that of captorhinids (Peabody, 1952; Sumida, 1990) and varanopids (Campione and Reisz, 2011), which also bears a deep nothochordal pit in posterior view. The atlantal centrum of MNHN.F.MAP317a partially obscures a plate-like bone lying just posterior to the parabasisphenoid, which may represent the basioccipital (Fig. 8A).

Otic Capsule - Several fragments in MNHN.F.MAP317a may belong to the otic capsule. An elongate rectangular structure in contact with the posterolateral portion of the parabasisphenoid bears a complex system of ridges and is pierced by at least one foramen. This structure may accommodate semicircular canals. However, it is too poorly preserved to be anatomically identified with certainty.

A large element lying immediately anterior to the left exoccipital is interpreted as the opisthotic based on its position and our identification of the paroccipital process (Fig. 8A). We identify the paroccipital process based on its length, shape and blunt terminus, suggesting a contact with the dermal skull roof, as in several early diapsids (Evans, 1986; Flynn et al., 
2010; Sobral and Müller, 2019). However, we are unable to identify its area of contact. In contrast, the paroccipital ends freely in Claudiosaurus and Hovasaurus (Carroll, 1981; Currie, 1981). The paroccipital process of MNHN.F.MAP317a is rectangular and thin, which conforms well with that of several archosauromorphs, where this process is anteroposteriorly flattened (Flynn et al., 2010; Sobral and Müller, 2019). Based on the position of the proximal portion of the bone, this comparison suggests that the opisthotic is visible in anterior view (Fig. 8A). The proximal portion of the bone is only identified thanks to its relation to the paroccipital process. We were unable to identify structures unequivocally.

\section{Mandible}

We interpret previously unidentified bones in MNHN.F.MAP317a as the posterior portion of the right mandibular ramus (Fig. 4), which is transversely crushed and visible in dorsolabial view. The preserved bones correspond to the surangular and possibly the articular.

Surangular-We interpret the largest of the two elements as the posterior portion of the right surangular, visible in labial view (Fig. 4). This identification is based on the subtle irregular sculpturing of the bone, its blunt, irregular posterior extremity, and its smooth and slightly concave margin on the right. In these aspects, this bone conforms well to the posterior portion of the surangular of the Weigeltisaurus holotype, which is of similar shape, also shows a very subtle sculpturing on its labial surface, and bears a smooth, concave dorsal margin forming the labial wall of the adductor fossa (VB, pers. obs.; Bulanov and Sennokov, 2015b). Based on this identification, the dorsal margin of the surangular of MNHN.F.MAP317a faces to the right side of the animal, indicating that the bone is the right surangular in lateral view (Fig. 4). 
The dorsal surface of the bone expands medially to form a shelf overhanging the adductor fossa, as in Weigeltisaurus (Bulanov and Sennikov, 2015b) and Rautiania, although the dorsal shelf almost closes the adductor fossa in dorsal view in the latter (Bulanov and Sennikov, 2010). Similar surangular dorsomedial shelves have been considered as a synapomorphy of varanopids (Ford and Benson, 2019, 2020), and have been described for Acerosodontosaurus and Hovasaururs (Currie, 1980, 1981). The irregular ventral margin of the bone may indicate breakage, or the articular surface for the angular, which is not preserved on the specimen (Fig. 4). There is no trace of the posterior surangular spikes reported in Rautiania and Weigeltisaurus (Bulanov and Sennikov, 2010, 2015b).

?Articular-A small crescentic element lies near the posterior margin of the surangular. Based on its position relative to the surangular and thus the adductor fossa, we tentatively identify this element as a portion of the articular bone, forming the posteriormost portion of the mandibular ramus (Fig. 4). The posterior surface of the element is concave, although the articular cotyles for the quadratoarticular articulation cannot be identified. We were able to identify neither the retroarticular process, which is prominent in Rautiania and the Weigeltisaurus holotype (Bulanov and Sennikov, 2010, 2015b), nor the dorsal and medial processes described for Rautiania and the Weigeltisaurus holotype (Bulanov and Sennikov, 2010, 2015b).

\section{DISCUSSION}

A detailed analysis of the phylogenetic position of weigeltisaurids among PermoTriassic reptiles is out of the scope of this study, pending a re-description of the weigeltisaurid postcranium, which is currently under study by the authors. However, the reexamination of 


\section{Cranial Reconstruction}

Our reconstruction of the skull of Coelurosauravus resembles that of Bulanov and Sennikov (2015a:fig. 3A) although we highlight subtle differences. It allows for new comparisons within weigeltisaurids, focusing on peculiarities such as the large skull openings, the parietosquamosal frill, and putative muscle attachment areas.

The dermal bones of the skull are very light and hollow in weigeltisaurids, which Bulanov and Sennikov (2010) interpret as an adaptation to their aerial lifestyle. However, the truss-like skull structure of weigeltisaurids (Fig. 2) presumably housed large eyeballs and temporal muscles (as discussed below) which, in addition to the frill and ornamentation, might have added to the skull weight. As bone matter is not preserved in the Malagasy material, we focus here on the macrostructural aspects of the skull.

Preorbital Fenestra-Weigeltisaurids possess a small preorbital fenestra enclosed between the nasal and maxilla and excluded from the lacrimal (Figs. 2, 6; Bulanov and Sennikov, 2015a-b). Apertures anterior to the orbit have not been reported in stem-saurians with the possible exception of drepanosauromorphs (Calzavara et al., 1980 but see Renesto, 1994), but have been extensively studied in saurians (Witmer, 1995, 1997 and references therein). Yet, neither the function nor the homology of this structure in weigeltisaurids has been discussed.

Antorbital openings are present in a wide range of unrelated taxa (e.g., mesosaurid and thalattosaurian reptiles; Rieppel et al., 2005; Modesto, 2006; Piñeiro et al., 2012) but are 
better known in archosauriforms (Nesbitt, 2011). In archosauriforms, the antorbital fenestra is typically formed by the maxilla and lacrimal, and houses the pathways of the paranasal air sinus and that for the nasolacrimal duct more dorsomedially (Witmer, 1995, 1997). As described above (see "maxilla" section), the nasolacrimal duct of weigeltisaurids passes ventral to the preorbital fenestra, differentiating the latter from the antorbital fenestra of archosauriformes. In addition, the preorbital fenestra of weigeltisaurids is formed solely by the maxilla and nasal, in contrast to the condition in archosauriforms and other nonarchosauriform reptiles where other bones contribute to the antorbital openings (Rieppel et al., 2005; Modesto, 2006; Piñeiro et al., 2012).

The weigeltisaurid preorbital fenestra is thus distinct from the antorbital openings of other reptiles, at least in its topography. On the Weigeltisaurus holotype, this fenestra lies dorsal to the supralabial row of foramina for the maxillary branch of the trigeminal nerve (Fig. 6C-D). It is thus likely not derived from this innervation. The lack of extant homologues prevents us from identifying a possible function.

Orbit—Bulanov and Sennikov (2015a:fig. 3A) reconstructed Coelurosauravus with a very broad postorbital region, due to the lateral expansion of the frontal, postorbital and parietal bones. As a result, that study depicted this taxon with large, laterally positioned and anterolaterally oriented orbits. In contrast, we reconstruct Coelurosauravus with a much more slender postorbital region (Fig. 2A). While we concur with the reconstruction of the parietal and postorbital bones based on MNHN.F.MAP327a-b, we found evidence of enlarged posterolateral processes of the frontals neither in the lectotype nor in MNHN.F.MAP317b (Figs. 3-4). The frontal of MNHN.F.MAP327b is preserved in ventral view. What is visible of the lateral margin of the bone does not indicate such enlarged processes. Thus, we disagree with Bulanov and Sennikov's (2015a) reconstruction of the frontal of Coelurosauravus. In our reconstruction, the orbits of Coelurosauravus are oriented laterally instead of anterolaterally 
as they suggested. However, we concur with Bulanov and Sennikov (2015a) that the orbits of Coelurosauravus are positioned on the lateral face of the skull, in contrast to the more dorsolaterally positioned orbits of Youngina (Gow, 1975).

The orbits are very large in Coelurosauravus, forming roughly a third of the reconstructed basal skull length (tip of rostrum to occipital condyle; Fig. 2, Table 2). This 1/3 ratio of the orbit also occurs on the Weigeltisaurus holotype (28\%, Bulanov and Sennikov, 2015b:1104) and the Ellrich specimen (30\%, Table 2), and is also reconstructed for Rautiania (Bulanov and Sennikov, 2010:pl. 9). In Glaurung, the orbits are much smaller, occupying only $24 \%$ of the basal skull length (Bulanov and Sennikov, 2015c).

Pineal Foramen-Forming approximately $56 \%$ of the length of interparietal suture, the pineal foramen of Coelurosauravus is very large (Fig. 2; Table 2), suggesting a fully functional parietal eye (Edinger, 1955; Gundy and Wurst, 1976). This is also the case in the Ellrich specimen (62\%, Table 2) and on the reconstruction of Rautiania of Bulanov and Sennikov (2006:fig.1). Although the relative size of the pineal foramen of weigeltisaurids shows a slight variability (see above), it is significantly larger than that of coeval diapsids such as Youngina (ca. 28\% of interparietal suture length, BP/1/3859, VB pers. obs.), Claudiosaurus (ca. 31\%, Carroll, 1981:fig. 15) and Hovasaurus (ca. 35\%, MNHN.F.MAP373, VB pers. obs.).

Temporal Fenestration-Temporal fenestration has long been used in the classification of amniotes based on the presence or absence of an infratemporal fenestra (ITF) and a supratemporal fenestra (STF) (e.g., Osborn, 1903). In anatomically diapsid skulls, the ITF is typically bordered by the postorbital, jugal, quadratojugal and squamosal while the STF is bordered by the postorbital, parietal and squamosal (Reisz, 1981). However, several phylogenetic studies have questioned the universality of these characters (e.g., Müller, 2003; Laurin and Piñeiro, 2017, 2018; MacDougall et al., 2018; Ford and Benson, 2020). 
The possession of both an ITF and an STF is probably plesiomorphic in diapsids (Müller, 2003). However, the temporal fenestration is subjected to a very high degree of plasticity in reptiles (e.g. Piñeiro et al., 2012; Werneburg, 2019; Ford and Besnon, 2020), as exemplified by the loss of the ITF in Araeoscelis (Reisz et al., 1984) and the multiple convergent losses and reacquisitions of the ITB in later diapsids (e.g., Claudiosaurus, sauropterygians, squamates, archosauromorphs, Müller, 2003; Curtis et al., 2011). However, the preservation of the supratemporal bar (STB) appears much more conservative (Rieppel, 1984a, 1993b; Werneburg, 2019).

A short posterodorsal process of the postorbital underlying the parietal and forming the anterodorsal margin of the temporal fenestra was reported in Glaurung (Bulanov and Sennikov, 2015c). Bulanov and Sennikov (2015c:1363) consider this process as homologous to that of other diapsids, although its relationships to the parietal and sole temporal fenestra are more similar to that found in edaphosaurian synapsids, where the posterior process of the postorbital abuts the lateral margin of the parietal (e.g., Romer and Price, 1940; Modesto, 1995). Under that interpretation, the temporal fenestra of weigeltisaurids would result from the dorsal expansion of the ITF and the loss of contact between the postorbital and squamosal. Whether weigeltisaurids underwent a prior reduction of the STF is unknown, but the temporal morphology and the continuous postorbitoparietal contact suggest its absence in Glaurung (Bulanov and Sennikov, 2015c:fig. 2). Alternatively, the postorbital posterior process described by Bulanov and Sennikov (2015c) might be a misinterpreted bone fragment of unknown anatomical attribution, owing to the poor preservation of the badly crushed specimen.

Additionally, the quadratojugal of weigeltisaurids is very small, with reduced anterior and dorsal processes (see description above). The ITB of weigeltisaurids is thus formed mostly by the posterior process of the jugal (Fig. 2). We note that in those stem-saurians with 
a complete ITB, the latter is formed by subequal contributions of the jugal and quadratojugal (Gow, 1975; Reisz, 1981; Reisz et al., 1984), but is mostly formed by the jugal in saurians with a complete ITB (e.g., archosauromorphs, rhyncocephalians, borioteiioid squamates, Whiteside, 1986; Evans and Jones, 2010; Nesbitt, 2011; Simões et al., 2016). As the absence of a complete ITB may be plesiomorphic for saurians, previous studies argue that the morphology in saurians with a complete ITB is indicative of a secondarily acquired diapsid condition (i.e. a reappearance of the ITB) in the context of bite force enhancement and/or skull stabilization (e.g., Müller, 2003; Curtis et al., 2011; Simoes et al., 2016). The morphology of the weigeltisaurid ITB may thus suggests a similar reacquisition, indicating more crownward saurian affinities for weigeltisaurids. However, a convergent acquisition of this morphology from a fully diapsid skull by posterior extension of the jugal and reduction of the quadratojugal is also possible.

Ornamentation - The weigeltisaurid skull is ornamented, even in the very small Wolfsberg specimen (Schaumberg, 1976, 1982, 1986). This ornamentation covers the circumorbital, temporal and posterior mandibular bones and comprises both elongate spikes and smaller tubercles (Fig. 2; Bulanov and Sennikov, 2015a-c).

Based on computed tomography, Bulanov and Sennikov (2010) interpreted the circumorbital and frill spikes of Rautiania as hollow osteoderms that have fused to the underlying bone. However, the small tubercles on the posttemporal processes of Coelurosauravus and Glaurung have not been examined. By analogy with pachycephalosaurian dinosaurs, the spikes of weigeltisaurids may be of osteodermal origin, but the smaller tubercles could alternatively be protrusions of the bones (Goodwin and Evans, 2016). Similarly, micro-CT and histological data show that the tubercles of extant chamaeleonids consist of regionalized outgrowths of the bones (Prötzel et al., 2018). Further 
studies focusing on the microstructure or histology of the ornamentation of weigeltisaurids are needed to assess their homology.

Parietosquamosal Frill—All known weigeltisaurids specimens with articulated skulls show a conspicuous parietosquamosal frill (Schaumberg et al., 2007; Bulanov and Sennikov, 2015a-c). Even the small-sized Wolfsberg specimen exhibits this peculiar morphology (Schaumberg, 1976, 1982, 1986). In addition, the fossiliferous Russian deposits have failed to yield remains lacking a frill, despite numerous specimens being recovered (Bulanov and Sennikov, 2006, 2010, 2014, 2015c). It is thus likely that all weigeltisaurid individuals bore ornamented frills regardless of their ontogenetic stage, and that the presence of this structure is not sexually dimorphic, although this cannot be ascertained in light of the rarity of articulated cranial remains (seven specimens preserve articulated skull portions). Similarly, the casque of chamaeleonids forms at very early ontogenetic stages (e.g., Rieppel, 1993a), and its presence is not sexually dimorphic, although males show a relatively larger and more ornamented casque in some taxa (Stuart-Fox et al., 2006; Stuart-Fox, 2013). In ceratopsians, even the smallest known individuals have a parietosquamosal frill (Goodwin et al., 2006; Horner and Goodwin, 2006).

\section{Jaw Adductor Musculature}

The parietosquamosal frill of weigeltisaurids is formed by the elongation of the parietal and squamosal (Fig. 2). A similar morphology occurs in the casque of chamaeleonid squamates and frill of ceratopsian dinosaurs, which have been proposed as analogs for weigeltisaurids (Weigelt, 1930a; Huene, 1930; Schaumberg et al., 2007). This elongation has been linked to changes (observed in chamaeleonids, only inferred in ceratopsians) in the jaw 
adductor musculature, especially that inserting in the STF (Haas, 1955; Ostrom, 1964, 1966; Rieppel, 1981, 1987; Maiorino et al., 2017).

The excellent preservation of the Coelurosauravus skull allows for a preliminary discussion on the adductor musculature of weigeltisaurids. The adductor musculature of extant reptiles includes several muscles, with the $\mathrm{m}$. adductor mandibulae A2 being dominant (Diogo et al., 2018; = “m. adductor mandibulae externus" of other authors e.g., Romer, 1956; Haas, 1973; Abdala and Morro, 2003; Holliday and Witmer, 2007). This muscle is divided in three portions: superficialis (A2-S), medialis (A2-M), and profundus (A2-P).

An origin area of the A2-S could not be identified unequivocally in Coelurosaravus. This muscle typically originates from the medial margin of the STB in extant lepidosaurians (Haas, 1973) and from the medial surface of the quadratojugal in crocodilians (Schumacher, 1973; Holliday, 2009). However, these structures are absent or reduced in weigeltisaurids (see above). It is possible that the A2-S covered the A2-M laterally as in geckos (Haas, 1973; Rieppel, 1984b), or that it had a fleshy origin leaving no trace on the bones (Bryant and Seymour, 1990). Alternatively, the A2-S originates on the squamosal in birds (Holliday and Witmer, 2007; Holliday, 2009). Owing to the slightly concave dorsal surface of the squamosal (Fig. 7), this may also have been the case in Coelurosauravus, although we found no insertion rugosity for bundles of Sharpey fibers. In addition, as proposed for those saurians with a complete ITB (see above), the presence of a complete ITB in weigeltisaurids prevented the expansion of the A2-S over the labial surface of the mandible (Rieppel and Gronowski, 1981; Simões et al., 2016). This is further supported by the presence of elongate spikes on the posterior lateral surface of the mandible in Rautiana and on the Weigeltisaurus holotype (Bulanov and Sennikov, 2010, 2015b). Consequently, the A2-S insertion was mostly limited to the dorsal margin of the mandible, possibly to the surangular dorsomedial shelf. 
The A2-M and A2-P differ greatly among extant reptiles. The A2-M is typically large in lepidosaurs and may occupy a shallow fossa on the posteromedian margin of the STF, while the A2-P is smaller (Haas, 1973). In contrast, the A2-M is small and less differentiated in extant archosaurs while the A2-P is large and typically originates from the posteromedian margin of the STF (Schumacher, 1973; Holliday, 2009). As weigeltisaurids are generally considered as stem-saurians (Müller, 2004; Simões et al., 2018; Pritchard and Sues, 2019), their general muscular pattern cannot be confidently inferred. However, the parasagittal ridge on the ventral surface of the posttemporal process of the parietal of Coelurosauravus almost certainly served as the origin of the adductor musculature (Fig. 7). Thus, a large A2-M and/or A2-P probably originated from the dorsal margin of the single temporal fenestra of weigeltisaurids. The origin surface of those adductor muscles also possibly extended onto the slightly concave anterodorsal margin of the squamosal.

Given our interpretation is correct, the adductor muscles thus had a very long surface of origin lateral to the posttemporal adductor ridge (Fig.7). Owing to the size of the identified area of origin and its position relative to the mandible, those muscles not only had long fibers, resulting in a rapid jaw adduction and likely a wide gape, but also a large diameter, resulting in an increased adduction power (Herrel et al., 1999, 2001; Huyghe et al., 2009).

Interestingly, the reacquisition of a complete ITB has been correlated with an increased bite force in sphenodontians and archosauromorphs by strengthening the skull against strains during feeding (e.g., Müller, 2003; Curtis et al., 2011). The presence of a complete ITB thus conforms well to the increased muscle mass and size described above, although further phylogenetic analyses will confirm whether the presence of a complete ITB in weigeltisaurids results from a reacquisition, or was present ancestrally. 


\section{Paleoecology of Weigeltisaurids}

Weigeltisaurid paleoecology has been repeatedly discussed, mostly concerning their aerial lifestyle by comparison to the agamid Draco and the gliding kuehneosaurids (Carroll, 1978; Evans and Haubold, 1987; Frey et al., 1997). In contrast, their peculiar cranial morphology has been considerably less addressed (Schaumberg et al., 2007; Bulanov and Sennikov, 2015a-c). Based mostly on their postcranial anatomy, weigeltisaurids have been considered insectivorous arboreal and gliding reptiles, an interpretation followed here. Referring to the crested skulls, to arboreality or gliding capability, we suggest that ceratopsian dinosaurs, chamaeleonid squamates and the gliding agamid Draco may be well-suited to reconstruct the paleoecology of weigeltisaurids (e.g. Weigelt, 1930a; Schaumberg et al., 2007). Based on their spiky ornamentation, phrynosomatid iguanids could also serve as good analogues for weigeltisaurids.

By applying the principle of actualism (e.g. Vorobyeva, 2007), we thus provide elements to reconstruct the paleoecology of Coelurosauravus and other weigeltisaurids based on their cranium (Fig. 9). However, as the functional interpretation of a structure in the fossil record is notoriously difficult (Gould, 1974; Benton, 2010; Knell and Sampson, 2011; Padian and Horner, 2011, 2014; Hone et al., 2012; Mendelson and Shaw, 2012, 2013; Hone and Naish, 2013), and in light of the scarcity of weigeltisaurids specimens and that of their recent analogues, we stress that the interpretations discussed below remain speculative.

Biting and Diet - As discussed above, the elongation of the parietosquamosal frill of weigeltisaurids may be correlated with an increase in size of the m. adductor mandibulae A2, in particular its medialis and/or profundus sections, as observed in chamaeleonids (Rieppel, 1981, 1987). 
Chamaeleonids are known to consume relatively large prey compared to other lizards, due to their ballistic tongue (e.g. Herrel et al., 2000), and to their relatively high bite force resulting from their large adductor musculature (Vanhooydonck et al., 2007; Measey et al., 2013; da Silva et al., 2016; Dollion et al., 2017). Similarly, an increase in bite force has been linked to an increase in head height and thus in the size of the adductor musculature in several extant squamates, allowing for the consumption of large and/or hard preys (Herrel et al., 1999, 2001; Verwaijen et al., 2002). The large jaw adductor musculature in weigeltisaurids may generate a relatively strong bite force and a rapid jaw adduction (snapping), even if they lack a well-developed coronoid process for the insertion of the jaw adductor muscles (Bulanov and Sennikov, 2010, 2015b).

Previous studies have proposed an insectivorous diet for weigeltisaurids based on their dentition (Carroll, 1978; Bulanov and Sennikov, 2015a-c). We concur that the simple conical teeth of Coelurosauravus seem well suited for piercing arthropod integuments (e.g. Evans and Sanson, 1998). However, variation in crown shape has been reported in weigeltisaurids, with Glaurung and Rautiania showing labiolingually flattened teeth with a slight apical mesiodistal expansion (Bulanov and Sennikov, 2006; 2015c). Bulanov and Sennikov (2015c) argued that these differences could indicate differences in trophic specialization, but this is hard to ascertain in light of the lack of associated prey items (e.g. insects), and the wide range of food sources exploited by extant squamates, including vegetation (Bels et al., 2019, and references therein). These differences in tooth morphology could also be linked to the size of the frill and bite force. However, as the relationships between these structures are not well understood in extant taxa (e.g. chamaeleonids), they will not be discussed further here (Measey et al., 2009, 2011, 2013; da Silva et al., 2016; Dollion et al., 2017).

Display Structures - Extant squamates undertake stereotypical displays to signal conspecifics - males and females - and to deter predators (Carpenter and Ferguson, 1977; 
Greene, 1987). For example, chamaeleonids undertake lateral displays using their casque to appear larger (Kelso and Verrell, 2002; Stuart-Fox, 2013), and phrynosomatids, which exhibit a spiky ornamentation reminiscent of that of weigeltisaurids, assumes a chin-down posture to position their horn vertically to deter predators (Bergmann and Berk, 2012). By analogy, similar display behaviors have been proposed for ceratopsian dinosaurs (e.g., Maiorino et al., 2017).

The elongate and ornamented parietosquamosal frill of weigeltisaurids may have functioned as a display structure as well (Fig. 9). Previous studies have suggested that the frill was mobile, and could be extended for courtship and/or to deter predators (Schaumberg et al., 2007). However, we concur with Bulanov and Sennikov (2015b) that the frill was rigid due to constricting joints. Weigelt (1930a) also proposed that the spines could mimic surrounding coniferous branches to serve as camouflage (Weigelt, 1930a). However, this is highly hypothetical since camouflage is highly dependent on coloration (Stevens and Merilaita, 2006; Cuthill, 2019), which is unknown in weigeltisaurids.

Additionally, many squamates show intraspecific aggressive behavior (Carpenter and Ferguson, 1977). Chamaeleonids may fight through biting and horn thrusts, in which case individuals with a larger casque generally win (Stuart-Fox et al., 2006; Stuart-Fox, 2013). These fights can lead to injury, but it is unclear whether the casque protected the neck and occipital region of the head. For many authors, the horns of ceratopsians were likely used in sexual combat or defense against predators, during which the frill prevented injuries caused by horn thrusts, thus protecting the temporal muscles and the neck (Farlow and Dodson, 1975, Farke, 2004, 2014; Farke et al., 2009, 2010; Krauss et al., 2010 but see Tanke and Rothschild, 2010). Their horns are indeed composed of solid bone, giving them sufficient resistance to be used as weapons (Sampson et al., 1997; Horner and Goodwin, 2008). Secondarily possible 
functions such as thermoregulation have also been proposed as potential exaptations of the frill (e.g., Barrick et al. 1998).

While there is no basis to infer aggressive behavior in weigeltisaurids, this would add evolutionary advantage on an increased bite force. Their frill and ornamentation, highly reminiscent of those of chamaeleonid squamates and ceratopsian dinosaurs (Fig. 9), could thus have served as a defense mechanism, to deter small predators or conspecifics and/or to protect the temporal muscles and the neck during male to male combats. We note, however, that gliding flight escape was likely a more efficient defensive mechanism, at least against predators, as in Draco (Greene, 1987).

\section{CONCLUSION}

The detailed re-description of all known specimens of Coelurosauravus elivensis highlights several hitherto unknown anatomical details. We interpret several bones on MNHN.F.MAP317a as portions of the palate and braincase, which were previously undescribed in weigeltisaurids. This allows for the first reconstruction of the palate of $C$. elivensis and as such the first palatal reconstruction for weigeltisaurids. C. elivensis differs from all other known weigeltisaurids in its large anterior marginal dentition and cranial ornamentation, particularly in its parietosquamosal frill. Our detailed osteological redescription of the cranium and comparisons with other weigeltisaurids and other reptiles provide a background that should be useful in future phylogenetic and biomechanical analyses. Elucidating the systematic position of weigeltisaurids is out of the scope of this paper, but a phylogenetic analysis is currently under work by the authors. However, the novel anatomical data allow for a discussion on the functional anatomy of the unique cranial 
morphology of C. elivensis and other weigeltisaurids. Our data support the insectivorous, arboreal and aerial lifestyle suggested by previous works. In analogy with extant chamaeleonids and more tentatively ceratopsian dinosaurs, we suggest that the elongation of the parietosquamosal frill, the loss of the upper temporal bar and the enlargement of the temporal fenestra are linked with a size increase of the external jaw adductor musculature, resulting in an increased gape, bite force and jaw adduction speed. Additionally, the ornamentation of the frill and orbital series likely served as display structures for intraspecific communication and/or for deterring predators.

\section{ACKNOWLEDGMENTS}

We thank N.-E. Jalil (MNHN) for access to the MNHN specimens and for his constructive comments on the manuscript. Many thanks to C. Letenneur (MNHN) for her life reconstruction of Coelurosauravus. We thank O. Béthoux (MNHN) for his help in RTI methodology and loaning the necessary hardware to VB, and P. Loubry (CNRS) and D. Germain (MNHN) for their help in photography. Many thanks to J.-M Pacaud (MNHN) for his help in nomenclature. We also thank J. Falconnet (MNHN), A. Pritchard (VMNH) and H.D. Sues (NMNH) for constructive discussions on weigeltisaurids and Permo-Triassic reptiles. Finally, we thank G. Sobral and an anonymous reviewer for their constructing reviews, and H.-D. Sues for his editorial work. This work is supported by the French Ministry of Superior Education and Research (annual credits of the CR2P and Ph.D. grant to VB). 
The data underlying this article are available in Zenodo, at http://doi.org/10.5281/zenodo.4300212.

\section{LITERATURE CITED}

Abdala, V., and S. Moro. 2003. A cladistic analysis of ten lizard families (Reptilia: Squamata) based on cranial musculature. Russian Journal of Herpetology 10:53-78.

Anderson, C. V., and T. E. Higham. 2013. Chameleon anatomy; pp. 7-55 in K. A. Tolley and A. Herrel (eds.), The Biology of Chameleons. University of California Press, Berkley, CA.

Barrick, R. E., M. K. Stoskopf, J. D. Marcot, D. A. Russell, and W. J. Showers. 1998. The thermoregulatory functions of the Triceratops frill and horns: heat flow measured with oxygen isotopes. Journal of Vertebrate Paleontology 18:746-750.

Bels, V., A.-S. Paindavoine, L.-N. Zghikh, E. Paulet, J.-P. Pallandre, and S. J. Montuelle. 2019. Feeding in lizards: form-function and complex multifunctional system; pp. 469-525 in V.

Bels and I. Q. Whishaw (eds.), Feeding in Vertebrates: Evolution, Morphology, Behavior, Biomechanics. Springer International Publishing, Cham, Switzerland.

Benton, M. J. 1985. Classification and phylogeny of the diapsid reptiles. Zoological Journal of the Linnean Society 84:97-164.

Benton, M. J. 2010. Studying function and behavior in the fossil record. PLoS Biology 8:e1000321.

Bergmann, P. J., and C. P. Berk. 2012. The evolution of positive allometry of weaponry in horned lizards (Phrynosoma). Evolutionary Biology 39:311-323. 
Bertin, T. J. C., B. Thivichon-Prince, A. R. H. LeBlanc, M. W. Caldwell, and L. Viriot. 2018. Current perspectives on tooth implantation, attachment, and replacement in Amniota. Frontiers in Physiology 9:1630.

Besairie, H. 1972. Géologie de Madagascar. I. Les terrains sédimentaires. Annales Géologiques de Madagascar 35:1-465.

Besairie, H. 1973. Précis de géologie malgache. Annales Géologiques de Madagascar 36:1-141. Béthoux, O., A. Llamosi, and S. Toussaint. 2016. Reinvestigation of Protelytron permianum (Insecta; Early Permian; USA) as an example for applying reflectance transformation imaging to insect imprint fossils. Fossil Record 20:1-7.

Bhullar, B.-A. S. 2012. A phylogenetic approach to ontogeny and heterochrony in the fossil record: cranial evolution and development in anguimorphan lizards (Reptilia: Squamata). Journal of Experimental Zoology Part B: Molecular and Developmental Evolution 318:521-530.

Bickel, R., and J. B. Losos. 2002. Patterns of morphological variation and correlates of habitat use in Chameleons. Biological Journal of the Linnean Society 76:91-103.

Boule, M. 1910. Sur le Permien de Madagascar. Bulletin de la Société Géologique de France 10:314-316.

Brinkman, D. 1988. A weigeltisaurid reptile from the Lower Triassic of British Columbia. Palaeontology 31:951-956.

Bryant, H. N., and K. L. Seymour. 1990. Observations and comments on the reliability of muscle reconstruction in fossil vertebrates. Journal of Morphology 206:109-117.

Buffrénil, V. de, F. Clarac, A. Canoville, and M. Laurin. 2016. Comparative data on the differentiation and growth of bone ornamentation in gnathostomes (Chordata: Vertebrata). Journal of Morphology 277:634-670. 
Buffrénil, V. de, F. Clarac, M. Fau, S. Martin, B. Martin, E. Pellé, and M. Laurin. 2015.

Differentiation and Growth of Bone Ornamentation in Vertebrates: A Comparative

Histological Study Among the Crocodylomorpha. Journal of Morphology 276:425-445.

Bulanov, V. V., and A. G. Sennikov. 2006. The first gliding reptiles from the Upper Permian of Russia. Paleontological Journal 40:S567-S570.

Bulanov, V. V., and A. G. Sennikov. 2010. New data on the morphology of Permian gliding weigeltisaurid reptiles of Eastern Europe. Paleontological Journal 44:682-694.

Bulanov, V. V., and A. G. Sennikov. 2014. New localities of the Upper Permian gliding diapsids

(Weigeltisauridae) in European Russia. Journal of Vertebrate Paleontology 74A:100.

Bulanov, V. V., and A. G. Sennikov. 2015a. New data on the morphology of the Late Permian gliding reptile Coelurosauravus elivensis Piveteau. Paleontological Journal 49:413-423.

Bulanov, V. V., and A. G. Sennikov. 2015b. Substantiation of validity of the Late Permian genus Weigeltisaurus Kuhn, 1939 (Reptilia, Weigeltisauridae). Paleontological Journal 49:11011111.

Bulanov, V. V., and A. G. Sennikov. 2015c. Glaurung schneideri gen. et sp. nov., a new weigeltisaurid (Reptilia) from the Kupfershiefer (Upper Permian) of Germany. Paleontological Journal 49:1353-1364.

Caldwell, M. W. 1995. Developmental constraints and limb evolution in Permian and extant lepidosauromorph diapsids. Journal of Vertebrate Paleontology 14:459-471.

Calzavara, M., G. Muscio, and R. Wild. 1980. Megalancosaurus preonensis ng, n. sp., a new reptile from the Norian of Friuli, Italy. Gortiana 2:49-64.

Camp, C. L. 1945. Prolacerta and the protorosaurian reptiles. Part I. American Journal of Science 243:17-32.

Campione, N. E., and R. R. Reisz. 2011. Morphology and evolutionary significance of the atlasaxis complex in varanopid synapsids. Acta Palaeontologica Polonica 56:739-748. 
Carpenter, C. C., and G. W. Ferguson. 1977. Variation and evolution of stereotyped behavior in reptiles; pp. 335-554 in C. Gans and D. W. Tinkle (eds.), Biology of the Reptilia, Volume 7, Ecology and Behaviour A. Academic Press, London, UK.

Carroll, R. L. 1975. Permo-Triassic "lizards" from the Karroo. Paleontologia Africana 18:71-87. Carroll, R. L. 1978. Permo-Triassic "lizards” from the Karoo System. Part II. A gliding reptile from the Upper Permian of Madagascar. Paleontologia Africana 21:143-159.

Carroll, R. L. 1981. Plesiosaur ancestors from the Upper Permian of Madagascar. Philosophical Transactions of the Royal Society of London. Series B, Biological Sciences 293:315-383.

Carroll, R. L., and W. Lindsay. 1985. Cranial anatomy of the primitive reptile Procolophon. Canadian Journal of Earth Sciences 22:1571-1587.

Cavicchini, I., M. Zaher, and M. J. Benton. 2020. An enigmatic neodiapsid reptile from the Middle Triassic of England. Journal of Vertebrate Paleontology 40:e1781143.

Chun, L., O. Rieppel, C. Long, and N. C. Fraser. 2016. The earliest herbivorous marine reptile and its remarkable jaw apparatus. Science Advances 2:e1501659.

Conrad, J. L. 2008. Phylogeny and systematics of Squamata (Reptilia) based on morphology. Bulletin of the American Museum of Natural History 310:1-182.

Cui, Y., S. Toussaint, and O. Béthoux. 2018. The systematic position of the stonefly $\uparrow$ culonga Sinitshenkova, 2011 (Plecoptera: Leuctrida) reassessed using Reflectance Transforming Imaging and cladistic analysis. Arthropod Systematics \& Phylogeny 72:173-178.

Currie, P. J. 1980. A new younginid (Reptilia: Eosuchia) from the Upper Permian of Madagascar. Canadian Journal of Earth Sciences 17:500-511.

Currie, P. J. 1981. Hovasaurus boulei, an aquatic eosuchian from the Upper Permian of Madagascar. Paleontologia Africana 24:99-168.

Currie, P. J., and R. L. Carroll. 1984. Ontogenetic changes in the eosuchian reptile Thadeosaurus. Journal of Vertebrate Paleontology 4:68-84. 
Curtis, N., M. E. H. Jones, J. Shi, P. O’Higgins, S. E. Evans, and M. J. Fagan. 2011. Functional relationship between skull form and feeding mechanics in Sphenodon, and implications for diapsid skull development. PLoS ONE 6:e29804.

Cuthill, I. C. 2019. Camouflage. Journal of Zoology 308:75-92.

deBraga, M., and R. R. Reisz. 1995. A new diapsid reptile from the uppermost Carboniferous (Stephanian) of Kansas. Palaeontology 38:199-199.

deBraga, M., and O. Rieppel. 1997. Reptile phylogeny and the interrelationships of turtles. Zoological Journal of the Linnean Society 120:281-354.

Diogo, R., J. M. Ziermann, J. Molnar, N. Siomava, and V. Abdala. 2018. Muscles of Chordates: Development, Homologies, and Evolution. CRC Press, 664 pp.

Dodson, P., C. A. Forster, and S. D. Sampson. 2007. Ceratopsidae; pp. 494-513 in D. B. Weishampel, P. Dodson, and H. Osmólska (eds.), The Dinosauria. University of California Press, Berkley, CA.

Dollion, A. Y., G. J. Measey, R. Cornette, L. Carne, K. A. Tolley, J. M. da Silva, R. Boistel, A.-C. Fabre, and A. Herrel. 2017. Does diet drive the evolution of head shape and bite force in chameleons of the genus Bradypodion? Functional Ecology 31:671-684.

Druckenmiller, P. S., N. P. Kelley, E. T. Metz, and J. Baichtal. 2020. An articulated Late Triassic (Norian) thalattosauroid from Alaska and ecomorphology and extinction of Thalattosauria. Scientific Reports 10:1746.

Edinger, T. 1955. The size of parietal foramen and organ in reptiles: a rectification. Bulletin of the Museum of Comparative Zoology, Harvard College 114:1-34.

Evans, A. R., and G. D. Sanson. 1998. The effect of tooth shape on the breakdown of insects. Journal of Zoology 246:391-400.

Evans, S. E. 1980. The skull of a new eosuchian reptile from the Lower Jurassic of South Wales. Zoological Journal of the Linnean Society 70:203-264. 
Evans, S. E. 1982. The gliding reptiles of the Upper Permian. Zoological Journal of the Linnean Society 76:97-123.

Evans, S. E. 1986. The braincase of Prolacerta broomi (Reptilia, Triassic). Neues Jahrbuch Für Geologie Und Paläontologie. Abhandlungen 173:181-200.

Evans, S. E. 1987. The braincase of Youngina capensis (Reptilia: Diapsida; Permian). Neues Jahrbuch Für Geologie Und Paläontologie. Monatshefte 1987:193-203.

Evans, S. E. 1991. A new lizard-like reptile (Diapsida: Lepidosauromorpha) from the Middle Jurassic of England. Zoological Journal of the Linnean Society 103:391-412.

Evans, S. E. 2003. At the feet of the dinosaurs: the early history and radiation of lizards. Biological Reviews 78:513-551.

Evans, S. E. 2008. The skull of lizards and tuatara; pp. 1-347 in C. Gans, A. S. Gaunt, and K. Adler (eds.), Biology of the Reptilia, Volume 20, Morphology H. The Skull of Lepidosauria. Society for the Study of Amphibians and Reptiles, Ithaca, New York.

Evans, S. E. 2009. An early kuehneosaurid reptile from the Early Triassic of Poland. Palaeontologia Polonica 65:145-178.

Evans, S. E., and H. Haubold. 1987. A review of the Upper Permian genera Coelurosauravus, Weigeltisaurus and Gracilisaurus (Reptilia: Diapsida). Zoological Journal of the Linnean Society 90:275-303.

Evans, S. E., and M. Borsuk-Białynicka. 2009. A small lepidosauromorph reptile from the Early Triassic of Poland. Palaeontologia Polonica 65:179-202.

Evans, S. E., and M. E. H. Jones. 2010. The origin, early history and diversification of lepidosauromorph reptiles; pp. 27-44 in S. Bandyopadhyay (ed.), New Aspects of Mesozoic Biodiversity. vol. 132. Springer Berlin Heidelberg, Berlin, Heidelberg.

Ezcurra, M. D. 2016. The phylogenetic relationships of basal archosauromorphs, with an emphasis on the systematics of proterosuchian archosauriforms. PeerJ 4:e1778. 
Ezcurra, M. D., T. M. Scheyer, and R. J. Butler. 2014. The origin and early evolution of Sauria: reassessing the Permian saurian fossil record and the timing of the crocodile-lizard divergence. PLoS ONE 9:e89165.

Fabbri, M., N. Mongiardino Koch, A. C. Pritchard, M. Hanson, E. Hoffman, G. S. Bever, A. M. Balanoff, Z. S. Morris, D. J. Field, J. Camacho, T. B. Rowe, M. A. Norell, R. M. Smith, A. Abzhanov, and B.-A. S. Bhullar. 2017. The skull roof tracks the brain during the evolution and development of reptiles including birds. Nature Ecology \& Evolution 1:1543-1550.

Farke, A. A. 2004. Horn use in Triceratops (Dinosauria: Ceratopsidae): testing behavioral hypotheses using scale models. Palaeontologia Electronica 7:1-10.

Farke, A. A. 2014. Evaluating combat in ornithischian dinosaurs. Journal of Zoology 292:242-249.

Farke, A. A., E. D. S. Wolff, and D. H. Tanke. 2009. Evidence of combat in Triceratops. PLoS ONE 4:e4252.

Farke, A. A., R. E. Chapman, and A. Andersen. 2010. Modeling structural properties of the frill of Triceratops; pp. 264-270 in M. J. Ryan, B. J. Chinnery-Allgeier, and D. A. Eberth (eds.), New Perspectives on Horned Dinosaurs: The Royal Tyrrell Museum Ceratopsian Symposium. Indiana University Press.

Farlow, J. O., and P. Dodson. 1975. The behavioral significance of frill and horn morphology in ceratopsian dinosaurs. Evolution 353-361.

Flynn, J. J., S. J. Nesbitt, J. M. Parrish, L. Ranivoharimanana, and A. R. Wyss. 2010. A new species of Azendohsaurus (Diapsida: Archosauromorpha) from the Triassic Isalo Group of southwestern Madagascar: cranium and mandible. Palaeontology 53:669-688.

Ford, D. P., and R. B. J. Benson. 2019. A redescription of Orovenator mayorum (Sauropsida, Diapsida) using high-resolution $\mu \mathrm{CT}$, and the consequences for early amniote phylogeny. Papers in Palaeontology 5:197-239. 
Ford, D. P., and R. B. J. Benson. 2020. The phylogeny of early amniotes and the affinities of Parareptilia and Varanopidae. Nature Ecology \& Evolution 4:57-65.

Fraser, N. C. 1988. The osteology and relationships of Clevosaurus (Reptilia: Sphenodontida). Philosophical Transactions of the Royal Society of London. B, Biological Sciences 321:125178.

Frey, E., H.-D. Sues, and W. Munk. 1997. Gliding mechanism in the Late Permian reptile Coelurosauravus. Science 275:1450-1452.

Gardner, N. M., C. M. Holliday, and F. R. O'Keefe. 2010. The braincase of Youngina capensis (Reptilia, Diapsida): new insights from high-resolution CT scanning of the holotype. Palaeontologia Electronica 13:19A.

Gauthier, J. A., M. Kearney, J. A. Maisano, O. Rieppel, and A. D. Behlke. 2012. Assembling the squamate Tree of Life: perspectives from the phenotype and the fossil record. Bulletin of the Peabody Museum of Natural History 53:3-308.

Glynne, E., J. D. Daza, and A. M. Bauer. 2020. Surface sculpturing in the skull of gecko lizards (Squamata: Gekkota). Biological Journal of the Linnean Society 131:801-813.

Goodwin, M. B., and D. C. Evans. 2016. The early expression of squamosal horns and parietal ornamentation confirmed by new end-stage juvenile Pachycephalosaurus fossils from the Upper Cretaceous Hell Creek Formation, Montana. Journal of Vertebrate Paleontology 36:e1078343.

Goodwin, M. B., W. A. Clemens, J. R. Horner, and K. Padian. 2006. The smallest known Triceratops skull: new observations on ceratopsid cranial anatomy and ontogeny. Journal of Vertebrate Paleontology 26:103-112.

Gottmann-Quesada, A., and P. M. Sander. 2009. A redescription of the early archosauromorph Protorosaurus speneri Meyer, 1832, and its phylogenetic relationships. Palaeontographica Abteilung A 123-220. 
Gould, S. J. 1974. The origin and function of "bizarre" structures: antler size and skull size in the “Irish Elk," Megaloceros giganteus. Evolution 28:191-220.

Gow, C. E. 1975. The morphology and relationships of Youngina capensis Broom and Prolacerta broomi Parrington. Paleontologia Africana 89-131.

Greene, H. W. 1987. Antipredator mechanisms in reptiles; pp. 1-152 in C. Gans and R. B. Huey (eds.), Biology of the Reptilia, Volume 16, Ecology B. Defense and Life History. vol. 16. Alan R. Liss, inc., New York, NYS.

Griffin, C. T., M. R. Stocker, C. Colleary, C. M. Stefanic, E. J. Lessner, M. Riegler, K. Formoso, K. Koeller, and S. J. Nesbitt. 2021. Assessing ontogenetic maturity in extinct saurian reptiles. Biological Reviews 96:470-525.

Gundy, G. C., and G. Z. Wurst. 1976. Parietal eye-pineal morphology in lizards and its physiological implications. The Anatomical Record 185:419-431.

Haas, G. 1955. The jaw musculature in Protoceratops and in other ceratopsians. American Museum Novitates 1-24.

Haas, G. 1973. Muscles of the jaws and associated structures in the Rhynchocephalia and Squamata; pp. 285-490 in C. Gans and T. S. Parsons (eds.), Biology of the Reptilia, Volume 4, Morphology D. vol. 4. Academic Press, London and New York.

Hammer, Ø., S. Bengtson, T. Malzbender, and D. Gelb. 2002. Imaging fossils using reflectance transforation and interactive manipulation of virtual light sources. Palaeontologia Electronica $5: 1-9$

Hankel, O. 1994. Early Permian to Middle Jurassic rifting and sedimentation in East Africa and Madagascar. Geologische Rundschau 83:703-710.

Haubold, H., and G. Schaumberg. 1985. Die Fossilien Des Kupferschiefers. A. Ziemsen Verlag, Wittenberg, $223 \mathrm{pp}$. 
Heaton, M. J. 1979. Cranial anatomy of primitive captorhinid reptiles from the Late Pennsylvanian and Early Permian, Oklahoma and Texas. Bulletin of the Oklahoma Geological Survey 127:1-84.

Herrel, A., L. Spithoven, R. V. Damme, and F. D. Vree. 1999. Sexual dimorphism of head size in Gallotia galloti: testing the niche divergence hypothesis by functional analyses. Functional Ecology 13:289-297.

Herrel, A., J. J. Meyers, P. Aerts, and K. C. Nishikawa. 2000. The mechanics of prey prehension in chameleons. Journal of Experimental Biology 203:3255-3263.

Herrel, A., R. V. Damme, B. Vanhooydonck, and F. D. Vree. 2001. The implications of bite performance for diet in two species of lacertid lizards. Canadian Journal of Zoology 79:662670.

Holliday, C. M. 2009. New insights into dinosaur jaw muscle anatomy. The Anatomical Record 292:1246-1265.

Holliday, C. M., and L. M. Witmer. 2007. Archosaur adductor chamber evolution: integration of musculoskeletal and topological criteria in jaw muscle homology. Journal of Morphology $268: 457-484$.

Hone, D. W. E., and D. Naish. 2013. The 'species recognition hypothesis' does not explain the presence and evolution of exaggerated structures in non-avialan dinosaurs. Journal of Zoology 290:172-180.

Hone, D. W. E., D. Naish, and I. C. Cuthill. 2012. Does mutual sexual selection explain the evolution of head crests in pterosaurs and dinosaurs? Lethaia 45:139-156.

Horner, J. R., and M. B. Goodwin. 2006. Major cranial changes during Triceratops ontogeny. Proceedings of the Royal Society B: Biological Sciences 273:2757-2761.

Horner, J. R., and M. B. Goodwin. 2008. Ontogeny of cranial epi-ossifications in Triceratops. Journal of Vertebrate Paleontology 28:134-144. 
Huene, F. R. von. 1930. Palaeochameleo und Coelurosauravus. Centralblatt Für Geologie Und Paläontologie (B) 440-441.

Huene, F. R. von. 1956. Paläontologie und Phylogenie der Niederen Tetrapoden. Veb Gustav Fischer Verlag, Jena, 716 pp.

Huyghe, K., A. Herrel, D. Adriaens, Z. Tadić, and R. Van Damme. 2009. It is all in the head: morphological basis for differences in bite force among colour morphs of the Dalmatian wall lizard. Biological Journal of the Linnean Society 96:13-22.

ICZN. 1999. International Code of Zoological Nomenclature. Fourth Edition. The International Trust for Zoological Nomenclature, London, UK, 306 pp.

Jenkins, K. M., M. E. H. Jones, T. Zikmund, A. Boyde, and J. D. Daza. 2017. A Review of Tooth Implantation Among Rhynchocephalians (Lepidosauria). Journal of Herpetology 51:300-306. Jenkins, R., and W. Tanner. 1968. Osteology and myology of Phrynosoma p. platyrhinos Girard and Phrynosoma d. hernandesi Girard. Brigham Young University Science Bulletin, Biological Series 9:1-35.

Kelso, E. C., and P. A. Verrell. 2002. Do male veiled chameleons, Chamaeleo calyptratus, adjust their courtship displays in response to female reproductive status? Ethology 108:495-512.

Knell, R. J., and S. Sampson. 2011. Bizarre structures in dinosaurs: species recognition or sexual selection? A response to Padian and Horner: Bizarre structures in dinosaurs. Journal of Zoology 283:18-22.

Krauss, D., A. N. Pezon, P. E. Nguyen, I. S. Salame, and S. Rywkin. 2010. Evolutionary interactions between horn and frill morphology in chasmosaurine ceratopsians; pp. 282-292 in M. J. Ryan, Chinnery-Allgeier, and D. A. Eberth (eds.), New Perspectives on Horned Dinosaurs: The Royal Tyrrell Museum Ceratopsian Symposium. Indiana University Press. Kuhn, O. 1939. Schädelbau und systematische Stellung von Weigeltisaurus. Paläontologische Zeitschrift 21:163-167. 
Laurin, M. 1991. The osteology of a Lower Permian eosuchian from Texas and a review of diapsid phylogeny. Zoological Journal of the Linnean Society 101:59-95.

Laurin, M., and R. R. Reisz. 1995. A reevaluation of early amniote phylogeny. Zoological Journal of the Linnean Society 113:165-223.

Laurin, M., and G. H. Piñeiro. 2017. A reassessment of the taxonomic position of mesosaurs, and a surprising phylogeny of early amniotes. Frontiers in Earth Science 5:88.

Laurin, M., and G. H. Piñeiro. 2018. Response: Commentary: A reassessment of the taxonomic position of mesosaurs, and a surprising phylogeny of early amniotes. Frontiers in Earth Science 6:1-9.

LeBlanc, A. R. H., and R. R. Reisz. 2015. Patterns of tooth development and replacement in captorhinid reptiles: a comparative approach for understanding the origin of multiple tooth rows. Journal of Vertebrate Paleontology 35:e919928.

LeBlanc, A. R. H., I. Paparella, D. O. Lamoureux, M. R. Doschak, and M. W. Caldwell. 2020. Tooth attachment and pleurodont implantation in lizards: histology, development, and evolution. Journal of Anatomy 00:1-23.

Lee, M. S. Y. 1995. Historical burden in systematics and the interrelationships of "parareptiles." Biological Reviews 70:459-547.

Lucas, S. G. 2017. Permian tetrapod biochronology, correlation and evolutionary events. Geological Society, London, Special Publications 450:405-444.

MacDougall, M. J., S. P. Modesto, N. Brocklehurst, A. Verrière, R. R. Reisz, and J. Fröbisch. 2018. Commentary: A reassessment of the taxonomic position of mesosaurs, and a surprising phylogeny of early amniotes. Frontiers in Earth Science 6:1-6.

Maiorino, L., A. A. Farke, T. Kotsakis, and P. Piras. 2017. Macroevolutionary patterns in cranial and lower jaw shape of ceratopsian dinosaurs (Dinosauria, Ornithischia): phylogeny, 
morphological integration, and evolutionary rates. Evolutionary Ecology Research 18:123167.

Maisano, J. A. 2002. Postnatal skeletal ontogeny in five Xantusiids (Squamata: Scleroglossa). Journal of Morphology 254:1-38.

Matsumoto, R., and S. E. Evans. 2017. The palatal dentition of tetrapods and its functional significance. Journal of Anatomy 230:47-65.

Measey, G. J., K. Hopkins, and K. A. Tolley. 2009. Morphology, ornaments and performance in two chameleon ecomorphs: is the casque bigger than the bite? Zoology 112:217-226.

Measey, G. J., A. Raselimanana, and A. Herrel. 2013. Ecology and life history of chameleons; pp. 85-113 in K. A. Tolley and A. Herrel (eds.), The Biology of Chameleons. University of California Press, Berkley, CA.

Measey, G. J., A. D. Rebelo, A. Herrel, B. Vanhooydonck, and K. A. Tolley. 2011. Diet, morphology and performance in two chameleon morphs: do harder bites equate with harder prey? Journal of Zoology 285:247-255.

Mendelson, T. C., and K. L. Shaw. 2012. The (mis)concept of species recognition. Trends in Ecology \& Evolution 27:421-427.

Mendelson, T. C., and K. L. Shaw. 2013. Further misconceptions about species recognition: a reply to Padian and Horner. Trends in Ecology \& Evolution 28:252-253.

Merck, J. 2003. An arboreal radiation of non-saurian diapsids. Journal of Vertebrate Paleontology 23:78A.

de Miguel Chaves, C., F. Ortega, and A. Pérez-García. 2018. New highly pachyostotic nothosauroid interpreted as a filter-feeding Triassic marine reptile. Biology Letters 14:20180130.

Modesto, S. P. 1995. The skull of the herbivorous synapsid Edaphosaurus boanerges from the Lower Permian of Texas. Palaeontology 38:213. 
Modesto, S. P. 2006. The cranial skeleton of the Early Permian aquatic reptile Mesosaurus tenuidens: implications for relationships and palaeobiology. Zoological Journal of the Linnean Society 146:345-368.

Modesto, S. P., and R. R. Reisz. 2003. An enigmatic new diapsid reptile from the Upper Permian of eastern Europe. Journal of Vertebrate Paleontology 22:851-855.

Modesto, S. P., and H.-D. Sues. 2004. The skull of the Early Triassic archosauromorph reptile Prolacerta broomi and its phylogenetic significance. Zoological Journal of the Linnean Society 140:335-351.

Müller, J. 2003. Early loss and multiple return of the lower temporal arcade in diapsid reptiles. Naturwissenschaften 90:473-476.

Müller, J. 2004. The relationships among diapsid reptiles and the influence of taxon selection; pp. 379-408 in M. V. H. Arratia and R. Cloutier (eds.), Recent advances in the origin and early radiation of vertebrates. Dr. Friedrich Pfeil, München.

Müller, J., J. Sterli, and J. Anquetin. 2011. Carotid circulation in amniotes and its implications for turtle relationships. Neues Jahrbuch Für Geologie Und Paläontologie. Abhandlungen 261:289-297.

Nesbitt, S. J. 2011. The early evolution of archosaurs: relationships and the origin of major clades. Bulletin of the American Museum of Natural History 352:1-292.

Osborn, H. F. 1903. On the primary division of the Reptilia into two sub-classes, Synapsida and Diapsida. Science 17:275-276.

Ostrom, J. H. 1964. A functional analysis of jaw mechanics in the dinosaur Triceratops. Postilla $88: 1-35$

Ostrom, J. H. 1966. Functional morphology and evolution of the ceratopsian dinosaurs. Evolution 20:290-308. 
Padian, K., and J. R. Horner. 2011. The evolution of 'bizarre structures' in dinosaurs: biomechanics, sexual selection, social selection or species recognition? Journal of Zoology 283:3-17.

Padian, K., and J. R. Horner. 2014. The species recognition hypothesis explains exaggerated structures in non-avialan dinosaurs better than sexual selection does. Comptes Rendus Palevol 13:97-107.

Peabody, F. E. 1952. Petrolacosaurus kansensis Lane, a Pennsylvanian reptile from Kansas. University of Kansas Paleontological Contributions, Vertebrata 1:1-41.

Piñeiro, G., J. Ferigolo, A. Ramos, and M. Laurin. 2012. Cranial morphology of the Early Permian mesosaurid Mesosaurus tenuidens and the evolution of the lower temporal fenestration reassessed. Comptes Rendus Palevol 11:379-391.

Piveteau, J. 1926. Paléontologie de Madagascar: XII. amphibiens et reptiles Permiens. Annales de Paléontologie 1-151.

Powell, G. L., A. P. Russell, H. A. Jamniczky, and B. Hallgrímsson. 2017. Shape variation in the dermatocranium of the greater short-horned lizard Phrynosoma hernandesi (Reptilia: Squamata: Phrynosomatidae). Evolutionary Biology 44:240-260.

Presch, W. 1969. Evolutionary osteology and relationships of the horned lizard genus Phrynosoma (family Iguanidae). Copeia 1969:250-275.

Pritchard, A. C. 2015. The early evolution of diapsid reptiles and the origin of Sauria. Ph.D. dissertation, Stony Brook University, Stony Brook, NY, 791 pp.

Pritchard, A. C., and H.-D. Sues. 2019. Postcranial remains of Teraterpeton hrynewichorum (Reptilia: Archosauromorpha) and the mosaic evolution of the saurian postcranial skeleton. Journal of Systematic Palaeontology 17:1745-1765. 
Pritchard, A. C., H.-D. Sues, D. Scott, and R. R. Reisz. in press. Osteology, relationships, and functional morphology of Weigeltisaurus jaekeli (Diapsida, Weigeltisauridae) based on a complete skeleton from the Upper Permian Kupferschiefer of Germany. PeerJ.

Prötzel, D., M. Heß, M. D. Scherz, M. Schwager, A. van’t Padje, and F. Glaw. 2018. Widespread bone-based fluorescence in chameleons. Scientific Reports 8:698.

Reisz, R. R. 1981. A diapsid reptile from the Pennsylvanian of Kansas. Special Publication of the Museum of Natural History, University of Kansas 7:1-74.

Reisz, R. R., D. S. Berman, and D. Scott. 1984. The anatomy and relationships of the Lower Permian reptile Araeoscelis. Journal of Vertebrate Paleontology 4:57-67.

Reisz, R. R., S. P. Modesto, and D. M. Scott. 2011. A new Early Permian reptile and its significance in early diapsid evolution. Proceedings of the Royal Society B: Biological Sciences 278:3731-3737.

Renesto, S. 1994. Megalancosaurus, a possibly arboreal archosauromorph (Reptilia) from the Upper Triassic of northern Italy. Journal of Vertebrate Paleontology 14:38-52.

Renesto, S., J. A. Spielmann, S. G. Lucas, and G. T. Spagnoli. 2010. The taxonomy and paleobiology of the Late Triassic (Carnian-Norian: Adamanian-Apachean) drepnosaurs (Diapsida: Archosauromorpha: Drepanosauromorpha). New Mexico Museum of Natural History and Science Bulletin 46:1-81.

Reynoso, V.-H. 1998. Huehuecuetzpalli mixtecus gen. et sp. nov: a basal squamate (Reptilia) from the Early Cretaceous of Tepexi de Rodríguez, Central México. Philosophical Transactions of the Royal Society of London. Series B: Biological Sciences 353:477-500.

Rieppel, O. 1981. The skull and jaw adductor musculature in chamaeleons. Revue Suisse de Zoologie 88:433-445.

Rieppel, O. 1984a. The upper temporal arcade of lizards: an ontogenetic problem. Revue Suisse de Zoologie 91:475-482. 
Rieppel, O. 1984b. The structure of the skull and jaw adductor musculature in the Gekkota, with comments on the phylogenetic relationships of the Xantusiidae (Reptilia: Lacertilia). Zoological Journal of the Linnean Society 82:291-318.

Rieppel, O. 1987. The phylogenetic relationships within the Chamaeleonidae, with comments on some aspects of cladistic analysis. Zoological Journal of the Linnean Society 89:41-62.

Rieppel, O. 1992. The skull in a hatchling of Sphenodon punctatus. Journal of Herpetology 26:8084.

Rieppel, O. 1993a. Patterns of diversity in the reptilian skull; pp. 344-390 in J. Hanken and B. K. Hall (eds.), The Skull, Volume 2: Patterns of Structural and Systematic Diversity. University of Chicago Press, Chicago, IL.

Rieppel, O. 1993b. Studies on skeleton formation in reptiles. II. Chamaeleo hoehnelii (Squamata: Chamaeleoninae), with comments on the homology of carpal and tarsal bones. Herpetologica 49:66-78.

Rieppel, O., and R. W. Gronowski. 1981. The loss of the lower temporal arcade in diapsid reptiles. Zoological Journal of the Linnean Society 72:203-217.

Rieppel, O., and C. Crumly. 1997. Paedomorphosis and skull structure in Malagasy chamaeleons (Reptilia: Chamaeleoninae). Journal of Zoology 243:351-380.

Rieppel, O., J. Müller, and J. Liu. 2005. Rostral structure in Thalattosauria (Reptilia, Diapsida). Canadian Journal of Earth Sciences 42:2081-2086.

Robinson, P. L. 1962. Gliding lizards from the Upper Keuper of Great Britain. Proceedings of the Geological Society of London 1601:137-146.

Romer, A. S. 1956. Osteology of the Reptiles, 3rd ed. University of Chicago Press, Chicago, IL, $772 \mathrm{pp}$.

Romer, A. S., and L. I. Price. 1940. Review of the Pelycosauria. Arno Press, New York, NYS, 533 pp. 
Sampson, S. D., M. J. Ryan, and D. H. Tanke. 1997. Craniofacial ontogeny in centrosaurine dinosaurs (Ornithischia: Ceratopsidae): taxonomic and behavioral implications. Zoological Journal of the Linnean Society 121:293-337.

Schaumberg, G. 1976. Zwei Reptilneufunde (Weigeltisaurus Kuhn [?], Lepidosauria [?], Reptilia) aus dem Kupferschiefer von Richelsdorf (Perm, Hessen). Philippia 3:3-8.

Schaumberg, G. 1982. Paläozoische Reptilien in Nordhessen. Philippia 5:3-10.

Schaumberg, G. 1986. Bemerkungen zu einem Neufund von Weigeltisaurus jaekeli (Weigelt) im nordhessischen Kupferschiefer. Paläontologische Zeitschrift 60:319-327.

Schaumberg, G., D. M. Unwin, and S. Brandt. 2007. New information on the anatomy of the Late Permian gliding reptile Coelurosauravus. Paläontologische Zeitschrift 81:160-173.

Schoch, R. R., and H.-D. Sues. 2018a. Osteology of the Middle Triassic stem-turtle Pappochelys rosinae and the early evolution of the turtle skeleton. Journal of Systematic Palaeontology 16:927-965.

Schoch, R. R., and H.-D. Sues. 2018b. A new lepidosauromorph reptile from the Middle Triassic (Ladinian) of Germany and its phylogenetic relationships. Journal of Vertebrate Paleontology 38:e1444619.

Schumacher, G.-H. 1973. The head muscles and hyolaryngeal skeleton of turtles and crocodilians; pp. 101-194 in C. Gans and T. S. Parsons (eds.), Biology of the Reptilia, Volume 4, Morphology D. vol. 4. Academic Press, London and New York.

Senter, P. 2004. Phylogeny of Drepanosauridae (Reptilia: Diapsida). Journal of Systematic Palaeontology 2:257-268.

da Silva, J. M., and K. A. Tolley. 2013. Ecomorphological variation and sexual dimorphism in a recent radiation of dwarf chameleons (Bradypodion). Biological Journal of the Linnean Society 109:113-130. 
da Silva, J. M., L. Carne, G. John Measey, A. Herrel, and K. A. Tolley. 2016. The relationship between cranial morphology, bite performance, diet and habitat in a radiation of dwarf chameleon (Bradypodion). Biological Journal of the Linnean Society 119:52-67.

Simões, T. R., M. W. Caldwell, R. L. Nydam, and P. Jiménez-Huidobro. 2017. Osteology, phylogeny, and functional morphology of two Jurassic lizard species and the early evolution of scansoriality in geckoes. Zoological Journal of the Linnean Society 180:216-241.

Simões, T. R., G. F. Funston, B. Vafaeian, R. L. Nydam, M. R. Doschak, and M. W. Caldwell. 2016. Reacquisition of the lower temporal bar in sexually dimorphic fossil lizards provides a rare case of convergent evolution. Scientific Reports 6:24087.

Simões, T. R., M. W. Caldwell, M. Tałanda, M. Bernardi, A. Palci, O. Vernygora, F. Bernardini, L. Mancini, and R. L. Nydam. 2018. The origin of squamates revealed by a Middle Triassic lizard from the Italian Alps. Nature 557:706-709.

Smith, R. M. H. 2000. Sedimentology and taphonomy of Late Permian vertebrate fossil localities in Southwestern Madagascar. Paleontologia Africana 36:25-41.

Sobral, G., and J. Müller. 2019. The braincase of Mesosuchus browni (Reptilia, Archosauromorpha) with information on the inner ear and description of a pneumatic sinus. PeerJ 7:e6798.

Sobral, G., T. R. Simões, and R. R. Schoch. 2020. A tiny new Middle Triassic stemlepidosauromorph from Germany: implications for the early evolution of lepidosauromorphs and the Vellberg fauna. Scientific Reports 10:2273.

Spielmann, J. A., S. G. Lucas, L. F. Rhinehart, and A. B. Heckert. 2008. The Late Triassic archosauromorph Trilophosaurus. New Mexico Museum of Natural History and Science Bulletin 43:1-177.

Stevens, M., and S. Merilaita. 2009. Animal camouflage: current issues and new perspectives. Philosophical Transactions of the Royal Society B: Biological Sciences 364:423-427. 
Stuart-Fox, D. 2013. Chameleon behavior and color change; pp. 115-130 in K. A. Tolley and A.

Herrel (eds.), The Biology of Chameleons. University of California Press, Berkley, CA.

Stuart-Fox, D. M., D. Firth, A. Moussalli, and M. J. Whiting. 2006. Multiple signals in chameleon contests: designing and analysing animal contests as a tournament. Animal Behaviour $71: 1263-1271$.

Sues, H.-D. 2019. The Rise of Reptiles: 320 Million Years of Evolution. Johns Hopkins University Press, Baltimore, MD, 401 pp.

Sumida, S. S. 1990. Vertebral Morphology, Alternation of Neural Spine Height, and Structure in Permo-Carboniferous tetrapods, and a reappraisal of primitive modes of terrestrial locomotion. University of California Publications, Zoology 122:1-129.

Tanke, D. H., and B. M. Rothschild. 2010. Paleopathologies in Albertan ceratopsids and their behavioral significance; pp. 355-384 in M. J. Ryan, B. J. Chinnery-Allgeier, and D. A. Eberth (eds.), New Perspectives on Horned Dinosaurs: The Royal Tyrrell Museum Ceratopsian Symposium. Indiana University Press.

Vanhooydonck, B., A. Herrel, and R. Van Damme. 2007. Interactions between habitat use, behavior, and the trophic niche of lacertid lizards; pp. 427-449 in D. B. Miles, L. B. McBrayer, and S. M. Reilly (eds.), Lizard Ecology. Cambridge University Press, Cambridge. Vaughn, P. P. 1955. The Permian reptile Araeoscelis restudied. Bulletin of the Museum of Comparative Zoology 113:1-467.

Verwaijen, D., R. V. Damme, and A. Herrel. 2002. Relationships between head size, bite force, prey handling efficiency and diet in two sympatric lacertid lizards. Functional Ecology $16: 842-850$.

Vickaryous, M. K., and B. K. Hall. 2008. Development of the dermal skeleton in Alligator mississippiensis (Archosauria, Crocodylia) with comments on the homology of osteoderms. Journal of Morphology 269:398-422. 
Vickaryous, M. K., and J.-Y. Sire. 2009. The integumentary skeleton of tetrapods: origin, evolution, and development. Journal of Anatomy 214:441-464.

Vorobyeva, E. I. 2007. The morphofunctional approach in paleontology. Paleontological Journal $41: 347-359$.

Waldman, M., and S. E. Evans. 1994. Lepidosauromorph reptiles from the Middle Jurassic of Skye. Zoological Journal of the Linnean Society 112:135-150.

Weigelt, J. 1930a. Palaeochamaeleo jaekeli nov. gen. nov. sp. Ein neuer Rhynchocephale aus dem Mansfelder Kupfer schiefer. Leopoldina 6:625-642.

Weigelt, J. 1930b. Über die vermutliche Nahrung von Protorosaurus und über einen körperlich erhaltenen Fruchtstand von Archaeopodocarpus germanicus aut. Leopoldina 6:269-280.

Werneburg, I. 2019. Morphofunctional categories and ontogenetic origin of temporal skull openings in amniotes. Frontiers in Earth Science 7:1-7.

Wescott, W. A., and J. N. Diggens. 1998. Depositional history and stratigraphical evolution of the Sakamena group (Middle Karoo Supergroup) in the southern Morondava Basin, Madagascar. Journal of African Earth Sciences 27:461-479.

Whiteside, D. I. 1986. The head skeleton of the Rhaetian sphenodontid Diphydontosaurus avonis gen. et sp.nov. and the modernizing of a living fossil. Philosophical Transactions of the Royal Society of London. B, Biological Sciences 312:379-430.

Witmer, L. M. 1995. Homology of facial structures in extant archosaurs (birds and crocodilians), with special reference to paranasal pneumaticity and nasal conchae. Journal of Morphology 225:269-327.

Witmer, L. M. 1997. The evolution of the antorbital cavity of archosaurs: a study in soft-tissue reconstruction in the fossil record with an analysis of the function of pneumaticity. Journal of Vertebrate Paleontology 17:1-76. 
Witzmann, F., H. Scholz, J. Müller, and N. Kardjilov. 2010. Sculpture and vascularization of dermal bones, and the implications for the physiology of basal tetrapods. Zoological Journal of the Linnean Society 160:302-340.

Submitted December 17, 2020; revisions received Month DD, YYYY; accepted Month DD, YYY. [dates left blank, to be completed by the editors] 


\section{Figure Captions}

FIGURE 1. Coelurosauravus elivensis Piveteau, 1926 (Madagascar, Lopingian), lectotype MNHN.F.MAP325a. Dorsal surface of individual preserved as a natural external mold. Scale bar equals $5 \mathrm{~cm}$. [planned for column]

FIGURE 2. Coelurosauravus elivensis Piveteau, 1926 (Madagascar, Lopingian), skull reconstruction based on all referred specimens. Poorly known or unpreserved elements outlined by dashed lines. A, dorsal view; B, ventral view; C, left lateral view. Abbreviations: bo, basioccipital; ect, ectopterygoid; pif, pineal foramen; fr, frontal; ju, jugal; la, lacrimal; mx, maxilla; na, nasal; pa, parietal; pal, palatine; pbs, parabasisphenoid; pif, pineal foramen; pmx, premaxilla; pob, postorbital; prf, prefrontal; prbf, preorbital fenestra; pt, pterygoid; q, quadrate; qj, quadratojugal; sq, squamosal; tf, temporal fenestra; th, tooth. Scale bar equals 1 $\mathrm{cm}$. [planned for page width]

FIGURE 3. Coelurosauravus elivensis Piveteau, 1926 (Madagascar, Lopingian), lectotype MNHN.F.MAP325a, skull. A, silicone cast of dorsal surface of individual preserved as a natural external mold; $\mathbf{B}$, interpretative drawing of A. Abbreviations: fm.m, dorsal margin of foramen magnum; fr, frontal; Mtt, metatarsal; pa, parietal; ph, phalange; phu, ungual phalange; pif, pineal foramen; pob, postorbital; qj, quadratojugal; soc, supraoccipital; sq, squamosal. Scale bars equal $1 \mathrm{~cm}$. [planned for page width]

FIGURE 4. Coelurosauravus elivensis Piveteau, 1926 (Madagascar, Lopingian), paralectotype MNHN.F.MAP317a-b, skull. A, silicone cast of MNHN.F.MAP317b, dorsal surface of individual preserved as a natural external mold; $\mathbf{B}$, interpretative drawing of $\mathbf{A} ; \mathbf{C}$, silicone cast of MNHN.F.MAP317a, ventral surface of individual preserved as a natural external mold; D, interpretative drawing of C. Abbreviations: adf, adductor fossa; art, articular; at, atlantal centrum; ax, axis; axi, axial intercentrum; bo, basioccipital; cv3, third 
cervical vertebra; exo, exoccipital; fr, frontal; na, nasal; opt, opisthotic; otc, otic capsule elements; pa, parietal; pata, patagial spar; pbs, parabasisphenoid; pif, pineal foramen; ph, phalange; pob, postorbital; prf, prefrontal; pt, pterygoid; pt.bp, pterygoid basicranial process; pt.q, pterygoid quadrate ramus; pt.tv, pterygoid, transverse flange; sang, surangular; soc, supraoccipital; sq, squamosal; sq.pl, squamosal posterior lamina. Scale bars equal $1 \mathrm{~cm}$. [planned for page width]

FIGURE 5. Coelurosauravus elivensis Piveteau, 1926 (Madagascar, Lopingian), MNHN.F.MAP327b, cranial remains preserved mostly in ventral (internal) view. A, silicone cast of individual preserved as a natural external mold; $\mathbf{B}$, interpretative drawing of $\mathbf{A} ; \mathbf{C}$, disarticulated right pterygoid, cropped out from $\mathbf{A} ; \mathbf{D}$, interpretative drawing of $\mathbf{C}$.

Abbreviations: cr.cr, crista cranii; df, dorsal flange of quadrate ramus of pterygoid; ect, ectopterygoid; fr, frontal; fr.vla, frontal ventral lamina; ju, jugal; la, lacrimal; mx, maxilla; na, nasal; nld, nasolacrimal duct; pa, parietal; pal, palatine; pal.th, palatal tooth; ph, phalange; pmx, premaxilla; pob, postorbital; pqf, paraquadrate foramen; prf, prefrontal; pt, pterygoid; pt. pal, pterygoid palatal process; pt.f, pterygoid facet; pt.q, pterygoid quadrate ramus; pt.tv, pterygoid transverse flange; q, quadrate; rec, recess; rid, ridge. Scale bars equal $1 \mathrm{~cm}(\mathbf{A}, \mathbf{B})$, and $5 \mathrm{~mm}(\mathbf{C}, \mathbf{D})$. [planned for page width]

FIGURE 6. Close-up views of weigeltisaurids specimens. A, Coelurosauravus elivensis Piveteau, 1926 (Madagascar, Lopingian), MNHN.F.MAP327b, medial surface of left maxilla, individual preserved as a natural external mold; $\mathbf{B}$, interpretative drawing of $\mathbf{A} ; \mathbf{C}$, Weigeltisaurus jaekeli (Weigelt, 1930a) (Germany, Lopingian), SMNK-PAL 34899a, cast of holotype SSWG 113/7, photograph of right anterior region in lateral view; D, interpretative drawing of the circumorbital bones of C. Abbreviations: alvc, alveolar canal; cav, cavity; for, foramen; ju, jugal; ju.f, jugal facet; la, lacrimal; la.f, lacrimal facet; mx, maxilla; orb, orbit; pal.f, palatine facet; pob, postorbital; prbf, preorbital fenestra; prf, prefrontal; prf.f, 
prefrontal facet; spk, spike; tb, tubercle; th, tooth. Arrow indicates preserved tooth 14. Scale bars equal $5 \mathrm{~mm}(\mathbf{A}, \mathbf{B})$, and $1 \mathrm{~cm}(\mathbf{C}, \mathbf{D})$. [planned for page width]

FIGURE 7. Coelurosauravus elivensis Piveteau, 1926 (Madagascar, Lopingian), MNHN.F.MAP327a-b, parietosquamosal frill, left half. A, silicone cast of MNHN.F.MAP327b, dorsal surface of individual preserved as a natural external mold; B, interpretative drawing of $\mathbf{A} ; \mathbf{C}$, silicone cast of MNHN.F.MAP327a, ventral surface of individual preserved as a natural external mold; D, interpretative drawing of $\mathbf{C}$.

Abbreviations: add.rid, ridge for origin of the adductor musculature; fr.f, frontal facet; pa, parietal; pa.f, parietal facet; pa.ptt, parietal posttemporal process; pif, pineal foramen; pob, postorbital; pp.la, postparietal lamina; q.f, quadrate facet; rid, ridge; spk, spikes; sq, squamosal; sq.f, squamosal facet; sq.pl, squamosal posterior lamina; tb, tubercles; tm, attachment point of taenia marginalis. Scale bars equal $1 \mathrm{~cm}$. [planned for page width]

FIGURE 8. Coelurosauravus elivensis Piveteau, 1926 (Madagascar, Lopingian), braincase and postcranial elements mostly in ventral view. A, close up view of paralectotype MNHN.F.MAP317a, as indicated in Fig. 4C. B, disarticulated elements in MNHN.F.MAP327a, silicone cast of individual preserved as a natural external mold; C, interpretative drawing of B. Abbreviations: atc, atlantal centrum; atn, atlantal neural arch; ax, axis; axi, axial intercentrum; bo, basioccipital; bpt, basipterygoid process; carp, carpal elements; cupr, cultriform process of parasphenoid; exo, exoccipital; ica, foramen for internal carotid artery; Mtc, metacarpal; oco, occipital condyle; opt, opisthotic; otc, otic capsule elements; pa.p, paroccipital process; pbs, parabasisphenoid; ph, phalange; ra, radius; ul, ulna; ver, ventrolateral crest; vmc, ventromedial concavity; vs, vidian sulcus; XII, foramen for hypoglossal nerve (CN XII). Scale bars equal $2 \mathrm{~mm}$. [planned for page width] FIGURE 9. Coelurosauravus elivensis Piveteau, 1926 (Madagascar, Lopingian), life reconstruction of the read, body hidden by Glossopteris leaves (found associated with $C$. 
elivensis in the fossil assemblage). The colors are based on extant chamaeleonids squamates.

Illustration by Charlène Letenneur (MNHN). [planned for column width] 


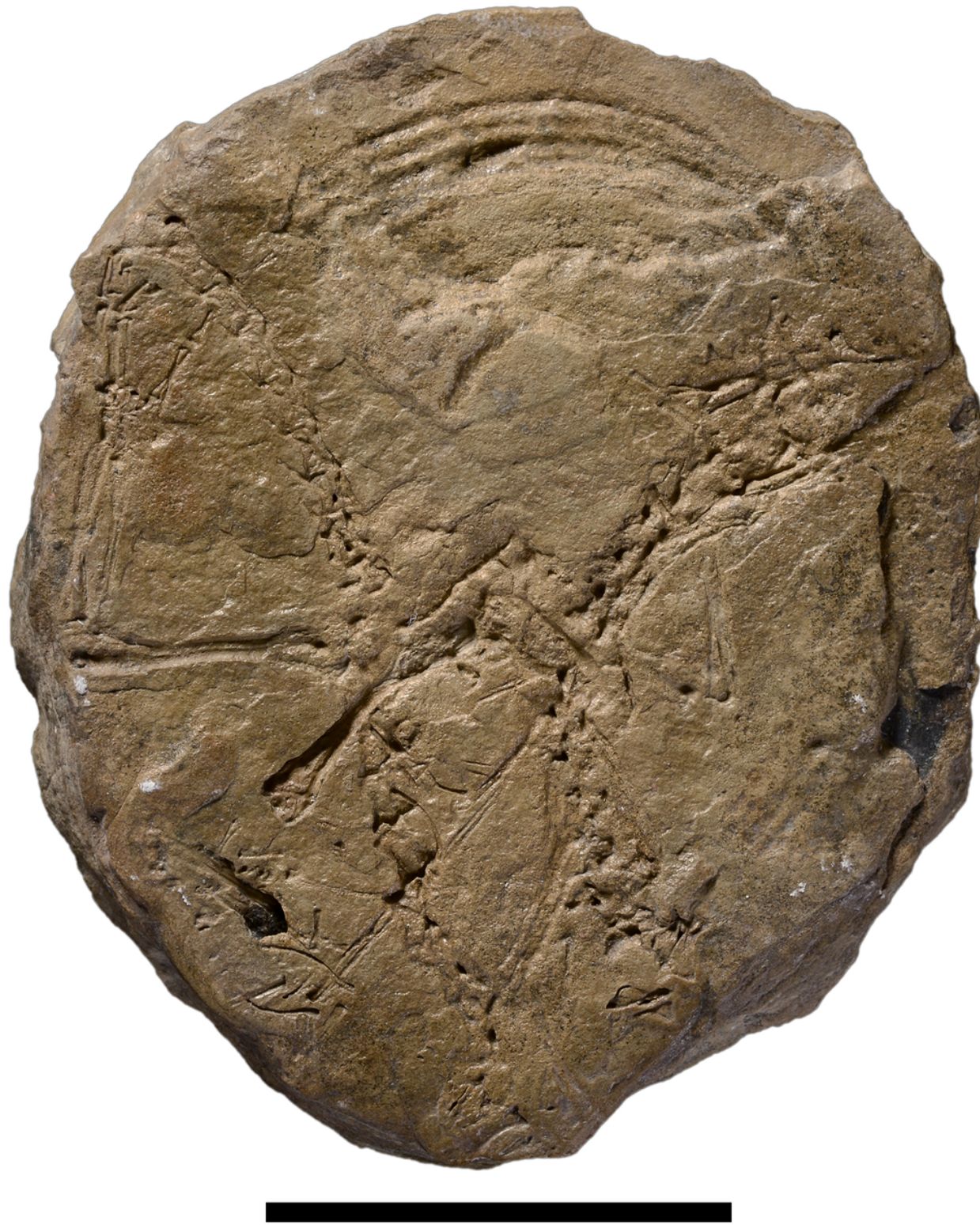

FIGURE 1. Coelurosauravus elivensis Piveteau, 1926 (Madagascar, Lopingian), lectotype MNHN.F.MAP325a. Dorsal surface of individual preserved as a natural external mold. Scale bar equals $5 \mathrm{~cm}$. [planned for column]

$88 \times 108 \mathrm{~mm}(300 \times 300 \mathrm{DPI})$ 


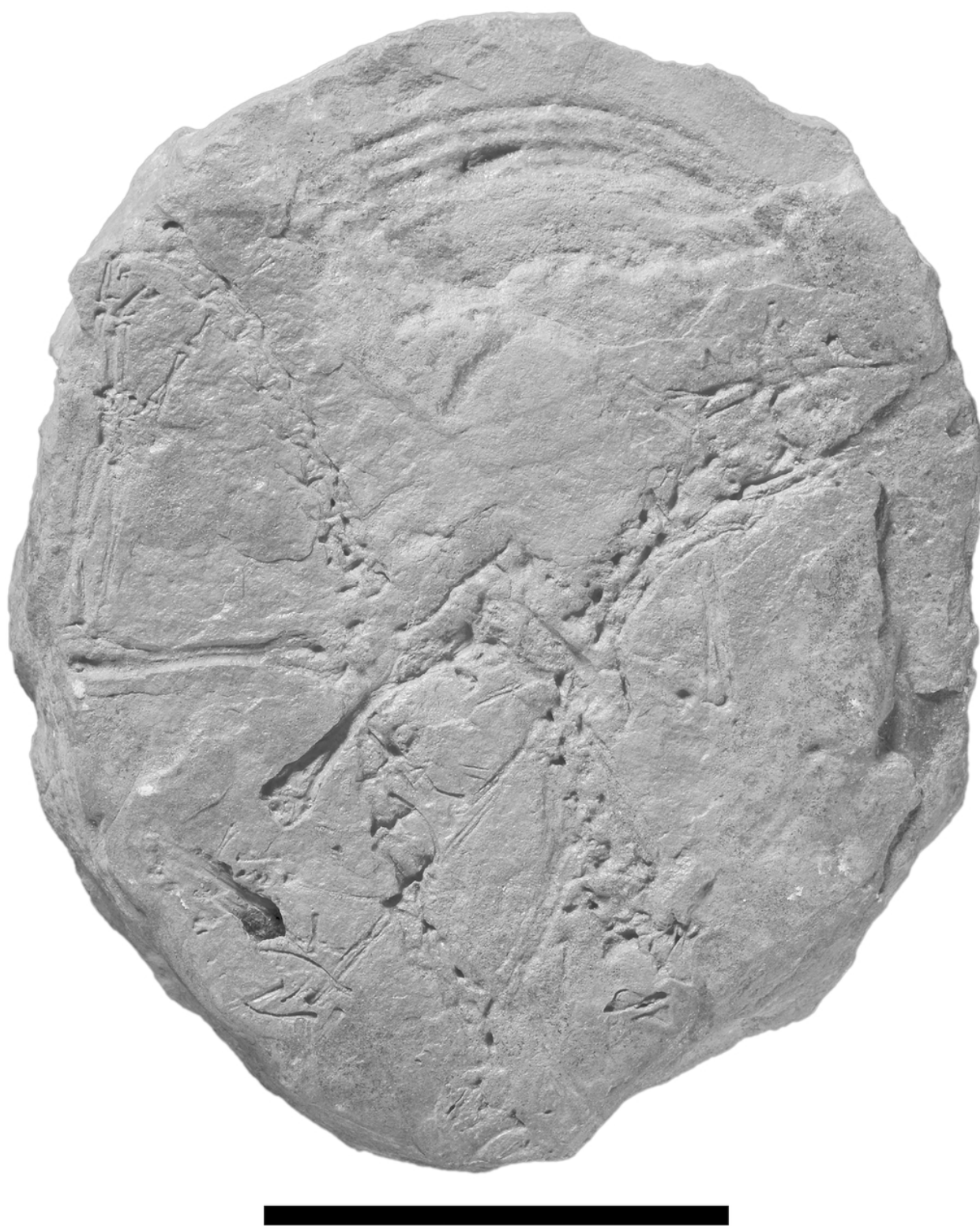

FIGURE 1. Coelurosauravus elivensis Piveteau, 1926 (Madagascar, Lopingian), lectotype MNHN.F.MAP325a. Dorsal surface of individual preserved as a natural external mold. Scale bar equals $5 \mathrm{~cm}$. [planned for column]

$88 \times 108 \mathrm{~mm}(300 \times 300$ DPI $)$ 

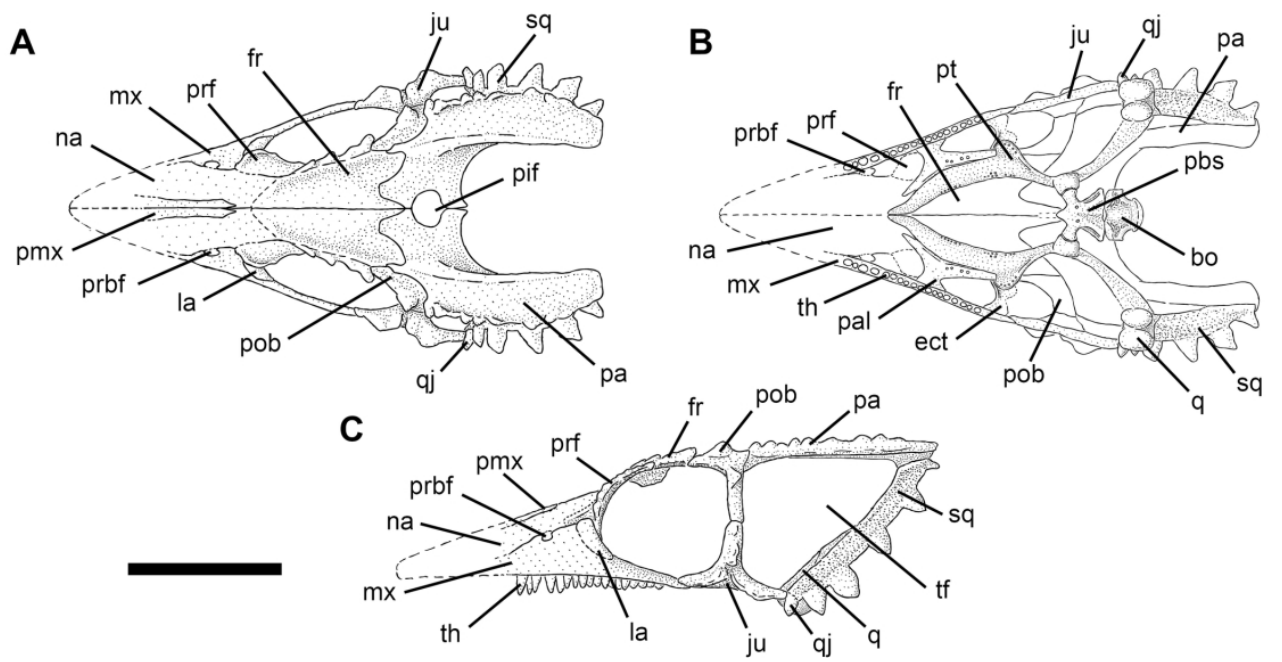

FIGURE 2. Coelurosauravus elivensis Piveteau, 1926 (Madagascar, Lopingian), skull reconstruction based on all referred specimens. Poorly known or unpreserved elements outlined by dashed lines. A, dorsal view; B, ventral view; C, left lateral view. Abbreviations: bo, basioccipital; ect, ectopterygoid; pif, pineal foramen; fr, frontal; ju, jugal; la, lacrimal; mx, maxilla; na, nasal; pa, parietal; pal, palatine; pbs, parabasisphenoid; pif, pineal foramen; pmx, premaxilla; pob, postorbital; prf, prefrontal; prbf, preorbital fenestra; pt, pterygoid; q, quadrate; qj, quadratojugal; sq, squamosal; tf, temporal fenestra; th, tooth. Scale bar equals $1 \mathrm{~cm}$. [planned for page width]

$$
182 \times 90 \mathrm{~mm}(300 \times 300 \mathrm{DPI})
$$



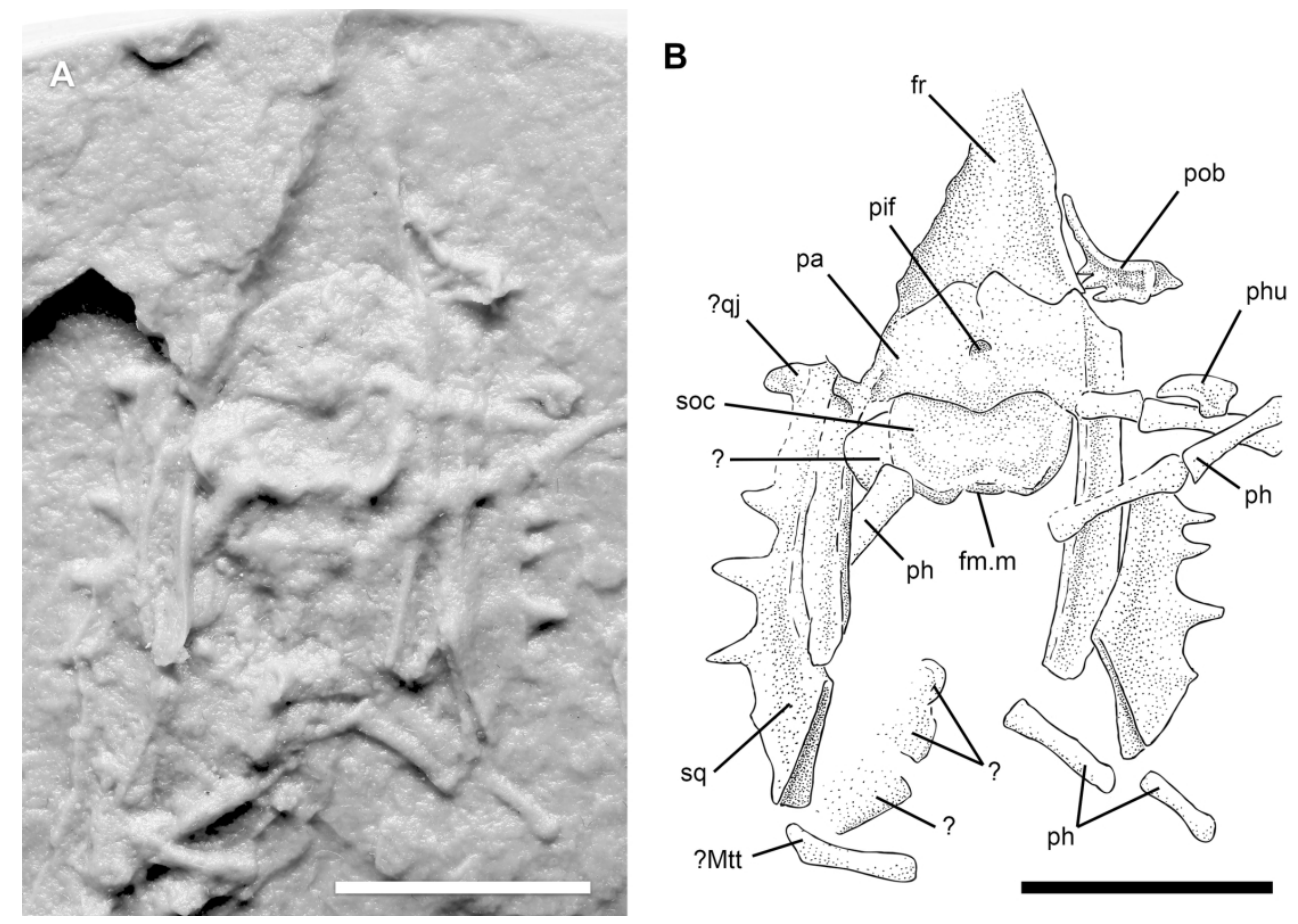

FIGURE 3. Coelurosauravus elivensis Piveteau, 1926 (Madagascar, Lopingian), lectotype MNHN.F.MAP325a, skull. A, silicone cast of dorsal surface of individual preserved as a natural external mold; B, interpretative drawing of A. Abbreviations: fm.m, dorsal margin of foramen magnum; fr, frontal; Mtt, metatarsal; pa, parietal; ph, phalange; phu, ungual phalange; pif, pineal foramen; pob, postorbital; qj, quadratojugal; soc, supraoccipital; sq, squamosal. Scale bars equal $1 \mathrm{~cm}$. [planned for page width]

$182 \times 126 \mathrm{~mm}(300 \times 300$ DPI $)$ 

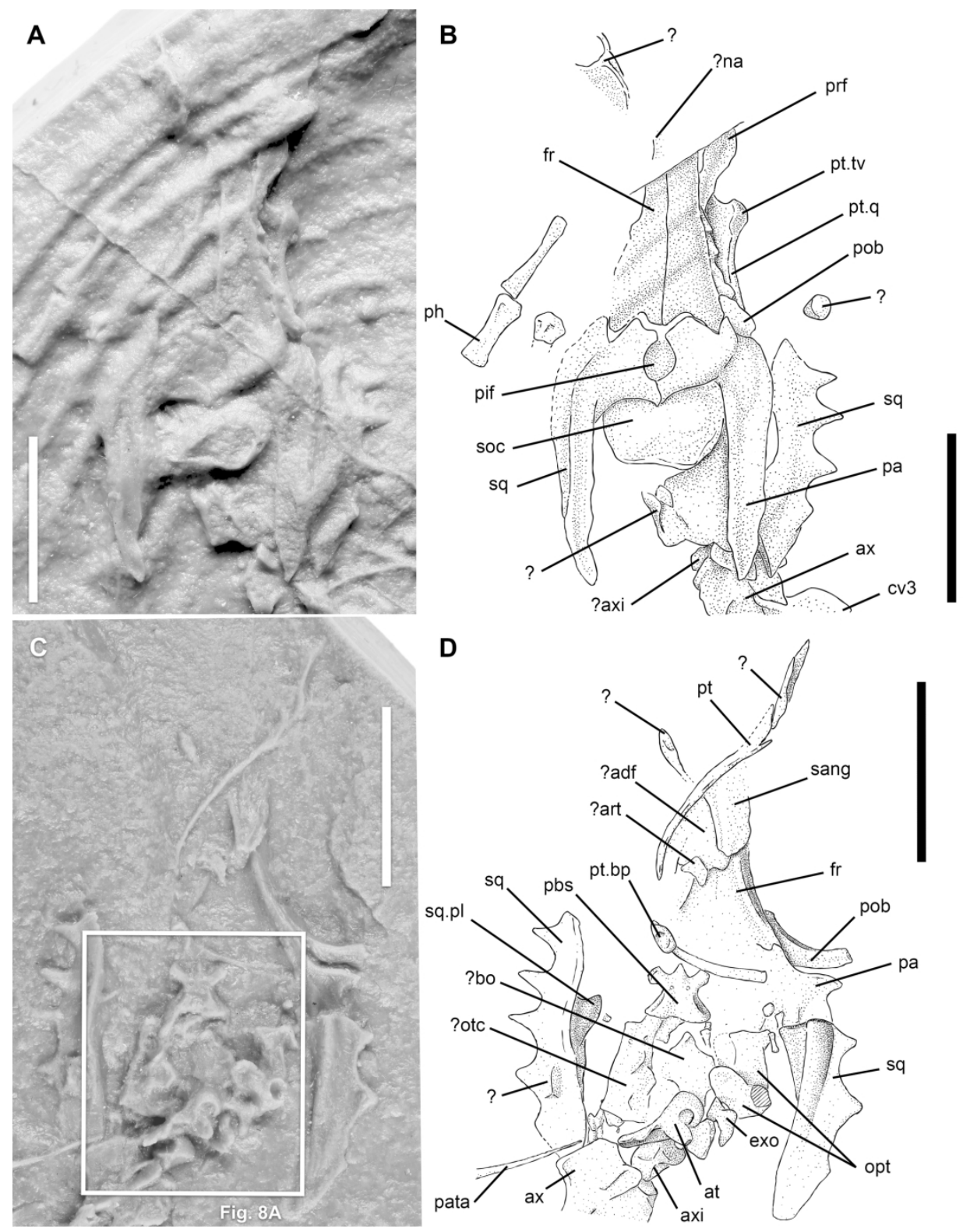

FIGURE 4. Coelurosauravus elivensis Piveteau, 1926 (Madagascar, Lopingian), paralectotype MNHN.F.MAP317a-b, skull. A, silicone cast of MNHN.F.MAP317b, dorsal surface of individual preserved as a natural external mold; B, interpretative drawing of $\mathbf{A} ; \mathbf{C}$, silicone cast of MNHN.F.MAP317a, ventral surface of individual preserved as a natural external mold; D, interpretative drawing of $\mathbf{C}$. Abbreviations: adf, adductor fossa; art, articular; at, atlantal centrum; ax, axis; axi, axial intercentrum; bo, basioccipital; cv3, third cervical vertebra; exo, exoccipital; fr, frontal; na, nasal; opt, opisthotic; otc, otic capsule elements;

pa, parietal; pata, patagial spar; pbs, parabasisphenoid; pif, pineal foramen; ph, phalange; pob, postorbital; prf, prefrontal; pt, pterygoid; pt.bp, pterygoid basicranial process; pt.q, pterygoid quadrate ramus; pt.tv, pterygoid, transverse flange; sang, surangular; soc, supraoccipital; sq, squamosal; sq.pl, squamosal posterior lamina. Scale bars equal $1 \mathrm{~cm}$. [planned for page width]

$182 \times 230 \mathrm{~mm}(300 \times 300 \mathrm{DPI})$ 


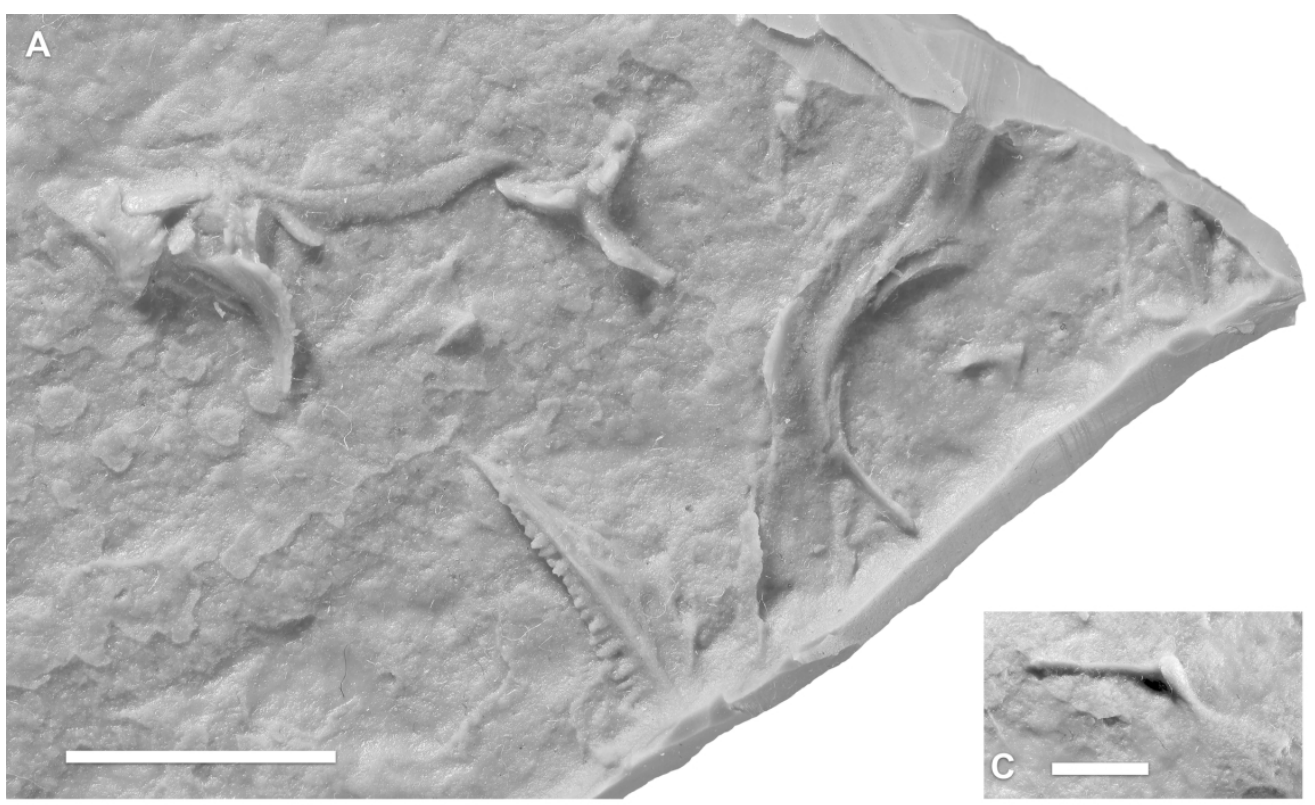

B

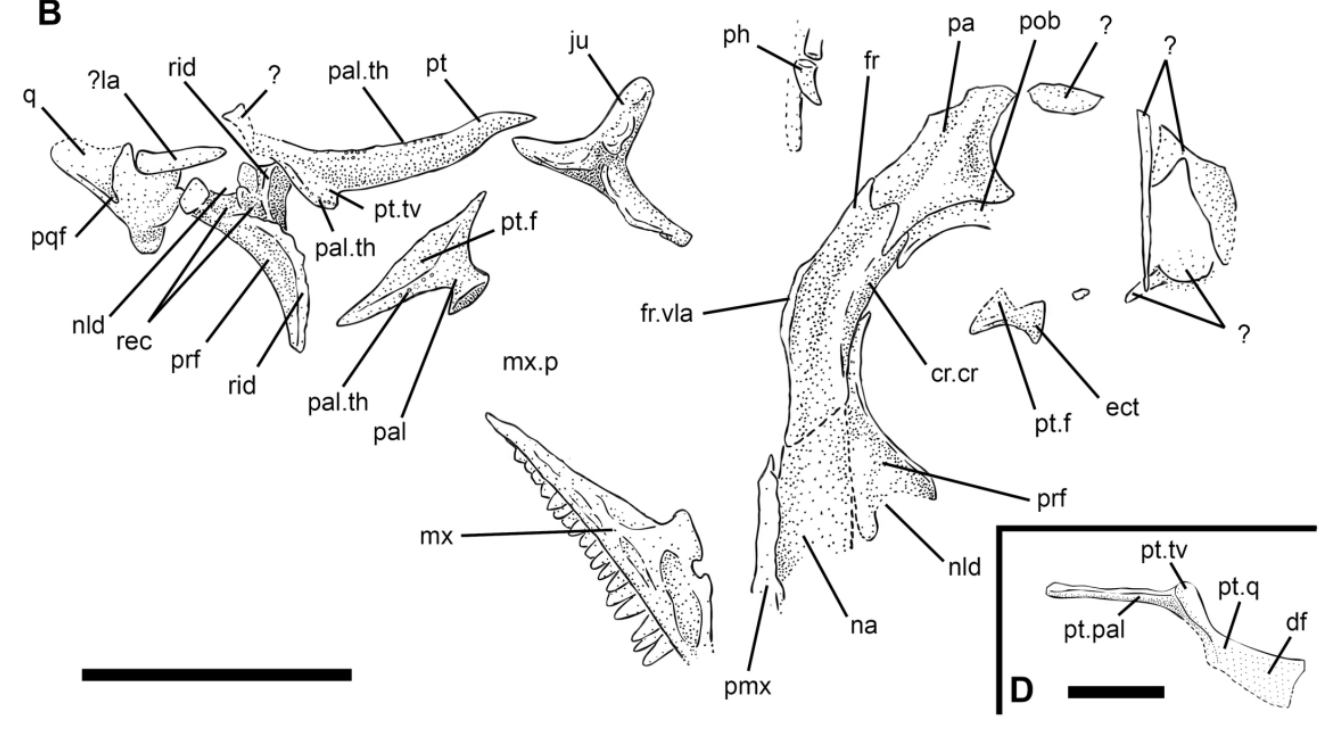

FIGURE 5. Coelurosauravus elivensis Piveteau, 1926 (Madagascar, Lopingian), MNHN.F.MAP327b, cranial remains preserved mostly in ventral (internal) view. A, silicone cast of individual preserved as a natural external mold; B, interpretative drawing of A; C, disarticulated right pterygoid, cropped out from A; D, interpretative drawing of C. Abbreviations: cr.cr, crista cranii; df, dorsal flange of quadrate ramus of pterygoid; ect, ectopterygoid; fr, frontal; fr.vla, frontal ventral lamina; ju, jugal; la, lacrimal; mx, maxilla; na, nasal; nld, nasolacrimal duct; pa, parietal; pal, palatine; pal.th, palatal tooth; ph, phalange; pmx, premaxilla; pob, postorbital; pqf, paraquadrate foramen; prf, prefrontal; pt, pterygoid; pt. pal, pterygoid palatal process; pt.f, pterygoid facet; pt.q, pterygoid quadrate ramus; pt.tv, pterygoid transverse flange; q, quadrate; rec, recess; rid, ridge. Scale bars equal $1 \mathrm{~cm}(\mathbf{A}, \mathbf{B})$, and $5 \mathrm{~mm}(\mathbf{C}, \mathbf{D})$. [planned for page width] 

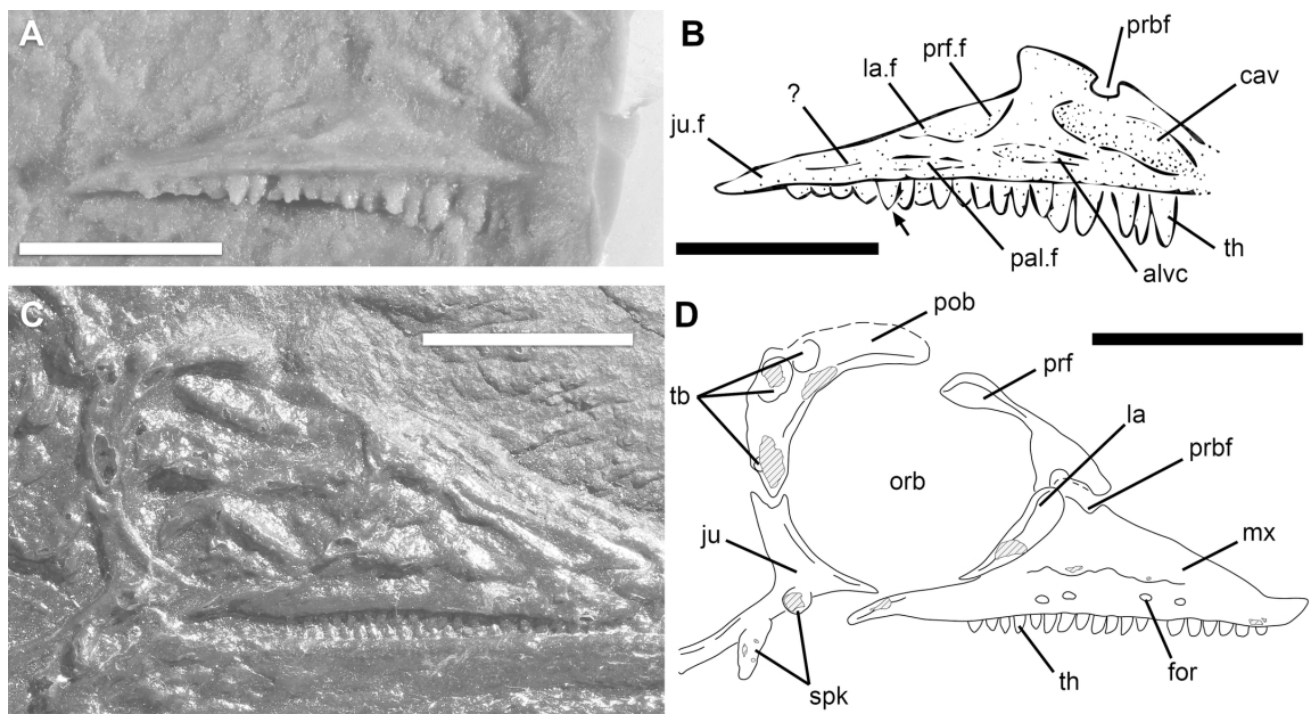

FIGURE 6. Close-up views of weigeltisaurids specimens. A, Coelurosauravus elivensis Piveteau, 1926 (Madagascar, Lopingian), MNHN.F.MAP327b, medial surface of left maxilla, individual preserved as a natural external mold; B, interpretative drawing of A; C, Weigeltisaurus jaekeli (Weigelt, 1930a) (Germany, Lopingian), SMNK-PAL 34899a, cast of holotype SSWG 113/7, photograph of right anterior region in lateral view; D, interpretative drawing of the circumorbital bones of C. Abbreviations: alvc, alveolar canal; cav, cavity; for, foramen; ju, jugal; ju.f, jugal facet; la, lacrimal; la.f, lacrimal facet; mx, maxilla; orb, orbit; pal.f, palatine facet; pob, postorbital; prbf, preorbital fenestra; prf, prefrontal; prf.f, prefrontal facet; spk, spike; tb, tubercle; th, tooth. Arrow indicates preserved tooth 14 . Scale bars equal $5 \mathrm{~mm}(\mathbf{A}, \mathbf{B})$, and $1 \mathrm{~cm}$ (C, D). [planned for page width]

$$
182 \times 98 \mathrm{~mm}(300 \times 300 \text { DPI })
$$



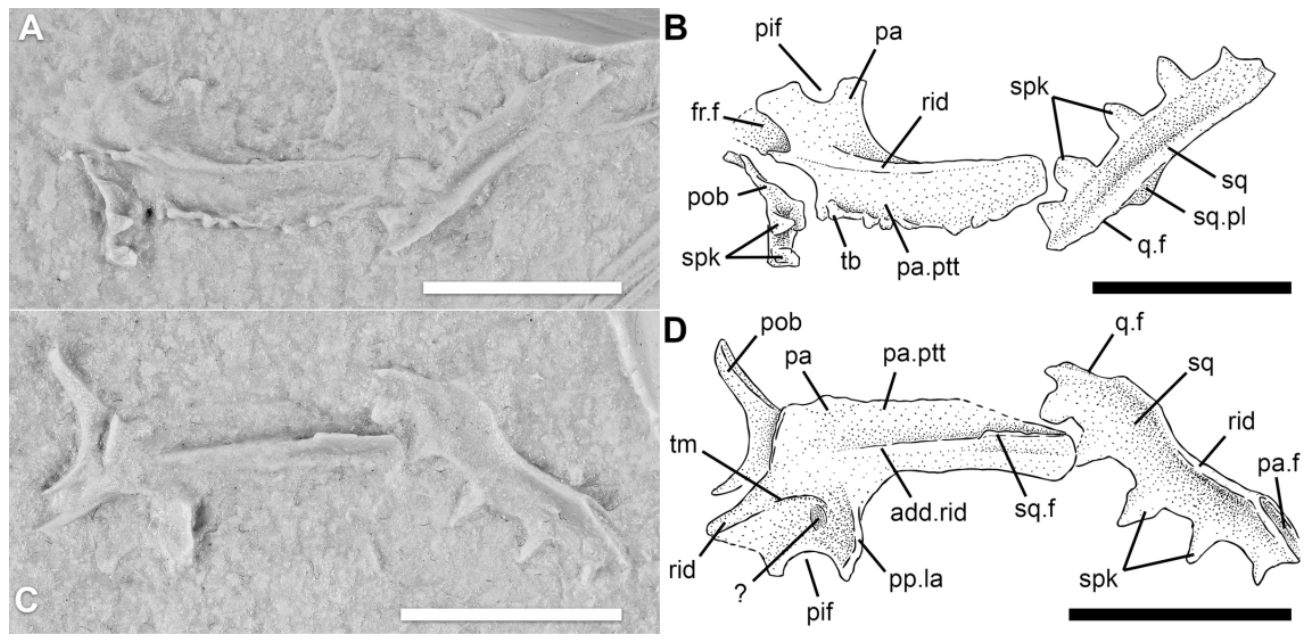

FIGURE 7. Coelurosauravus elivensis Piveteau, 1926 (Madagascar, Lopingian), MNHN.F.MAP327a-b, parietosquamosal frill, left half. A, silicone cast of MNHN.F.MAP327b, dorsal surface of individual preserved as a natural external mold; B, interpretative drawing of A; C, silicone cast of MNHN.F.MAP327a, ventral surface of individual preserved as a natural external mold; D, interpretative drawing of C. Abbreviations: add.rid, ridge for origin of the adductor musculature; fr.f, frontal facet; pa, parietal; pa.f, parietal facet; pa.ptt, parietal posttemporal process; pif, pineal foramen; pob, postorbital; pp.la, postparietal lamina;

q.f, quadrate facet; rid, ridge; spk, spikes; sq, squamosal; sq.f, squamosal facet; sq.pl, squamosal posterior lamina; tb, tubercles; tm, attachment point of taenia marginalis. Scale bars equal $1 \mathrm{~cm}$. [planned for page width]

$182 \times 87 \mathrm{~mm}(300 \times 300 \mathrm{DPI})$ 

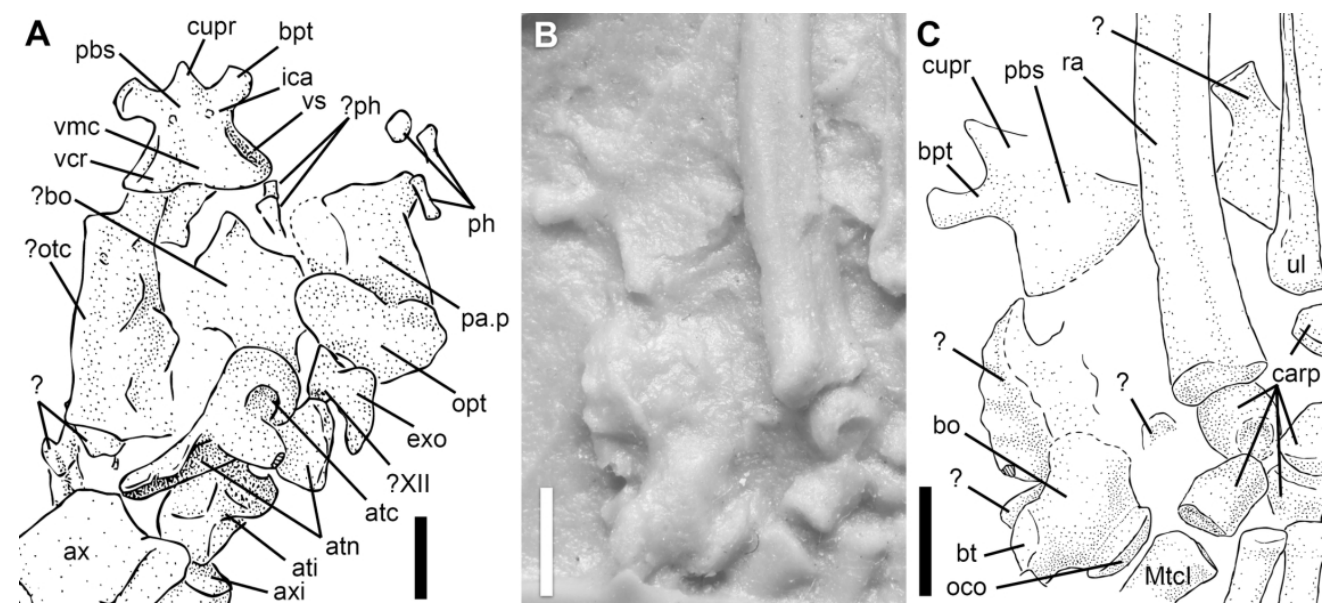

FIGURE 8. Coelurosauravus elivensis Piveteau, 1926 (Madagascar, Lopingian), braincase and postcranial elements mostly in ventral view. A, close up view of paralectotype MNHN.F.MAP317a, as indicated in Fig. 4C. B, disarticulated elements in MNHN.F.MAP327a, silicone cast of individual preserved as a natural external mold; C, interpretative drawing of B. Abbreviations: atc, atlantal centrum; atn, atlantal neural arch; ax, axis; axi, axial intercentrum; bo, basioccipital; bpt, basipterygoid process; carp, carpal elements; cupr, cultriform process of parasphenoid; exo, exoccipital; ica, foramen for internal carotid artery; Mtc, metacarpal; oco, occipital condyle; opt, opisthotic; otc, otic capsule elements; pa.p, paroccipital process; pbs, parabasisphenoid; ph, phalange; ra, radius; ul, ulna; vcr, ventrolateral crest; vmc, ventromedial concavity; vs, vidian sulcus; XII, foramen for hypoglossal nerve (CN XII). Scale bars equal $2 \mathrm{~mm}$. [planned for page width]

$182 \times 82 \mathrm{~mm}(300 \times 300 \mathrm{DPI})$ 
FIGURE 9. Coelurosauravus elivensis Piveteau, 1926 (Madagascar, Lopingian), life reconstruction of the read, body hidden by Glossopteris leaves (found associated with C. elivensis in the fossil assemblage). The colors are based on extant chamaeleonids squamates. Illustration by Charlène Letenneur (MNHN). [planned for column]

$88 \times 97 \mathrm{~mm}(300 \times 300 \mathrm{DPI})$ 
FIGURE 9. Coelurosauravus elivensis Piveteau, 1926 (Madagascar, Lopingian), life reconstruction of the read, body hidden by Glossopteris leaves (found associated with $C$. elivensis in the fossil assemblage). The colors are based on extant chamaeleonids squamates. Illustration by Charlène Letenneur (MNHN). [planned for column]

$88 \times 97 \mathrm{~mm}(300 \times 300 \mathrm{DPI})$ 
TABLE 1. Denominations and identifications of previously published specimens referred to the genera Coelurosauravus and Weigeltisaurus with preserved cranial remains.

\begin{tabular}{|c|c|c|c|}
\hline $\begin{array}{l}\text { Specimen } \\
\text { denomination }\end{array}$ & Identification & Material examined & Remarks \\
\hline MNHN.F.MAP325a & $\begin{array}{l}\text { Coelurosauravus } \\
\text { elivensis (Lectotype) }\end{array}$ & MNHN.F.MAP325a & $\begin{array}{l}\text { Patrimonial number } \\
1908-11-21 \mathrm{a}\end{array}$ \\
\hline MNHN.F.MAP317a- & Coelurosauravus & MNHN.F.MAP317a- & Patrimonial number \\
\hline$b$ & $\begin{array}{l}\text { elivensis } \\
\text { (Paralectotype) }\end{array}$ & . & $1908-11-22 a-b$ \\
\hline MNHN.F.MAP327a- & Coelurosaravus & MNHN.F.MAP327a- & Patrimonial number \\
\hline $\mathrm{b}$ & elivensis & $\mathrm{b}$ & $1908-5-2$ \\
\hline SSWG 113/7 & $\begin{array}{l}\text { Weigeltisaurus } \\
\text { jaekeli (Holotype) }\end{array}$ & $\begin{array}{l}\text { SMNK-PAL 34899a } \\
\text { (cast) }\end{array}$ & - \\
\hline Ellrich specimen & Weigeltisaurus sp. & SMNK-PAL 2882 & $\begin{array}{l}\text { Counterpart in } \\
\text { anonymous private } \\
\text { collection }\end{array}$ \\
\hline Wolfsberg specimen & Weigeltisaurus sp. & $\begin{array}{l}\text { SMNK-PAL } 34910 \\
\text { (cast) }\end{array}$ & $\begin{array}{l}\text { Specimens in Munk } \\
\text { private collection, } \\
\text { currently being } \\
\text { transferred to the } \\
\text { Naturkundemuseum } \\
\text { im Ottoneum, Kassel }\end{array}$ \\
\hline
\end{tabular}


TABLE 2. Skull measurements of weigeltisaurids. *measurements based on reconstructions; ${ }^{1}$ measurements from Bulanov and Sennikov (2015b).

\begin{tabular}{|c|c|c|c|}
\hline Measurements (mm) & $\begin{array}{c}\text { Coelurosauravus } \\
\text { (Fig. 1) }\end{array}$ & $\begin{array}{c}\text { Weigeltisaurus } \\
\text { (holotype) }\end{array}$ & $\begin{array}{l}\text { Ellrich specimen } \\
\text { SMNK-PAL } 2882\end{array}$ \\
\hline Total skull length & $35.63^{*}$ & 57.33 & 50.78 \\
\hline Basal skull length & $27.96^{*}$ & $42^{1}$ & 32.85 \\
\hline $\begin{array}{l}\text { Postorbital skull } \\
\text { height }\end{array}$ & $10.43^{*}$ & - & - \\
\hline $\begin{array}{l}\text { Skull width } \\
\text { (quadrate } \\
\text { articulation) }\end{array}$ & $17.96^{*}$ & - & - \\
\hline Orbit diameter & $8.44^{*}$ & $11.7^{1}$ & 9.96 \\
\hline Parietal total length & $14.74 *$ & - & 23.02 \\
\hline $\begin{array}{l}\text { Parietal main body } \\
\text { length }\end{array}$ & $5.65 *$ & - & 6.49 \\
\hline $\begin{array}{l}\text { Interparietal suture } \\
\text { length }\end{array}$ & $3.82 *$ & - & 4.47 \\
\hline $\begin{array}{l}\text { Posttemporal } \\
\text { process length }\end{array}$ & $9.09 *$ & $18^{1}$ & 16.53 \\
\hline $\begin{array}{l}\text { Pineal foramen } \\
\text { diameter }\end{array}$ & $2.14^{*}$ & - & 2.75 \\
\hline Humerus length & $29.9 *$ & 34.51 & 26.11 \\
\hline & MNHN.F.MAP325a & $\begin{array}{c}\text { MNHN.F.MAP317a- } \\
\text { b }\end{array}$ & $\begin{array}{c}\text { MNHN.F.MAP327a- } \\
\text { b }\end{array}$ \\
\hline
\end{tabular}


Total skull length

Basal skull length

Postorbital skull

height

Skull width

(quadrate

articulation)

Orbit diameter

$\begin{array}{lll}- & 8.34 & 8.86\end{array}$

Parietal total length

16.21

15.92

14.65

Parietal main body

5.56

4.96

5.53

length

Interparietal suture

4.25

3.85

length

Posttemporal

10.65

10.96

9.12

process length

Pineal foramen

2.43

2.04

diameter

Humerus length

29.04

30.62

30.05

TABLE 2. (Continued) 
A new cranial reconstruction of Coelurosauravus elivensis Piveteau, 1926 (Diapsida, Weigeltisauridae) and its implications on the paleoecology of the first gliding vertebrates VALENTIN BUFFA, ${ }^{*}, 1$ EBERHARD FREY, ${ }^{2}$ J.-SÉBASTIEN STEYER, ${ }^{1}$ and MICHEL LAURIN $^{1}$

${ }^{1}$ Centre de Recherche en Paléontologie - Paris, UMR 7207 CNRS-MNHN-SU, Muséum national d'Histoire naturelle, CP38, 8 rue Buffon, 75005 Paris, France, valentin.buffa@edu.mnhn.fr;

${ }^{2}$ Abteilung Geowissenshaften, Staatliches Museum für Naturkunde Karlsruhe, Germany

${ }^{*}$ Corresponding author 


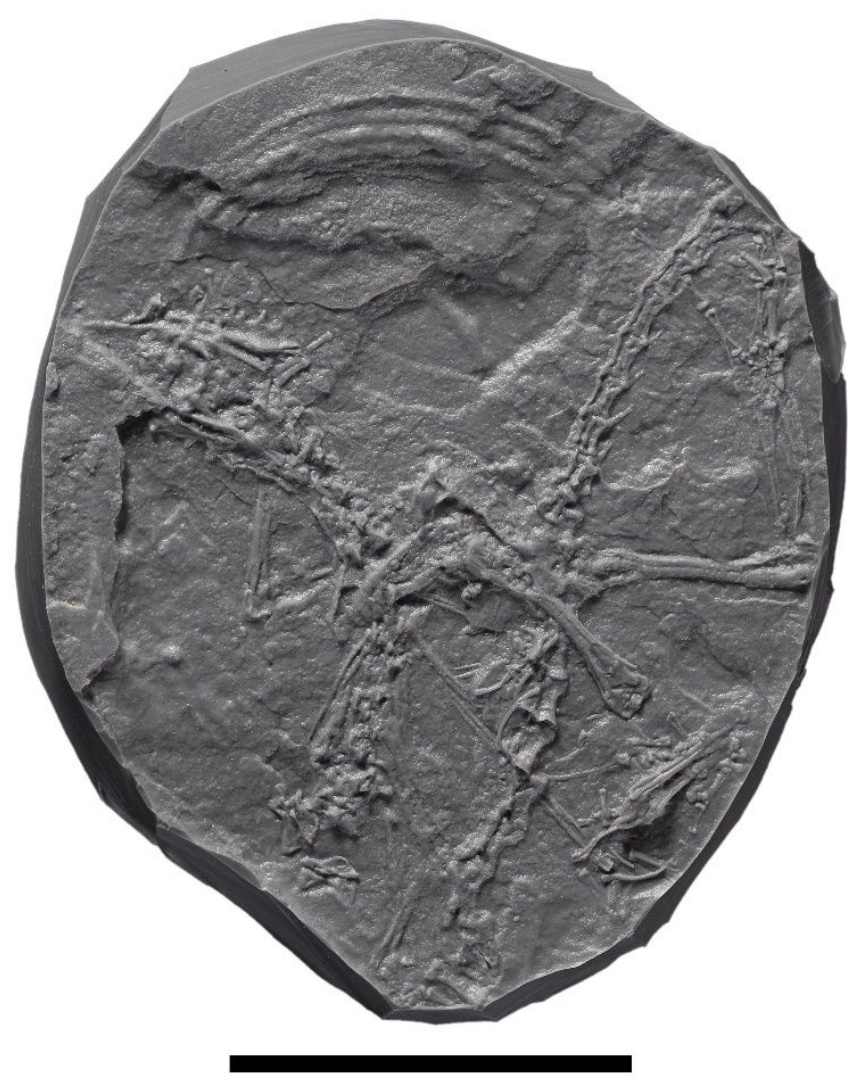

FIGURE S1. Coelurosauravus elivensis Piveteau, 1926 (Madagascar, Lopingian), lectotype MNHN.F.MAP325a. Silicone cast of dorsal surface of individual preserved as a natural external mold. Scale bar equals $5 \mathrm{~cm}$. 
Coelurosauravus elivensis Piveteau, 1926 MNHN.F.MAP325a

Skull, dorsal view

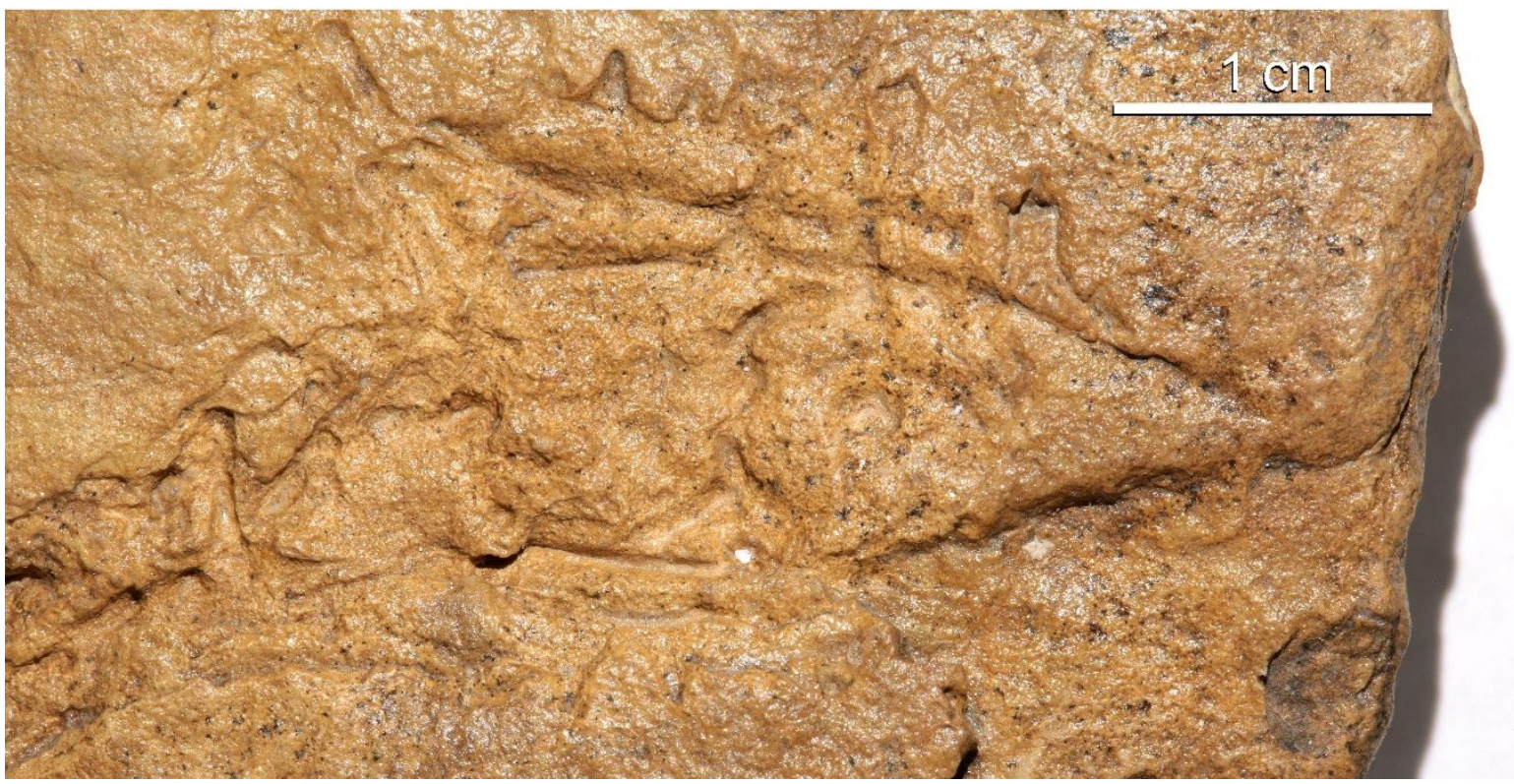

FIGURE S2. Coelurosauravus elivensis Piveteau, 1926 (Madagascar, Lopingian), lectotype

MNHN.F.MAP325a, skull. Dorsal surface of individual preserved as a natural external mold.

Extract from RTI file available in Zenodo, at http://doi.org/10.5281/zenodo.4300212. 
Coelurosauravus elivensis Piveteau, 1926 MNHN.F.MAP317a

Skull, ventral view

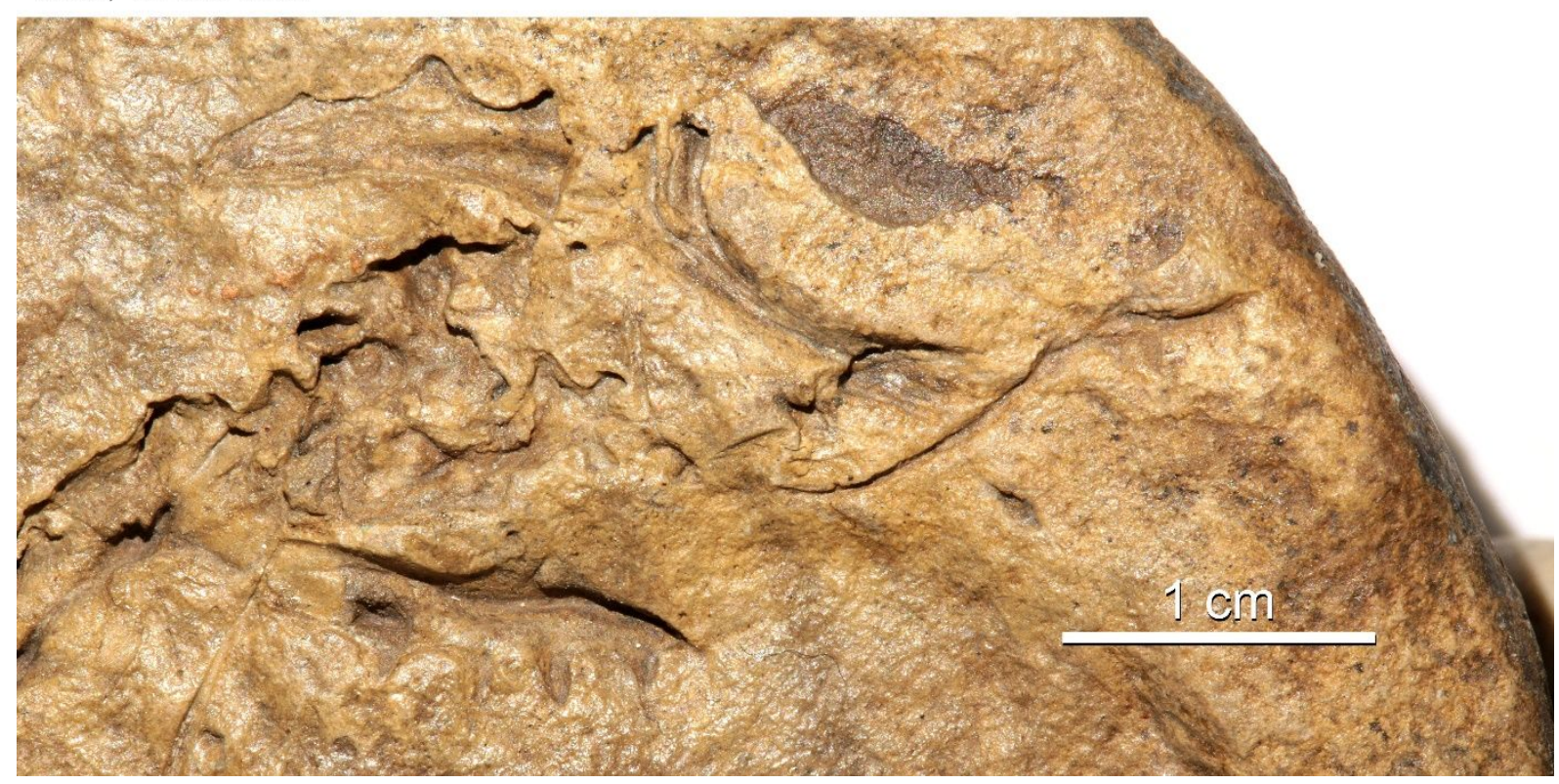

FIGURE S3. Coelurosauravus elivensis Piveteau, 1926 (Madagascar, Lopingian), paralectotype MNHN.F.MAP317a, skull. Ventral surface of individual preserved as a natural external mold. Extract from RTI file available in Zenodo, at

http://doi.org/10.5281/zenodo.4300212. 
Coelurosauravus elivensis Piveteau, 1926 MNHN.F.MAP317b

Skull, dorsal view

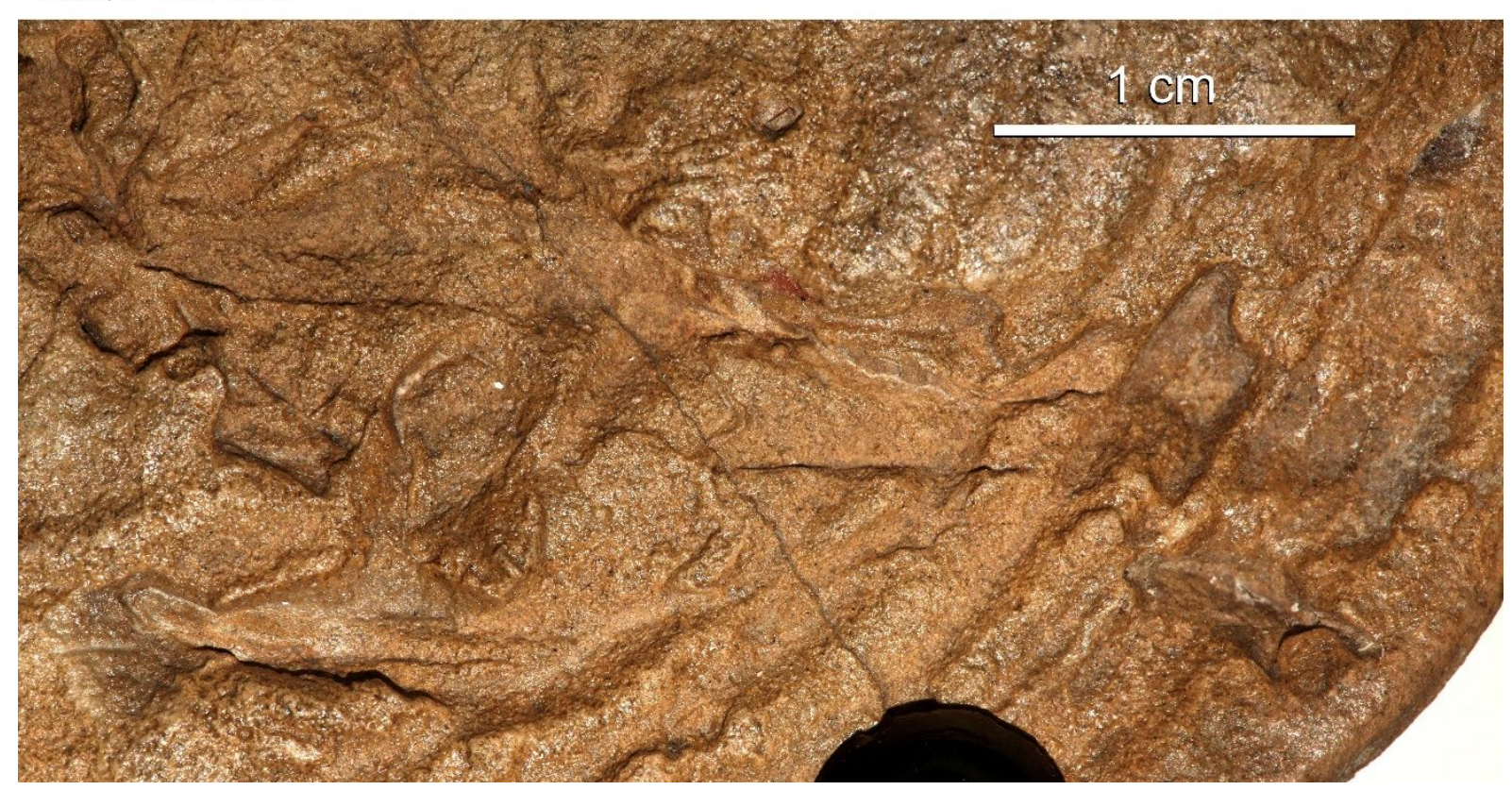

FIGURE S4. Coelurosauravus elivensis Piveteau, 1926 (Madagascar, Lopingian),

paralectotype MNHN.F.MAP317b, skull. Dorsal surface of individual preserved as a natural external mold. Extract from RTI file available in Zenodo, at

http://doi.org/10.5281/zenodo.4300212. 
Coelurosauravus elivensis Piveteau, 1926 MNHN.F.MAP327b

Skull

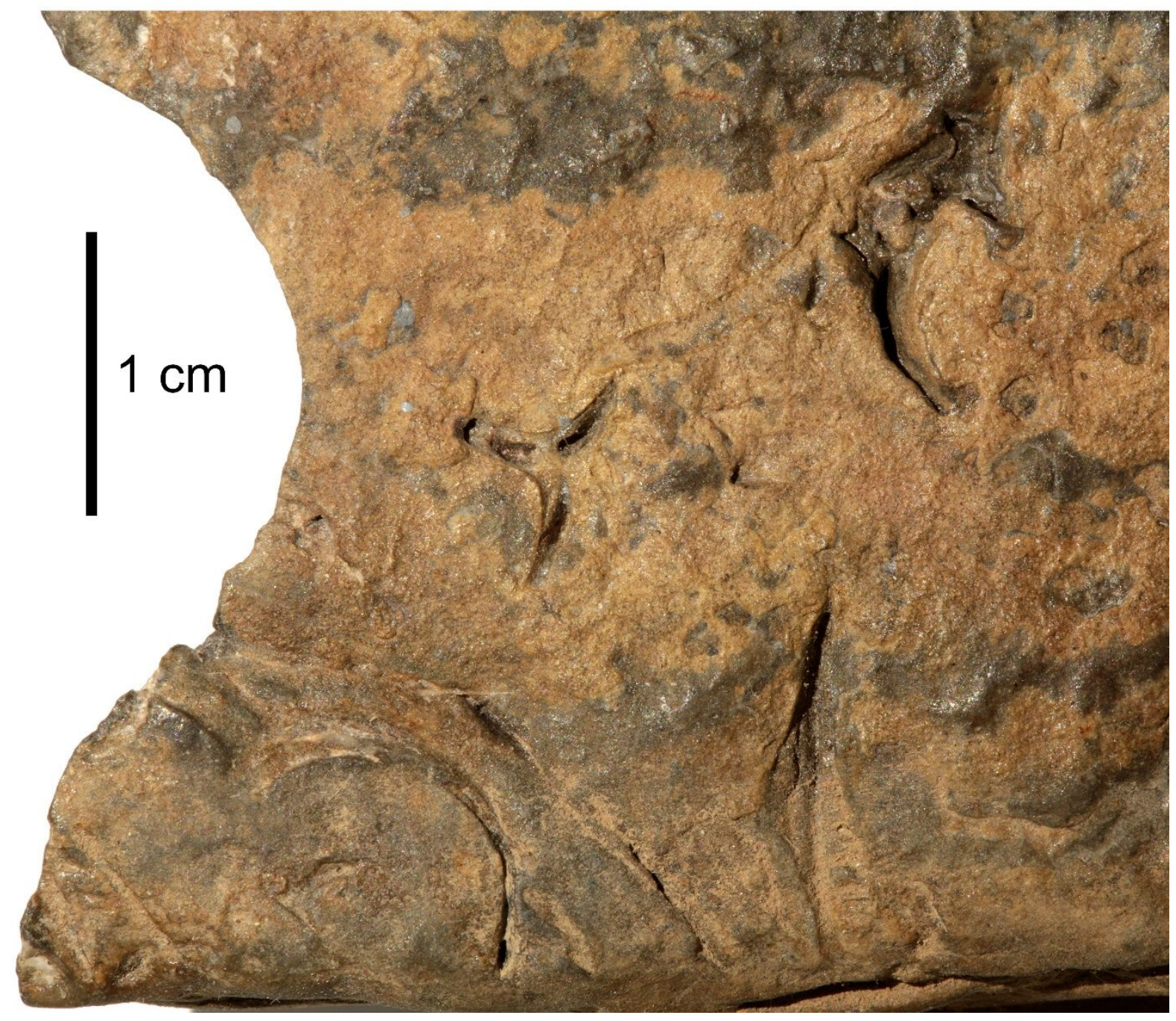

FIGURE S5. Coelurosauravus elivensis Piveteau, 1926 (Madagascar, Lopingian), lectotype MNHN.F.MAP327a, cranial remains preserved mostly in ventral view. Individual preserved as a natural external mold. Extract from RTI file available in Zenodo, at http://doi.org/10.5281/zenodo.4300212. 